\title{
Die Entwicklung von Lanice conchilega (Pallas) mit besonderer Berücksichtigung der Lebensweise
}

\author{
Von Margrit Keßler ${ }^{1}$ ) \\ Aus dem Zoologischen Staatsinstitut der Universität Hamburg \\ und der Biologischen Anstalt Helgoland
}

(Mit 12 Abbildungen im Text, 6 Tafeln und 1 Tabelle)

\section{Inhaltsübersicht}

\begin{abstract}
A. Einleitung: Probleme und Erforschungsgeschichte S. 425 - B. Material und Methode S. $428-$ C. Die systematische Stellung und Morphologie von Lanice conchilega (Pallas), ihr Vorkommen, ihre Verbreitung und Lebensweise in Anpassung an die Umwelt S. 429-D. Die Geschlechter und die Entwicklung der Gameten S. 440 - I. Unterscheidung der Geschlechter und Zeitpunkt der Geschlechtsreife S. 440 - II. Die weibliche Gametenentwidklung S. 441 III. Die männliche Gametenentwicklung S. 444-IV. Abgabe der Geschlechtsprodukte S. 444 - E. Die Entwicklungsvorgänge von der Befruchtung des Eies bis zum bodenreifen Stadium S. 448 - I. Die Embryonalentwicklung S. 448 - II. Die Larvalentwicklung S. $449-1$. Das Prototrochophora-Stadium S. 450 - 2. Das Trochophora-Stadium S. 451 - 3. Das Metatrochophora-I-Stadium S. 451 - 4. Das Metatrochophora-II-Stadium S. 452 - 5. Das Aulophora-Stadium S. 460 - a. Morphologische Veränderungen der Kopfregion S. 461 - b. Morphologische Veränderung der Rumpfregion S. 463 - III. Das bodenreife Stadium S. 468 F. Zusammenfassung S. $471-$ G. Literaturverzeichnis S. 473.
\end{abstract}

\section{A. Einleitung: Probleme und Erforschungsgeschichte}

Seit etwa 100 Jahren beschäftigen sich Zoologen mit der Erforschung planktischer Polychaeten-Larven, mit dem Ziel, durch Beschreibungen der äußeren Form die Artzugehörigkeit einzelner Larven zu bestimmen und ihre Entwicklung zu klären. Ihre Beobachtungen stützten sich jedoch immer auf Entwicklungsstadien, die sie dem Plankton entnahmen, so daß die Richtigkeit der Beurteilung in vielen Fällen in Frage gestellt werden muß und eine lückenlose Gesamtdarstellung der Embryonal- und Larvalentwicklung nicht erreicht werden konnte. Trotz großer Verdienste von Kleinenberg, Milne, Herpin, Salensky, Claparede, Meyer und anderen, ist unser gegenwärtiges Wissen um die Polychaeten-Entwicklung noch sehr fragmentarisch.

1) Inaugural-Dissertation der Mathematisch-Naturwissenschaftlichen Fakultät der Universität Hamburg. 
Die Ursache dieses Tatbestandes liegt in den Schwierigkeiten der Aufzucht von Polychaeten-Larven vom befruchteten Ei bis zum jungen Wurm.

Erst im Jahre 1932 begann WILSON mit der systematischen Aufzucht verschiedener Polychaeten-Larven. Mit seinen Arbeiten scheint sich auf dem Gebiet der Polychaeten-Entwicklung ein neuer Weg anzubahnen, obwohl noch immer die Neigung zu rein morphologischer Beschreibung der einzelnen Entwicklungsstadien bevorzugt besteht. ANDERson hingegen durchbricht 1959 die traditionelle Art der Betrachtung und versucht, die Gesamtdarstellung der Entwicklung gezüchteter Scoloplos armiger-Larven zu klären.

Auch die vorliegende Arbeit geht von der Aufzucht der Larven, vom befruchteten Ei bis zum bodenreifen Wurm, aus. Abgesehen von einer Beschreibung der äußeren Veränderungen, wie sie im Verlaufe einer vollständigen Entwicklung zu beobachten sind, wurde besonderes Gewicht auf die kausalen Zusammenhänge zwischen Organbildung, Funktion der Organe, Lebensweise und Verhalten der Larven in Abhängigkeit von ihrer Entwicklung gelegt. Ferner konnte festgestellt werden, wie der Körper von Lanice segmentiert wird und wie sich die für das adulte Tier charakteristischen Regionen durch den Zusammenschluß von Segmenten bilden.

Lanice conchilega (Pallas) wurde aus zwei Gründen als Untersuchungsobjekt ausgewählt. Einmal, weil die erwachsenen Tiere in großer Zahl und leicht zugänglich im Watt der Deutschen Bucht vorkommen und zum anderen, weil ihre Entwicklung nur unvollständig und mangelhaft bekannt ist.

Wegen der Häufigkeit des Vorkommens wird Lanice oft als "Regenwurm" des Watts bezeichnet. Um so verwunderlicher ist, daß man bis heute nichts über die Geschlechtsmerkmale, Geschlechtsprodukte, die gesamte Furchung und die Entwicklung der Trochophora und Metatrochophora wußte. Einige ältere Larven, die bereits eine hyaline Larvenröhre besitzen, sind zwar beschrieben worden, doch welche Unsicherheit in den Beschreibungen über die LaniceLarven herrscht, zeigt ein Überblick über die vorhandene Literatur deutlich.

Zum erstenmal erwähnt Claparede (1863) die Larven der Terebella conchilega (Synonym für Lanice conchilega). Seine Beobachtungen stützen sich auf Material aus der offenen See von St. Vaast la Hougue. Die guten Zeichnungen lassen zwar eine Ähnlichkeit mit den Larven von Lanice conchilega erkennen, täuschen jedoch niçht darüber hinweg, daß wegen morphologischer Verschiedenheiten eine sichere Zuordnung der von CLAPAREDE beschriebenen Larve zur Art Lanice conchilega nicht möglich ist. Nach CLAParede liegen die Statocysten der Larven im 4. Körpersegment und sollen mit fortschreitender Metamorphose rückgebildet werden. Demgegenüber wird die vorliegende Arbeit zeigen, daß die Lage der Statocysten bei den Larven von Lanice conchilega eine andere ist und daß es sich bei diesem Organ um kein Larvalorgan handelt.

1878 beschreibt GIARD aus Wimereux ein postlarvales Lanice-Stadium als eine neue Gattung, und zwar als Wartelia gonotheca. Er deutet die im Kopf gelegenen großen Zellen als Geschlechtszellen, also als Hoden und Ovarien. Deshalb hält er diese planktischen Formen für erwachsene Tiere. Die Statocysten und die besonders gestalteten Borsten veranlassen ihn, diese neuentdeckte Form in eine den Terebelliden entferntere Gattung zu stellen.

Weder Gunningham und Ramage (1888) noch Nordenskiöld (1901) bringen in ihren Darstellungen Neues über die Lanice-Larven. Erst $1907 \mathrm{kann}$ FAUvel an Hand von Schnitten Otholithen bei adulten Tieren von Lanice 
conchilega nachweisen und kommt daher zu dem berechtigten Schluß, daß die von GIARD neu eingeführte Gattung Wartelia gonotheca nichts anderes ist als die Larve von Lanice conchilega. Auf Grund sorgfältiger histologischer Untersuchungen klärt ELRINGTON (1908) die Frage nach den im Kopf gelegenen großen drüsigen Zellen. Claparede hatte sie als Gehirnzellen, Grard und NoRdenskiöLD als Geschlechtszellen bezeichnet. Beide Auffassungen sind nach ELRINGTON falsch. Nach seiner Ansicht handelt es sich um schleimabsondernde Drüsen, die er Dorsaldrüsen nennt. Sie sollen im Verlaufe der Entwicklung der Reduktion anheimfallen, da sie bei bodenreif gewordenen Stadien nicht mehr angetroffen werden.

Sowohl McIntosh (1922) als auch Hofker (1922) bringen in ihren Beschreibungen nichts Neues über die Larven, die sie im Plankton von St. Andrew und Helder (Holland) gefischt haben.

1925 gibt Herpin eine sehr schöne Zusammenfassung über die gesamte Literatur der Lanice-Larven.

1946 fügt THorson einer Übersichtsbetrachtung noch einige Beobachtungen über die aus dem Snekkerslen-Plankton stammenden Lanice-Larven hinzu. Die Größen der von ihm beobachteten Larven im Kattegat schwanken zwischen $780 \mu$ und $2600 \mu$. Die von ihm als jüngste Stadien bezeichneten Larven sind bereits im Besitz von 5 borstentragenden Segmenten, also ein schon recht weit entwickeltes Stadium.

Alle bisherigen Arbeiten stützen sich lediglich auf die vergleichende Betrachtung des Materials, das zu einem bestimmten Zeitpunkt dem Plankton entnommen wurde. Durch die Unvollständigkeit der bislang beobachteten Entwicklung fehlte jegliche Beweiskraft, so daß dadurch der vorliegenden Arbeit die Aufgabe gestellt war. Nur auf der Basis einer kontinuierlichen Beobachtung der gesamten Entwicklung können neue Erkenntnisse gewonnen werden.

Die am lebenden Objekt erworbenen Ergebnisse wurden durch histologische Untersuchungen unterbaut, um ein möglichst lückenloses Bild der Entwicklung von Lanice conchilega zu erhalten.

Die Arbeiten wurden auf Anregung von Herrn Dr. E. Ziegelmeier, Biologische Anstalt Helgoland, List/Sylt, in Angriff genommen. Für seine freundliche Unterstützung in allen praktischen Fragen und für seine Ratschläge während der Experimente am lebenden Objekt in List/Sylt sage ich meinen herzlichen Dank.

Die Auswertung des fixierten Materials und seine histologische Bearbeitung fand im Zoologischen Staatsinstitut der Universität Hamburg statt. Meinem sehr verehrten Lehrer Herrn Prof. Dr. K. v. Haffner sei ganz besonderer Dank für seine stets hilfreichen Bemühungen und seinen erfahrenen Rat bei allen Fragen und Problemen gesagt. Für die Beschaffung eines Arbeitsplatzes an der Biologischen Anstalt Helgoland in List/Sylt danke ich Herrn Prof. Dr. K. Kosswig, Direktor des Hamburger Zoologischen Staatsinstitutes, und darf meiner Freude Ausdruck geben, daß er den Problemen dieser Arbeit Aufmerksamkeit entgegengebracht hat.

Nicht zuletzt bedanke ich mich bei den technischen Angestellten des Zoologischen Staatsinstituts, die mir Hilfe leisteten, wo es not tat. 


\section{B. Material und Methoden}

Wie in der Einleitung bereits erwähnt wurde, ist die Ursache unseres unzureichenden Wissens auf dem Gebiet der Polychaeten-Entwicklung in den Aufzuchtschwierigkeiten zu suchen.

Wie schwer es ist, die Fülle der die Entwicklungsprozesse beeinflussenden Faktoren in ihrem Zusammenspiel zu erkennen, beweisen viele erfolglose Versuche verschiedener Autoren. Züchtungsprobleme treten besonders dann auf, wenn es sich um sedentäre Polychaeten handelt, deren Entwicklungsstadien eine kürzere oder längere Zeit mehr oder weniger pelagisch leben.

Diese Schwierigkeiten machen es verständlich, daß die Entwicklung von Lanice conchilega bislang ungeklärt blieb, obgleich Lanice mit zu den häufigsten Sedentaria der Deutschen Bucht gehört.

Wohl kannte man eine vorwiegend im Mai, Juni und Juli massenhaft im Plankton auftretende Larve, die zweifelsohne Wurmcharakter besaß und sich in einer hyalinen Röhre purzelbaumartig hin und herbewegte. Die Art der Bewegung innerhalb der Larvenröhre ähnelte derjenigen der erwachsenen Lanice conchilega, und so glaubten einige Autoren, daß es sich um Larven dieser Terebellide handele. Eine einwandfreie Zuordnung auf Grund dieser Schlußfolgerung ist jedoch nicht zulässig, zumindest ist die Zugehörigkeit zwischen freischwimmender Larve und sessilem Adult nicht bewiesen. Nur eine vollständige Entwicklung konnte Klarheit bringen.

Die zur Durchführung der Entwicklungsuntersuchungen notwendigen adulten Tiere stammten aus der Wattenzone des Lister Hakens, des Königshafens und des Lister Ellenbogens der Insel Sylt. Die ersten natürlichen Befruchtungsversuche - die künstliche Befruchtung ergab nur anormale Larven - fanden im Frühjahr 1960 an der Biologischen Anstalt Helgoland in List/Sylt statt und wurden im Frühjahr 1961 wiederholt.

Die geschlechtsreifen.Würmer wurden zum Ablaichen paarweise in sog. Akkugläser eingesetzt. Diese $50 \mathrm{~cm}$ hohen Versuchsbecken, deren Grundfläche $20 \times 20 \mathrm{~cm}$ betrug, wurden zu einer Hälfte mit gut gewaschenem Sediment, zur anderen Hälfte mit filtriertem Seewasser gefüllt. Auf einen Durchlauf bzw. auf eine ständige Erneuerung des Wassers der nebeneinanderstehenden Aquarien konnte zugunsten einer Sauerstoffdurchlüftung verzichtet werden. Die Becken wurden in einem ungeheizten Raum aufgestellt. Auf diese Weise wurden in den Versuchsbecken Temperaturverhältnisse geschaffen, die den Außenbedingungen glichen, da sie auch den Schwankungen der Außentemperatur unterworfen waren. (Weitere Angaben im Kapitel: Abgabe der Geschlechtsprodukte.) Diese im Labor erzeugten Lebensbedingungen sollten den Gegebenheiten am natürlichen Standort möglichst ähnlich sein. Die Befruchtung fand in den Akkugläsern statt. Danach wurden die Embryonen aus den Becken herauspipettiert, um sie in kleinen runden Glasschälchen weiterzuzüchten. Die mit entkeimtem Seewasser angefüllten. Schälchen wurden zum Schutz gegen Staub mit einer Glasplatte bedeckt. Auch die Temperatur innerhalb der Kulturschälchen wurde nicht konstant gehalten. Sie unterlag den gleichen Schwankungen wie diejenige der Zuchtbecken mit den erwachsenen Würmern.

Die Schälchen wurden vor direkter Sonneneinstrahlung geschützt, um einen raschen Temperaturanstieg und eine damit verbundene Verminderung des Sauerstoffs zu vermeiden. Versuche, das Seewasser der Schälchen zu durchlüften, erwiesen sich als unzweckmäßig, da die Luftblasen auch bei feinster Verteilung schädigend auf die jungen Larven wirkten. 
Der Wechsel des Wassers fand einmal, manchmal auch zweimal täglich statt.

Das schwierigste Problem innerhalb der Aufzuchtversuche bestand jedoch in der Beschaffung der richtigen Nahrung für die Larven. Vergeblich blieben alle Bemühungen, die Larven mit Chlamydomonas, Protococcus oder Prasinocladus am Leben zu erhalten. Sie nahmen die Algen zwar auf, konnten sie aber nur zum Teil verdauen. Alle Beobachtungen sprachen dafür, daß eine einseitige Pflanzennahrung den Ansprüchen der Larven nicht genügte. Schließlich gelang die Lösung des Problems und damit die Erhaltung der Entwicklungsstadien doch noch. Der einfachen Überlegung folgend, daß die planktischen Stadien im offenen Seewasser alles finden, was für das Wachstum und den Aufbau des Körpers notwendig ist, wurden die Larven nicht mehr in entkeimtem Seewasser unter Zusatz einer Futteralge gehalten, sondern in ungereinigtem, jeweils frisch geschöpftem Meerwasser.

Die Zeichnungen der einzelnen Entwicklungsstadien vom befruchteten $\mathrm{Ei}$ bis zum bodenreifen Stadium von Lanice conchileg $a$, wie sie die Tafelabbildungen darstellen, basieren alle auf Beobachtungen am lebenden Objekt. Um die Larven für das Zeichnen in ihrer Beweglichkeit zu behindern, genügte häufig ein Tropfen Speichel auf den Objektträger.

Zum Vergleich und zur Bestätigung der im Labor gewonnenen Ergebnisse dienten Planktonfänge in Bodennähe an der Lister Ablaufbahn mit einem kleinen Bechernetz, und im freien Wasser am Lister Hafen mit einem Horizontal-Planktonnetz.

Die Fixierung der einzelnen Entwicklungsstadien erfolgte in Bouin und Susa. Zur Herstellung von Schnitten wurden die Larven unter vorheriger Anfärbung mit Eosin über Methylbenzoat in Paraffin eingebettet. Das Anfärben der Larven bewährte sich insofern, als die Objekte später im Paraffinblock besser zu finden waren. Die Schnittdicke betrug meist $7 \mu$. Abgesehen von den Totalpräparaten, die mit Alaunkarmin und Boraxkarmin gefärbt wurden, wurden die Schnitte mit Azan gefärbt.

Die Untersuchungen an den Spermien wurden mit Carminessigsäure und Orceinmilchsäure durchgeführt und ergaben gute Ergebnisse.

C. Die systematische Stellung und Morphologie von Lanice conchilega (Pallas), ihr Vorkommen, ihre Verbreitung und Lebensweise in Anpassung an die Umwelt

Lanice conchilega gehört als sedentärer Polychaet zur Unterordnung der Terebellomorpha und innerhalb dieser zur Familie der Terebellidae.

Am Körper lassen sich deutlich zwei Regionen unterscheiden, der mit dorsalen Haarborstenbüscheln und ventralen hakentragenden Wülsten gekennzeichnete, 17 Segmente umfassende Thorax und das Abdomen, dem die Haarborsten fehlen und deren Hakenwülste durch flossenförmig umgestaltete Hakenborsten ersetzt sind.

Das schildförmige Prostomium (Kopflappen) trägt zahlreiche nicht in den Mund einziehbare Tentakeln. Es wird überragt von einer beweglichen, kapuzenförmigen Oberlippe, deren Bedeutung sowohl bei der Nahrungsaufnahme als auch beim Umgreifen und Verbauen von Sedimentmaterial wichtig ist. Die Annahme, die Oberlippe gehöre zum Prostomium, wie sie von Hempelmann 
(1934, S. [7] 196) und Zregelmeier (1952, S. 108) vertreten wird, kann wie die vorliegende Arbeit zeigen wird, in Zukunft nicht mehr aufrechterhalten werden. Auch bleibt es problematisch, ob die Unterlippe als Verschmelzungsprodukt von Metastomium und 1. Körpersegment zum sog. Buccalsegment = Peristomium angesehen werden kann. Das Prostomium ist von einer Anzahl lichtperzipierender Pigmentzellen bedeckt, die als primitive Lichtsinnesorgane angesprochen werden können.

Lange Zeit glaubte man, daß diese Gruppe keine Nuchalorgane besitze. Diese Ansicht resultierte aus den verallgemeinerten Ergebnissen Hessies (1917, S. 55) an Thelepus sitosus, wo ein Fehlen dieses Organs festgestellt worden ist. Erst RuLlier (1951, S. 276) konnte durch sehr sorgfältige Untersuchungen an allen Terebelliden diesen Irrtum beseitigen. Bei der Bearbeitung des Terebellidenmaterials stellte sich heraus, daß einige Arten z. B. Amphitrite gracilis, Terebella strömii und der von Hessle beschriebene Thelopus sitosus kein Nuchalorgan entwickeln, andere jedoch ein unvollständiges oder nur teilweise reduziertes Organ besitzen. Auf Grund dieser Tatsache kommt Rullier zu der Auffassung, daß das Nuchalorgan dieser Familie durch ihr Röhrendasein einer weitgehenden Reduktion anheimgefallen sei. In einigen Fällen aber, so auch bei Lanice conchilega, bleibt die Funktion des rückgebildeten Organs erhalten.

Das Nuchalorgan befindet sich bei Lanice zwischen Prostomium und Buccalsegment. Fs ist von einer dorsalen Hautfalte überdeckt und stellt nach RulliER ein chemorezeptorisches Organ dar. Eng schließt es sich an den hinteren Hirnteil an, so daß auf die Ausbildung eines besonderen Nuchalnervs und auf ein Nuchalganglion verzichtet werden konnte. Ein ebenso enges Verhältnis soll nach RULLIER mit dem nach hinten sich anschließenden Drüsengewebe bestehen. Das Nuchalorgan ist kein einheitliches Gebilde, sondern liegt in zwei getrennten Organen gleichweit der medialen Rückenlinie unter der oben erwähnten Hautfalte verborgen.

An die Kopfregion schließst sich im 2., 3. und 4. Segment das Gebiet der Kiemen an. Jedes dieser Segmente trägt dorsal 1 Paar baumartig verzweigter Kiemen, deren leuchtend rote Farbe auffällt. Sie deutet auf eine gute Durchblutung dieser Gewebe hin. Außer den Kiemen liegen im 2. Segment durch ektodermale Einstülpung entstandene paarige Statocysten, die Fauvel (1907) an den adulten Tieren entdeckte, im 3. Segment zwei laterale Lappen, deren Bedeutung noch nicht geklärt ist, und im 4. Segment die ersten Haarborstenbüschel, während die hakentragenden Wülste erst im 5. Segment beginnen.

Im ventralen Thorakalbereich liegen paarige Drüsenschilder oder auch Bauchplatten genannt, die den Schleim für den Röhrenbau abscheiden.

Das in vier warzige Papillen auslaufende Pygidium bildet den Endabschnitt des Körpers.

Die für die Polychaeten typische Metamerie ist auch bei Lanice conchilega vorhanden, obwohl die Dissepimente, als Trennungswände der einzelnen Metamere, zurückgebildet sind. Nur zwischen dem 4. und 5. Segment zieht sich von ventral nach dorsal ein kräftiges Diaphragma. Die Ausbildung dieser einen Körperscheidewand hat zur Folge, daß sich zwei in sich abgeschlossene Nephridialsysteme entwickelt haben.

Das vor dem Diaphragma, in der vorderen Thorakalkammer, liegende Nephridialsystem besteht aus drei Paar Metanephridien mit kleinen Wimpertrichtern, die in gemeinsame Nephridialkanäle übergehen und in jeweils einem 
Ausfuhrporus im 3. Segment hinter dem zweiten Kiemenpaar nach außen münden. Im Gegensatz zum vorderen gehören dem hinteren Nephridialsystem, also hinter dem Diaphragma gelegen, vier Paar Metanephridien an. Jedes Nephridium ist im Besitz eines großen, stark erweiterten Nephrostoms, welches neben seiner exkretorischen Funktion auch in der Lage ist, Geschlechtsprodukte, also geformte Teile, aufzunehmen. Die so entstandenen Nephromixia sind mit einem paarigen Exkretionsgang miteinander verbunden, der jedoch über den eigentlichen Nephridialbereich vom 5.-9. Segment weiter nach hinten wächst, um schließlich im 16. Segment blind zu enden. Trotz dieser Kommunikation weist jedes Nephridium einen eigenen Nephridialkanal auf, der sich entsprechend der Lage der vier Paar Nephridien zwischen 5. und 6., 6. und 7., 7. und 8., 8. und 9. Segment auf einem kegelförmigen Porus zwischen dem dorsalen Haarborstenbüschel und dem ventralen Hakenwulst des jeweiligen Segments nach außen öffnet.

Diese von MEYER (1887) stammenden Untersuchungen der Exkretionsorgane von Lanice conchilega (Pallas) weisen darauf hin, daß der nephridienlose Gangteil für eine Reduktion spricht.

Meyer hat auch die Lage der periodisch auftretenden Geschlechtsdrüsen festgestellt. Ihr paariges Vorkommen bleibt auf das 7. und 8. Segment beschränkt.

Der Verdauungskanal durchzieht ohne Windungen oder laterale Aussackungen die Leibeshöhle. Er beginnt mit einem ventral gelegenen Mund und endet in einem terminalen After. Er ist in mehrere Abschnitte gegliedert. Der Vorderdarm läßt sich in Mundhöhle, Pharynx und Oesophagus einteilen. Direkt hinter der Mundhöhle, im ventralen Schlundbereich, liegt ein blind endender Schlundsack, das sog. Buccalorgan. Diese muskulöse, vorstreckbare Schlundzone bewirkt offenbar eine Vergrößerung der Mundöffnung und ist für einen Strudler wichtig. Die zungenähnlichen Bewegungen des Buccalorgans spielen ganz sicher beim Röhrenbau eine wesentliche Rolle.

Eine magenförmige Erweiterung des bewimperten Oesophagus führt zum Mitteldarm und mündet schließlich in den kurzen Enddarm. Durch medial gelegene dorsale und ventrale Mesenterien wird der Darm befestigt.

Bei der Betrachtung der Organe des adulten Tieres, wie sie einführend geschildert wurden, sind nur diejenigen berücksichtigt worden, die während der Larvenentwicklung verfolgt werden konnten.

Für das Vorkommen von Lanice conchilega ist felsiger Untergrund nicht geeignet, da die Tiere sich senkrechte Wohnröhren in den Boden bauen. Dagegen scheinen die Tiere bevorzugt schlickigen Sand als Ansatzpunkt zu wählen. Man findet sie allerdings auch in grobkörnigem Sand oder in einem Boden, der mehr Schlickbestandteile enthält als Sand. Diese zuletzt genannten Möglichkeiten könnten z. B. durch sekundäre Überschüttung oder allmähliche Aufschlickung entstanden sein. Diese ständigen Bodenverlagerungen innerhalb des Wattgebietes erschweren die Auskunft über den Untergrund, der mit Vorliebe von Lanice aufgesucht wird, wenn man überhaupt von einem aktiven Aufsuchen des Sediments sprechen kann.

Als häufig vorkommender mariner Polychaet besiedelt Lanice conchilega sehr verschiedene Biotope. Wir finden sie in den rhythmisch trockenfallenden Wattgebieten mit extremen Temperaturen und starken Salzgehaltsveränderungen, in brackigen Flußmündungen mit gering prozentigem Salzwasser und schließlich auf dem Meeresboden mit relativ konstanten Bedingungen. 
Dieses Vorkommen sowohl im littoralen als auch im benthalen Abyssalbereich beruht auf der guten Befähigung zur Eurybathie und erklärt dadurch die Unempfindlichkeit der erwachsenen Würmer gegen Temperatur- und Salzgehaltsschwankungen.

Trotz der "Ungunst“ eines Wattgebietes kann die Siedlungsdichte hier besonders hoch sein, wie Ziegelmeier (1952, S. 113) in einer Aufnahme eines Lanice-Polsters am Sylter Ellenbogen-Nordstrand sehr eindrucksvoll zeigt. Wie sehr jedoch diese Besiedlungsrandzone der Gefahr der Brandung mit seiner zerstörenden Wirkung ausgesetzt ist, verdeutlicht die Tatsache, daß 1960, als Material für die vorliegende Arbeit gesammelt werden sollte, die von ZIEGELMeIER angegebene Stelle keinen Lanice-Bestand mehr aufwies.

Auf Grund der eben beschriebenen Widerstandsfähigkeit und der adaptiven Lebensweise ist Lanice weit verbreitet. Nach FrIEdRICH (1938, S. VI. b. 192) handelt es sich um eine boreal-lusitanische Verbreitung mit Vorkommen im Atlantik, Nordsee, Skagerrak, Kattegat, Armelkanal und Mittelmeer. Allerdings findet die von Hempelmann (1934, S. [7] 197) gemachte Angabe über das Vorhandensein der Tiere auch in arktischen Meeren und im Pazifik bei FrIEDRrCH keine Berücksichtigung.

Die weite Verbreitung von Lanice hängt jedoch nicht nur mit der Anpassungsfähigkeit zusammen, sondern ist auch auf die Langlebigkeit der pelagischen Larvenstadien zurüdkuführen. Trotz der Eigenbewegung der Larven wäre es ein Irrtum annehmen zu wollen, daß aktive Wanderung über größere Entfernungen von Larven stattfinden würden. Dazu sind die Lanice-Larven nicht in der Lage. Vielmehr muß an eine passive Verfrachtung durch die Bewegung des Meerwassers und seinen Strömungen gedacht werden. Obwohl die Möglichkeit einer Verbreitung über größere Distanzen hin sehr einleuchtend erscheint, fehlen vorläufig. Untersuchungen, die die Beziehungen zwischen Strömungen und Transport von Polychaeten-Larven beweisen.

Lanice lebt in einer senkrechten Wohnröhre im Boden, einzeln oder in großer Zahl beisammen. Als Baumaterial für die Röhrenherstellung dienen verschiedene Bestandteile, wie Sandkörner, Muschel- und Schneckenschalenbruchstücke, Seeigelstachel und was sonst noch zur Verfügung steht.

Beobachtungen ZiEgelmeIERs (1952) geben ein sehr klares Bild über den Bau der Röhren. Er beschreibt, wie ein schutzloser Wurm, der ohne Röhre auf das Sediment gelegt wurde, sich durch Schleimausscheidung sofort mit einer Schleimhülle umgibt, auf der umliegende Sedimentteilchen wahllos kleben bleiben. Dieser provisorische Schutz bildet den Ausgangspunkt alles weiteren Geschehens. Kopfwärts bohrt sich Lanice ins Sediment, wobei nach ZIEGELMEIER das Prostomium die Hauptfunktion ausübt. In diesem Punkt stimmen die eigenen Beobachtungen an bodenreif gewordenen Larven nicht mit denjenigen Ziegelmeiers überein. Doch darauf wind an späterer Stelle eingegangen. Der Röhrenteil, der senkrecht im Boden steht, wird als Schaft bezeichnet und entsteht auf dieselbe Weise wie die provisorische Schutzhülle. Dieser Röhrenschaft kann blind im Boden enden, er kann aber auch eine U-oder W-Röhre bilden. ZiegelmeIER führt die verschiedene Bauweise der Wohnröhre auf umweltbestimmte Faktoren zurück. Er konnte nachweisen, daß bei maximalen Ernährungsbedingungen die Röhren in Polstern zusammenstehen und eine senkrechte Form haben, während bei unzureichenden Nahrungsverhältnissen eine lockere Siedlungsweise mit u- bzw. w-förmigen Röhren entsteht. 
Die Röhre schließt nicht mit der Oberfläche des Bodens ab, sondern überragt sie um etwa $2-3 \mathrm{~cm}$. Dieser über dem Boden befindliche Teil ist das Lanice-Bäumchen, deren Äste innerhalb des Nahrungserwerbes Stellnetzfunktion ausüben. Im Gegensatz zur passiven Bauweise des Röhrenschaftes wird das Bäumdhen mit seiner Fransenkrone aktiv vom Tier zusammengefügt (nach Ziegelmeier). Zur Herbeischaffung des Baumaterials dienen die mit einer ventralen Cilienrinne ausgestatteten Tentakeln. Der Transport des Materials wird entweder durch gerichteten Cilienschlag oder durch peristaltische Bewegungen der Fangarme bewerkstelligt. Die eingebrachten Sedimentteilchen werden dann mit der Oberlippe umfaßt und mit Schleim umhüllt, der durch Kontraktionsbewegungen vom Erzeugungsort, den Basalplatten der Ventralseite, zum Mund gelangt. Haben sich ein oder mehrere Steinchen in der Oberlippe angesammelt, so setzt das Tier ein Steinchen an das andere, indem es sich mit dem Oberkörper über den Röhrenrand neigt.

Neben der Aufgabe, die den Tentakeln beim Antransport des Baustoffes für die Wohnröhre zukommt, spielen sie eine ebenso große Rolle für den Nahrungserwerb. Sowohl das im Einzugsbereich der Tentakeln liegende Gebiet als auch das selbst gebaute Bäumchen wird mit Hilfe der Fangarme nach Futter abgesucht.

Futtermangel existiert eigentlich nur in sehr seltenen Fällen, denn die vom Meer mitgeführten Sinkstoffe oder Detritusteilchen sind immer reichlich vorhanden und werden durch die ständige Bewegung des Wassers den seßhaften Tieren zugeführt.

Ein Verlassen der Röhren aus Nahrungsgründen kommt wohl kaum in Frage, da es mit großer Gefahr für die Tiere verbunden wäre. Ob ein Ortswechsel allerdings aus Wachstumsgründen notwendig ist, bleibt noch offen.

Ein sicherer Nachweis über das Verlassen der Röhren ist noch nicht erbracht. Die einzige Mitteilung hierüber bringt HempelmanN (1934, S. [7] 139): "Polymnia nebulosa Montagu, Lanice conchilega Malmgren, Amphitrite edwardsii Quatrefages, verlassen zwar unter Umständen ihre Wohnröhre, zum Beispiel bei hohem Wasserstande, suchen sie dann aber wieder auf." Dieser Vorgang erscheint doch sehr fragwürdig. Eigene Beobachtungen an erwachsenen Exemplaren zeigten vielmehr eine große Beharrlichkeit der Tiere in der schützenden Hülle ihrer Röhre. Bei Erschütterungen von oben reagieren die Tiere immer durch Zurückweichen ins Innere der Bodenröhre. Nur wenn der "Angriff" von unten erfolgt, wie z.B. beim Graben mit einem Spaten, kann es passieren, daß der Wurm nach der dem Druck entgegengesetzten Richtung zu entweichen versucht und deshalb nach oben aus der Röhre ,fährt". Die so entblößten Würmer schwimmen nicht oder kriechen über den Boden, wie von Polymnia nebulosa gesagt wird, sondern schleimen sich sofort wieder ein.

Innerhalb weniger Minuten ist das Tier bereits von einer inkrustierten Hülle umgeben und gräbt sich erneut in das Sediment. Diese Feststellung läßt vermuten, daß ein freiwilliges Verlassen der Wohnröhre nicht wahrscheinlich ist. Damit ist jedoch noch keine Antwort auf die Frage gegeben, wie die Tiere sich während des Körperwachstums verhalten, wenn ihnen die Röhre zu eng wird.

Bei seßhaft gewordenen Jungtieren zeigten eigene Beobachtungen, daß nach dem senkrechten Schaftstück und dem waagerecht im Boden verlaufenden Scheitelbogen, dieser sich wiederum in einen vertikalen nach oben führenden Schacht und einen horizontal weiterführenden Scheitelbogen gabelt. Dieser 

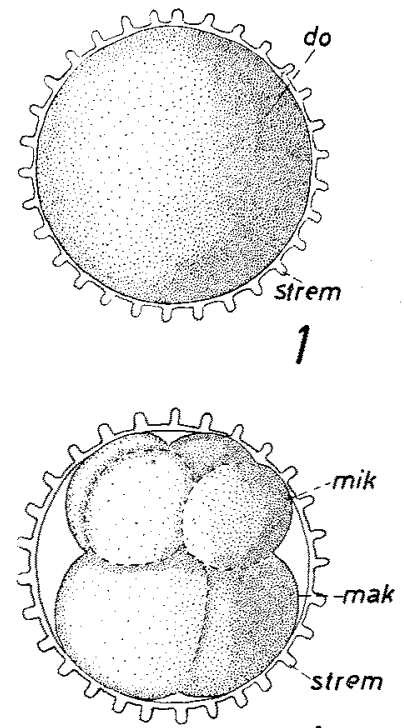

4

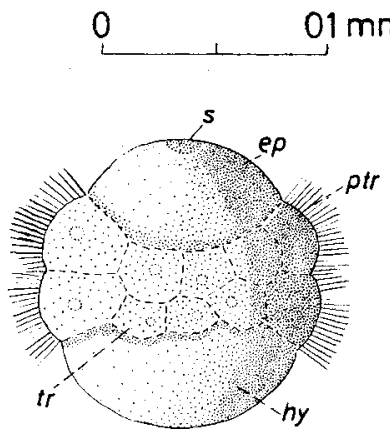

7

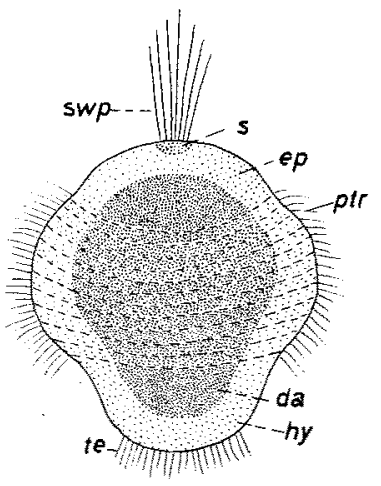

9
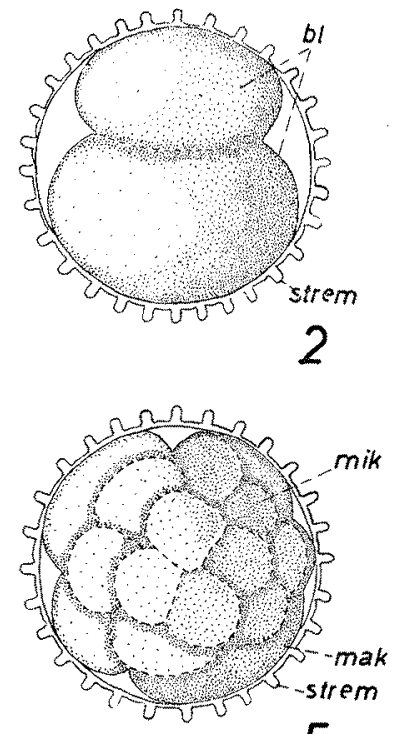

5

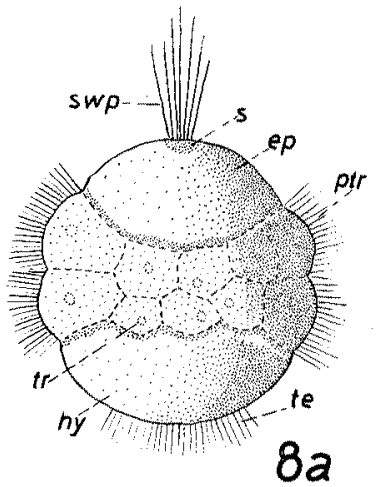

$8 a$

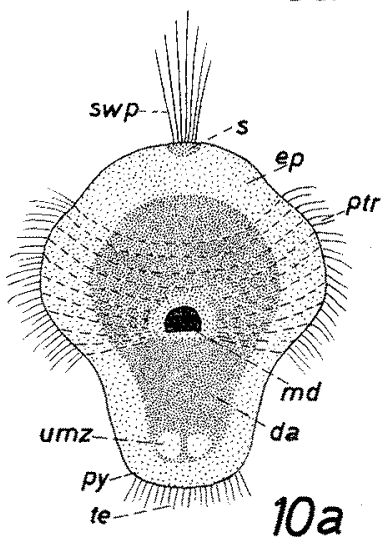

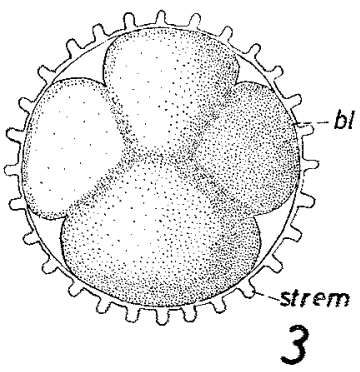

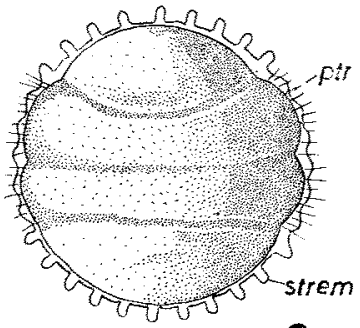

6
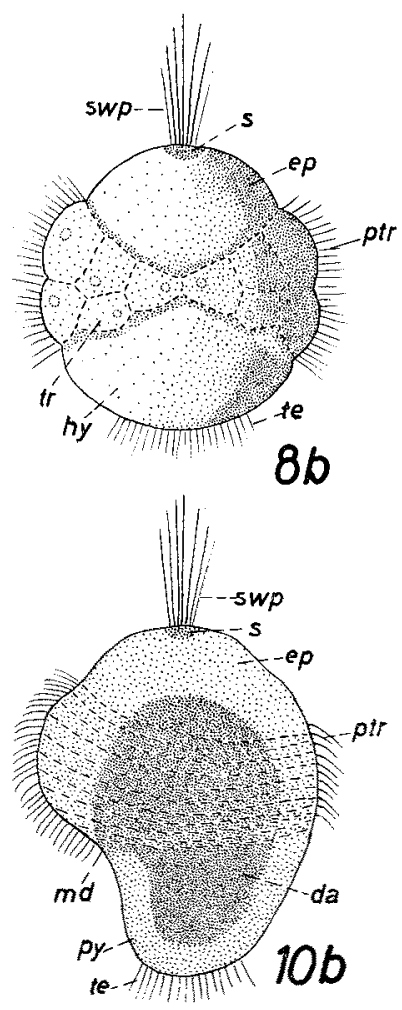

Tafel 1

Abb. 1. Befruchtetes Ei, Abb, 2. 2-Zellen-Stadium. Abb, 3, 4-Zellen-Stadium. Abb. 4. 8Zellen-Stadium. Abb. 5, 16-Zellen-Stadium. Abb. 6. 64-Zellen-Stadium (nach 12 Stunden). Durchbruch der Prototrochwimpern durch die Eimembran ist bereits erfolgt. Abb. 7. Prototrochophora-Larve. Abb. 8. Trochophora-Larve (nach 24 Stunden), a) ventral, b) dorsal. Abb. 9. Trochophora-Larve (2 Tage alt). Abb. 10. Trodhophora-Larve (3 Tage alt), a) ventral, b) seitlich 

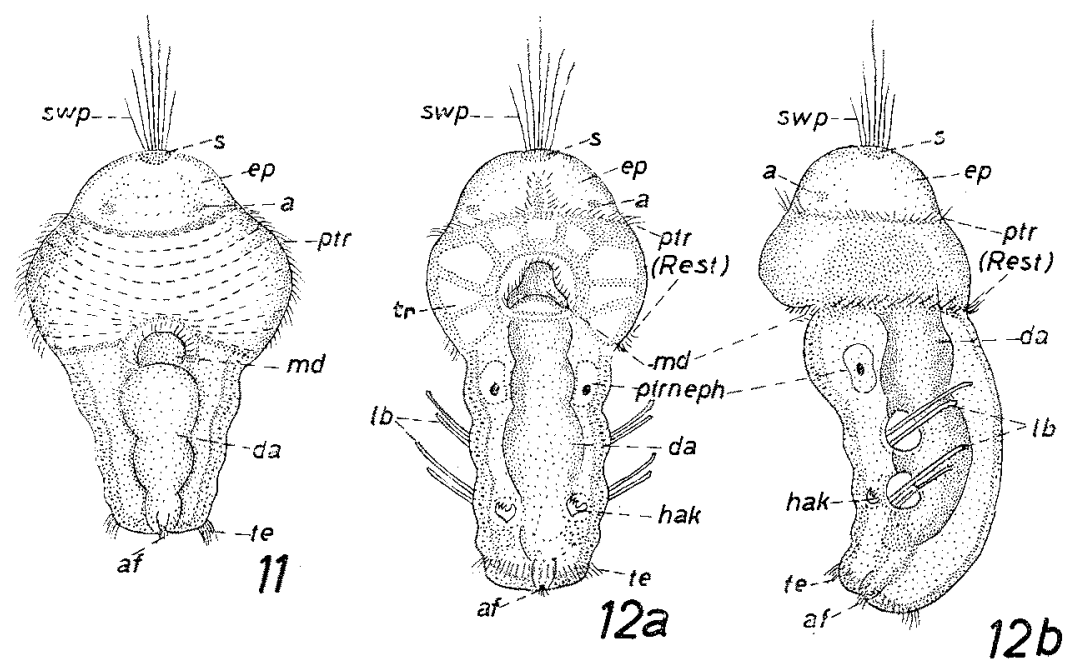

0

$0,1 \mathrm{~mm}$
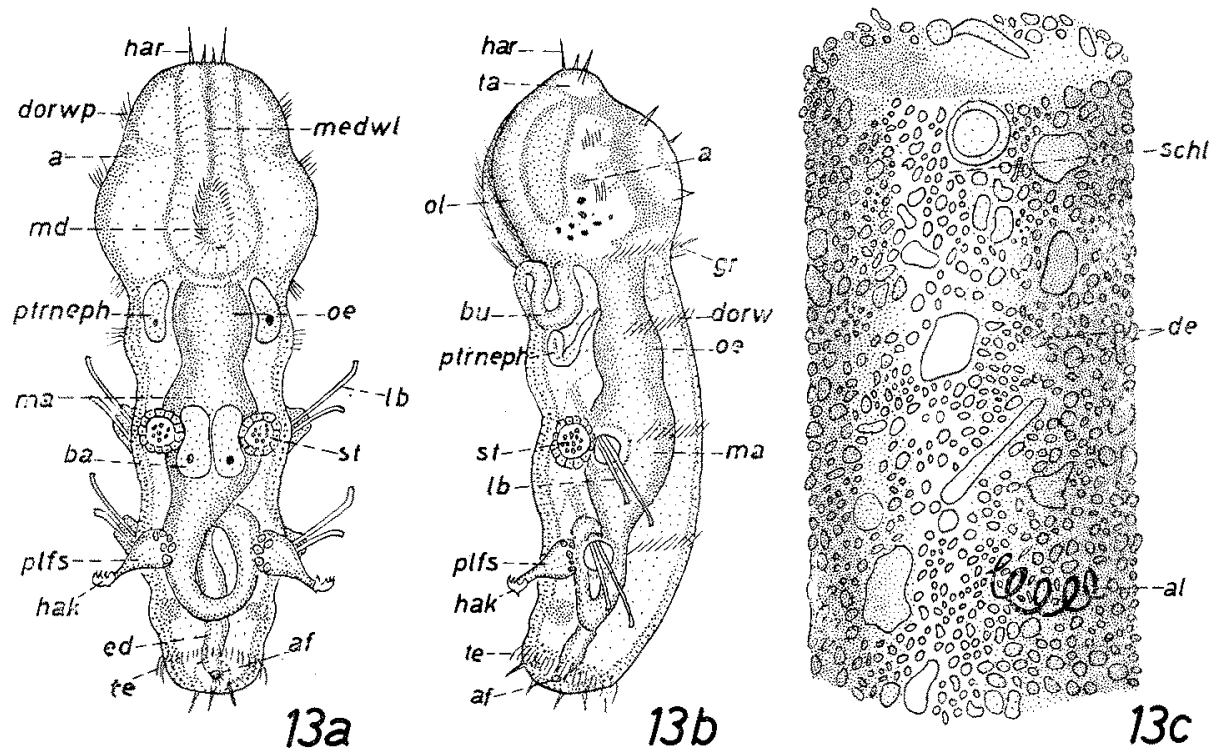

Tafel 2

Abb. 11. Metatrochophora I-Larve (4 Tage alt). Abb. 12. Metatrochophora II-Larve (5 Tage alt), a) ventral, b) seitlich. Abb. 13. Metatrochophora II-Larve (6 Tage alt) im Übergang zur Aulophora-Larve, a) ventral, b) seitlich, c) Detritusröhre 


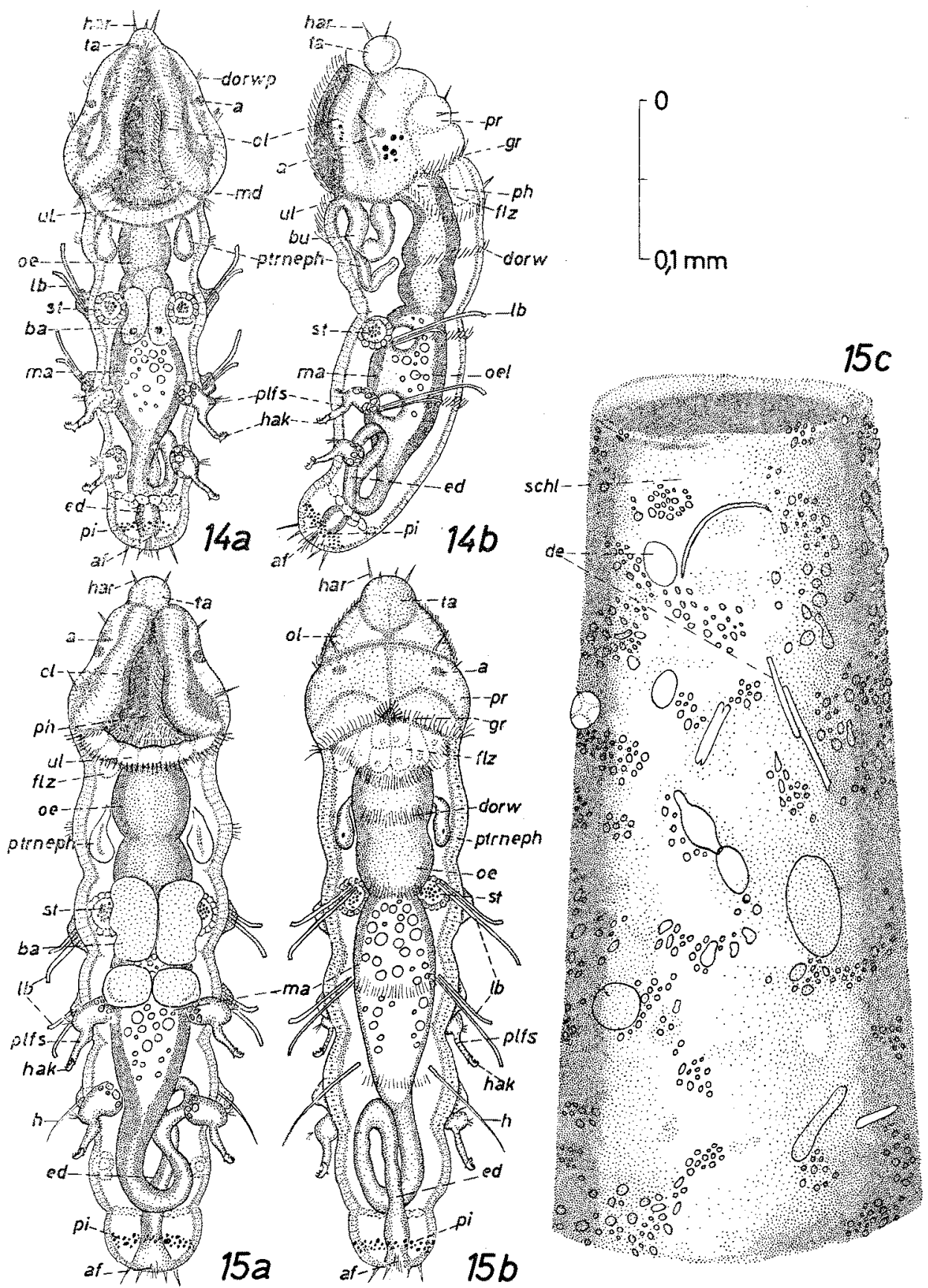

Tafel 3

Abb. 14. Aulophora-Larve (6-10 Tage alt), a) ventral, b) seitlich. Abb. 15. Aulophora-Larve (10-15 Tage alt), a) ventral, b) seitlich, c) Detritusröhre 

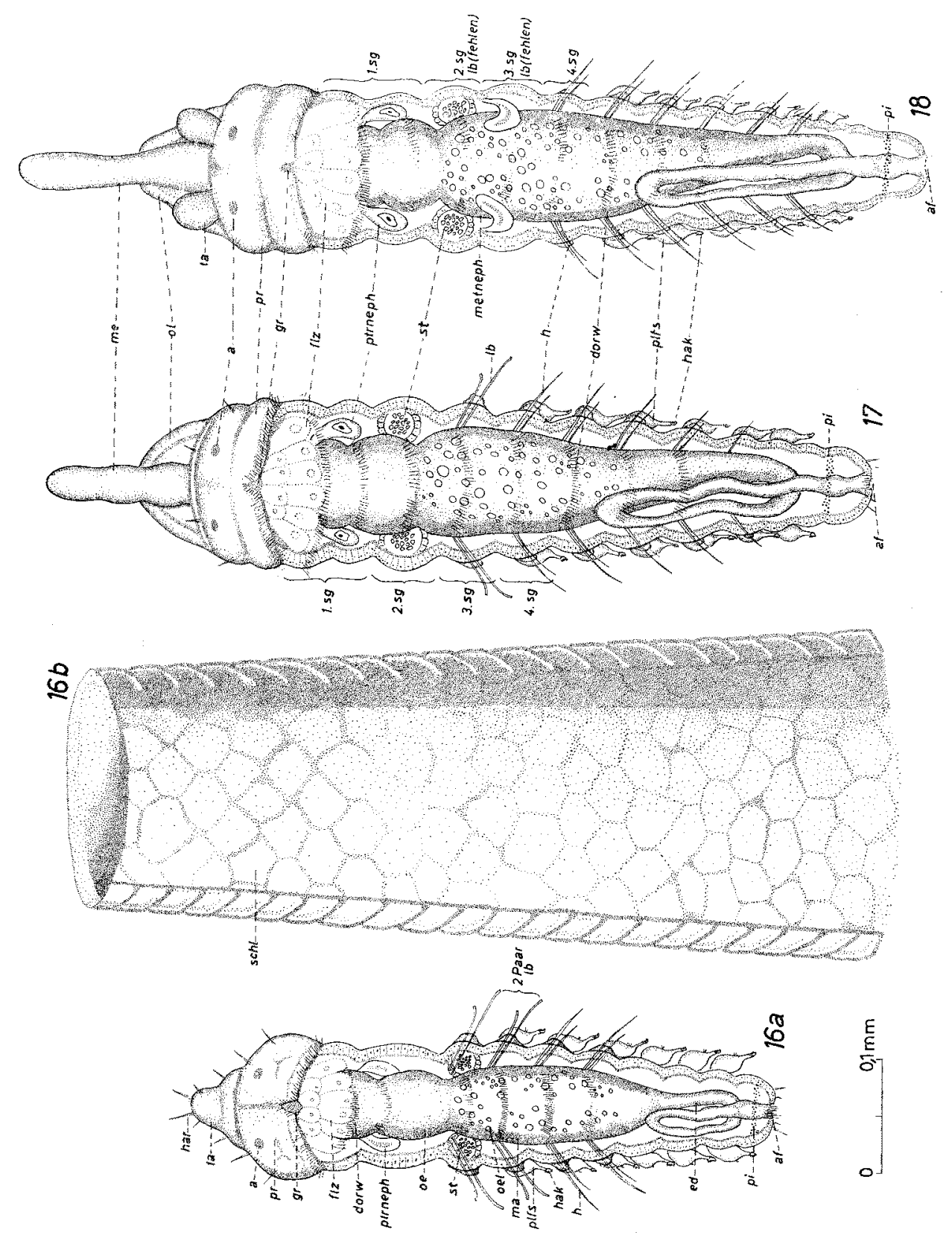

Tafel 4

Abb. 16. Aulophora-Larve (15-20 Tage alt), a) dorsal, b) hyaline Röhre. Abb. 17. AulophoraLarve (dorsal). Abb. 18. Aulophora-Larve (20-30 Tage alt), dorsal 

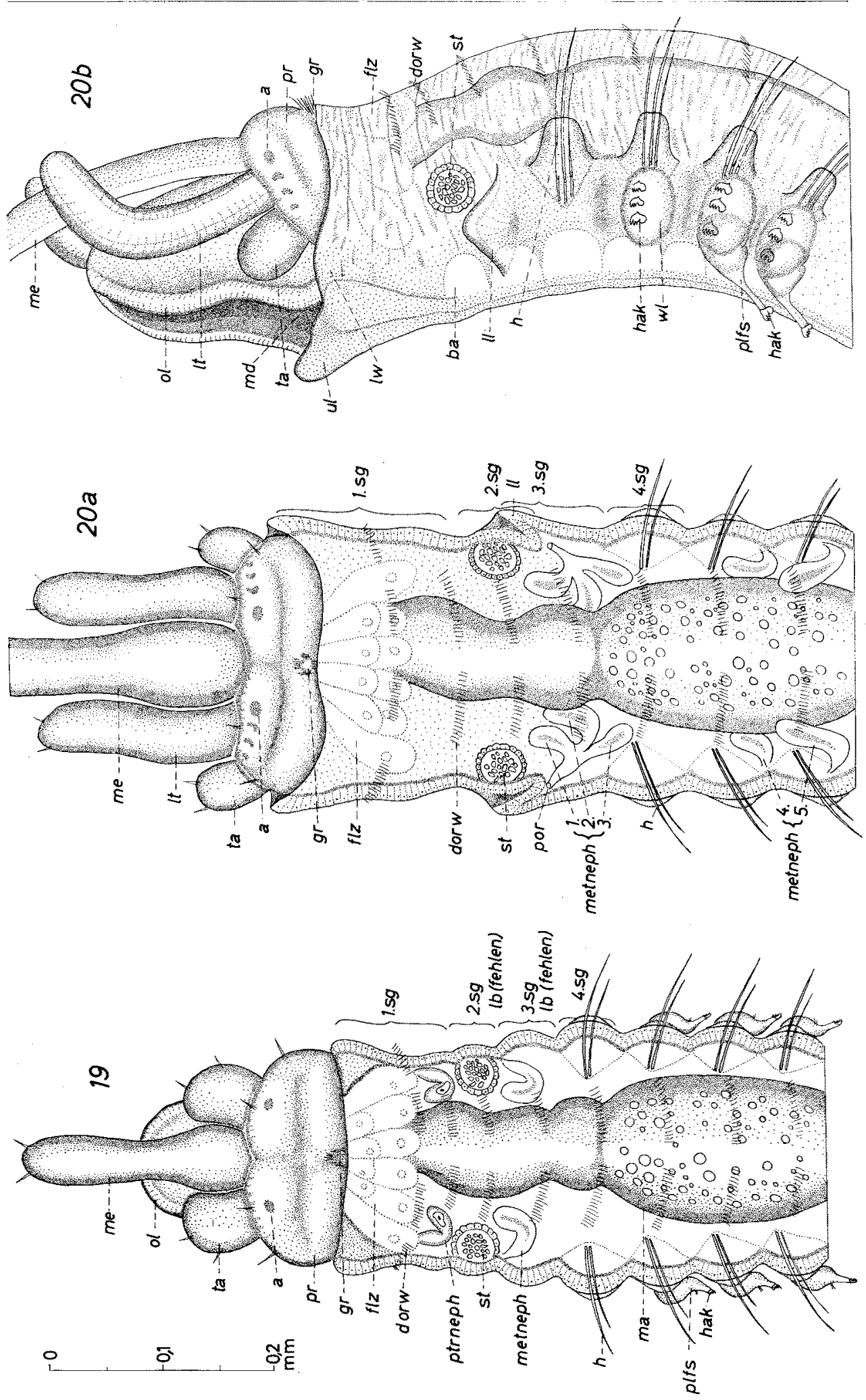

Tafel 5

Abb. 19. Aulophora-Larve (vorderer Körperabschnitt dorsal). Abb. 20. Aulophora-Larve, a) vorderer Körperabschnitt dorsal, b) vorderer Körperabschnitt seitlich 

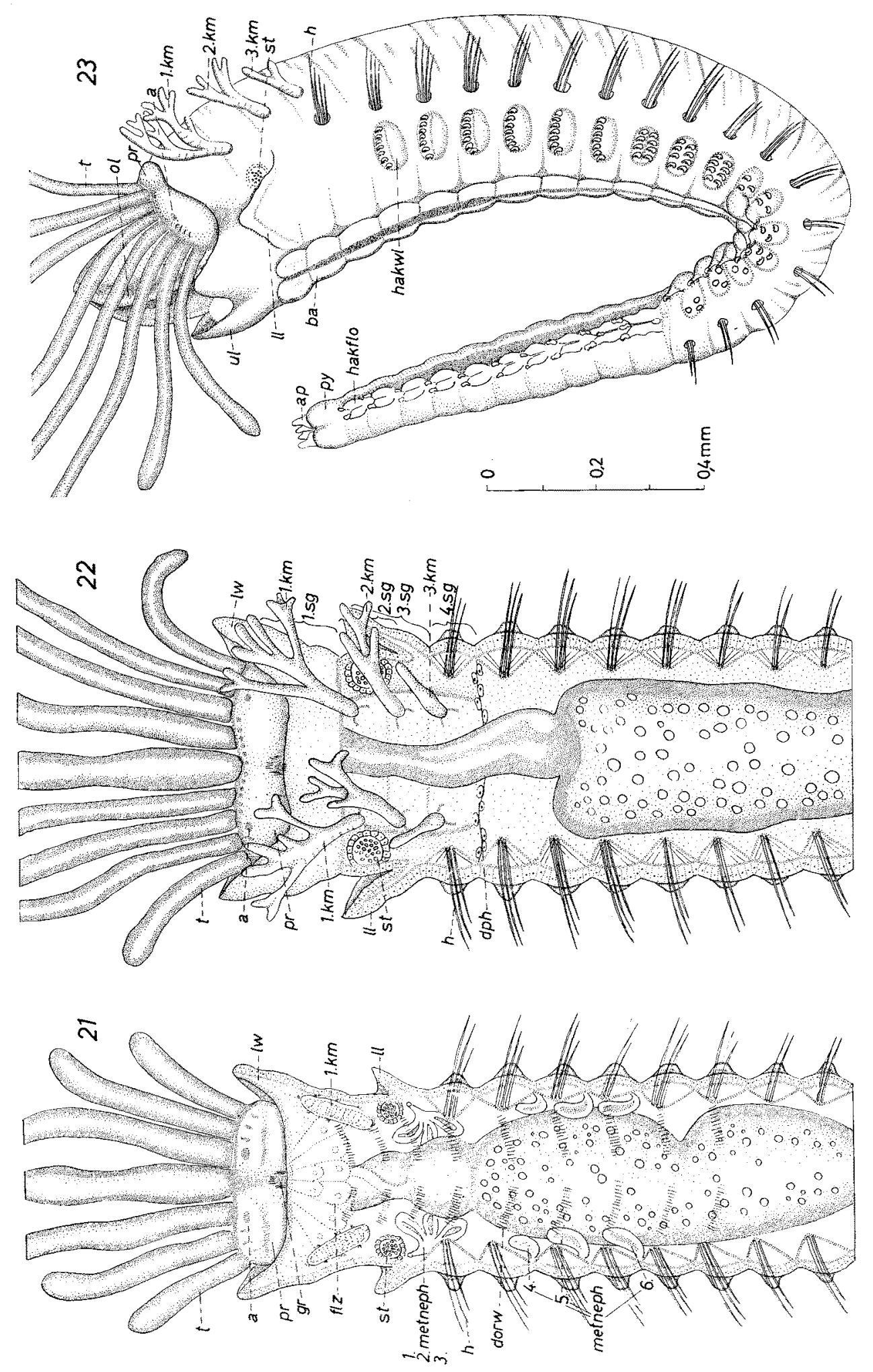

Tafel 6

Abb. 21. Bodenreifes Lanice-Stadium (58-60 Tage alt) dorsal. Abb, 22. Lanice-Juvenil (dorsal). Abb. 23. Lanice-Juvenil (seitlich) mit 20 Thoraxsegmenten und 10 Abdominalsegmenten 
Tatbestand deckt sich auch mit der Feststellung Seilachers (1951, S. 275) über die W-Bauten von Lanice-Röhren. Da die W-Röhre nach Senlacher „Ausdruck einer Entwicklung" ist, darf auch sie nicht als Endform gelten, da die Tiere nach Fertigstellung der w-förmigen Röhre noch längst nicht ausgewachsen sind.

So bleibt die Frage noch immer offen, ob die Tiere zu einer bestimmten Zeit ihre Wohnröhre verlassen, und wenn sie es tun, ob diese Wanderung im Zusammenhang mit Längen- und Dickenwachstum der Tiere gesehen werden muß. Daß die Würmer während des Geschlechtsaktes die Röhre nicht verlassen, konnte durch eigene Untersuchungen festgestellt werden.

Doch bleibt beispielsweise noch immer im Dunkeln, nach wieviel Jahren die Tiere geschlechtsreif werden und welches Alter sie erreichen können.

Nach diesen einleitenden Bemerkungen über systematische Stellung, Morphologie, Vorkommen, Verbreitung und Lebensweise von Lanice-conchilegaImago, soll nun die Frage erörtert werden, wie sich die Tiere vermehren, welche Entwicklungsphasen die Larven durchlaufen, welche larvale Bildungen in Anpassung an das pelagische Leben entstehen und welche Veränderungen sich bei Ohergang larvaler in bleibende Organe vollziehen.

\section{Die Geschlechter und die Entwicklung der Gameten} I. Unterscheidung der Geschlechter und Zeitpunkt der
Geschlechtsreife

Am Anfang der Experimente standen die fundamentalen Fragen nach den äußeren Unterscheidungsmerkmalen der Geschlechter und nach der zeitlichen Festlegung der Geschlechtsreife. Nur eine Beantwortung dieser Fragen konnte die Voraussetzung für die Durchführung der Befruchtung an Lanice conchileg $a$ schaffen.

Schon 1887 stellte Mexer fest, daß die meisten Terebelliden getrenntgeschlechtlich sind. Auch Lanice conchilega weist eine Trennung der Geschlechter auf, wobei „sich die Ovarien und Hoden vom Vas ventrale aus auch noch auf die medianen Enden der intersegmentalen Seitenzweige der ersteren", erstrecken. „Hier bilden sie eine krause Masse um die Blutgefäße herum und sind ganz von der Bauchdrüse verdeckt" (MeYer 1887, S. 642/643). Bei Lanice treten die Geschlechtsdrüsen nur im 7. und 8. Segment auf und zwar in periodischen Abständen, wie Mereks Arbeit bereits zeigte. Doch über den Zeitpunkt der sich bildenden Keimdrüsen wurde von MEYER nichts ausgesagt.

So bestand die erste Untersuchung darin, diesen Zeitpunkt zu fixieren bzw. das Auftreten der Geschlechtsprodukte in der Leibeshöhle festzustellen.

Da die zu untersuchenden Tiere alle aus List/Sylt stammten, beziehen sich die nun folgenden Angaben über den Zeitpunkt der Geschlechtsreife nur auf das Gebiet der Deutschen Bucht.

Innerhalb eines Jahres, in wöchentlichen Abständen, wurden jeweils 10 bis 15 erwachsene Tiere im Watt gegraben und ihre Cölomflüssigkeit nach dem Vorhandensein männlicher oder weiblicher Geschlechtsprodukte untersucht. Für die nach einem aufgestellten Zeitplan erfolgte Beschaffung und Fixierung des Materials (fixiert in 4\% Formol) durch technische Kräfte der Biologischen Anstalt Helgoland in List/Sylt, sage ich an dieser Stelle meinen besonders herz- 
lichen Dank. Wie schwierig das Graben von Lanice gerade in den Wintermonaten war, wenn das Watt mit Eisschollen bedeckt ist und die Tiere sich tief in den Boden zurückgezogen haben, läßt sich unschwer vorstellen.

Diese Untersuchung zeigte das erste Auftreten männlicher und weiblicher Gameten im Januar und Februar. Anfangs vereinzelt, später der Zahl nach zunehmend, ließen sich die Spermatocytenklumpen in ihrer scheibenförmigen Gestalt gut von den Cölomocyten unterscheiden, während sich die jüngsten Oocyten als $6 \mu$ große durchsichtige Scheiben kaum von den etwa gleichgroßen Cölomocyten abhoben.

Ende Februar bis Anfang März war dann eine starke Gametenvermehrung zu verzeichnen, wobei sich das Zahlenverhältnis zwischen Cölomocyten und Gameten zugunsten der Gameten verschiebt. Gleichzeitig lassen die Oocyten einen Größenzuwachs und Dottervermehrung erkennen. Mit zunehmender Braunfärbung, als Zeichen der Dotterzunahme, läuft die Durchmesservergrößerung der Oocyten parallel. Sie erreicht Mitte April bis Ende Juni ihren Höhepunkt. Auch im männlichen Geschlecht bahnt sich zu diesem Zeitpunkt die Reife an. Durch Teilung der Spermatocyten entstehen Spermatiden, die solange miteinander zusammenhängen, bis die Umbildung zu frei beweglichen Spermatozoen erfolgt ist.

In den folgenden Monaten: August, September, Oktober, November, Dezember treten reife Geschlechtsprodukte nur noch vereinzelt in der Leibeshöhlenflüssigkeit auf, wogegen sich die Cölomocyten wieder stark vermehrten. Die Existenz derartiger Restgameten ist wohl auf die Tatsache zurückzuführen, daß in einem Geschlechtstier verschieden weit entwickelte Gametenstadien vorhanden sind. Nach wiederholter Abgabe der reifen Geschlechtsprodukte können sich allerdings noch immer "Nachkömmlinge" in der Leibeshöhle befinden, die zwar heranreifen aber nicht mehr ausgestoßen werden.

In der Zeit zwischen Juli und Mitte April, also nach der Entleerung der Geschlechtsprodukte und während der beginnenden Neubildung, kann eine äußere sexuelle Differenzierung an den Tieren nicht festgestellt werden. Nur in der kurzen Periode der Vollreife, von Mitte April bis Ende Juni, färben sich die Weibchen durch die Anhäufung reifer Eier im Inneren rotbraun und die Männchen gelb-weiß. Diese Beobachtung eines charakteristischen „Reifekleides" stimmt mit Angaben in der Literatur über andere Sedentaria überein. Thorson (1946, S. 124) erwähnt z. B. für Terebella strömii (Sars) eine Beschreibung von WillemöEs-Suhm (1871), welche gelbgrüne Färbung beim Weibchen und milchig-weiße beim Männchen als sekundäres Geschlechtsmerkmal angibt. Ebenso stützt Anderson (1959, S. 91) seine Kenntnis über Scoloplos armiger auf eine Mitteilung von MAU (1882), der die Braunfärbung des Weibchens der Weißfärbung des Männchens gegenüberstellt. Abgesehen von einer spezifischen Farbveränderung während der Geschlechtsperiode, konnten bei Lanice conchilega keine weiteren morphologischen Unterscheidungsmerkmale zwischen den Geschlechtern beobachtet werden.

\section{Die weibliche Gametenentwicklung}

Öber die Entstehung der Gonaden im weiblichen Geschlecht kann im einzelnen nichts ausgesagt werden. Die durch intensive Zellteilung differenzierter Peritonealzellen entstandenen Oocyten proliferieren einzeln in die Leibeshöhle. Sie pulsieren durch die ständigen Kontraktionsbewegungen des Mutter- 
tieres so lange im Cölom, bis ihre Wachstums- und Reifezeit beendet ist und die reifen Eier entleert werden können.

In keinem Stadium der Dotterbildung lassen die Oocyten umhüllende Follikel- oder Nährzellen erkennen. Es handelt sich somit bei der LaniceEibildung um eine sog. solitäre im Gegensatz zur alimentären Eientwicklung.

Durchgeführte Messungen an verschiedenen Oocytenstadien ergaben Durchmessergrößen von $6 \mu$ als den kleinsten und $255 \mu$ als den größten gemessenen Entwicklungsstadien (Abb. $1 \mathrm{~A}$ ). Diese Meßergebnisse zeigen das erstaunliche Wachstum von etwa $250 \mu$ in einem Zeitraum von ungefähr 2 Monaten.

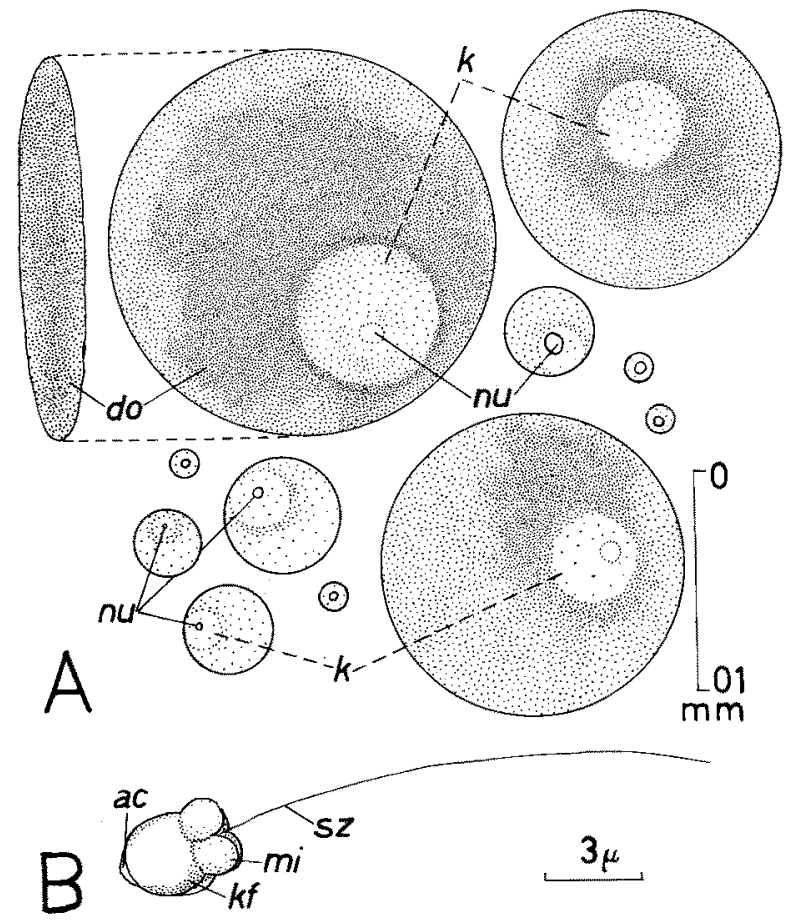

Abb. 1. $A=$ Oocytenstadien aus der Leibeshöhlenflüssigkeit (Aufsidht und Seitenansicht). $\mathrm{B}=$ Spermium. $\mathrm{ac}=$ Akrosom, $\mathrm{do}=$ Dotter, $\mathrm{k}=$ Kern, $\mathrm{kf}=\mathrm{Kopf}, \mathrm{mi}=$ Mittelstück, $\mathrm{nu}=$ Nukleolus, $\mathrm{sz}=$ Schwanz

Die Oocyten sind flache, wegen ihres geringen Dottergehaltes anfänglich farblose Scheiben. Sie erlangen mit zunehmender Dotterbildung eine rote bis dunkelbraune Farbe. Während dieser Wachstumsphase der Oocyten treten die Cölomocyten immer mehr zurück und es bleibt die Frage, ob die in der Leibeshöhle zirkulierenden Geschlechtsprodukte die Funktion der Cölomocyten übernehmen. Denn nach Abgabe der Genitalprodukte werden die eben erwähnten Cölomkörperchen wieder neu gebildet, so daß der ursprüngliche Hiatus wieder hergestellt ist.

Werden die befruchtungsfähigen Eier ins Seewasser ausgestoßen, so runden sie sich zu einer Kugel, wobei die Frage auftaucht, ob es sich bei dieser Formveränderung um eine Quellung oder auf Grund unterschiedlicher Druckverhältnisse um einen Verkleinerungsprozeß handelt. Die Abrundung zur Kugelgestalt erfolgt bei einem Durchmesserverlust von $255 \mu$ auf $132 \mu$. Damit gewinnt die Vermutung, daß die Ursache des Abrundungsprozesses in den un- 
terschiedlichen Druckverhältnissen zwischen Cölomdruck und Außendruck des Seewassers zu sehen ist, an Wahrscheinlichkeit, zumal auch die Volumina von Kugel (ausgestoßenes Ei mit $132 \mu$ Durchmesser) und Scheibe (reifes Ei im Cölom, mit $255 \mu$ Durchmesser und etwa $35 \mu$ Scheibendicke) mit dem Wert $1202000 \mu^{3}$ gleich sind.

Das unbefruchtete Ei ist von einer schützenden Eimembran umgeben, deren Oberfläche keine sichtbaren Strukturen aufweist, solange sich das Ei im Cölom bewegt. Diese Eihülle ist ein Ausscheidungsprodukt des Eies selbst und kann unter die Kategorie der primären Eihüllen gestellt werden.

Erst nach Ausstoßung der Eier tritt eine deutlich sichtbare Strukturierung der Eimembran auf (Abb. 2 und Taf. 1 Abb. 1). Leisten (vl) in Form eines Wabenmusters überziehen die gesamte Oberfläche, wobei jeweils eine Wabenspitze in einen kolbenförmigen nach außen stehenden Fortsatz (f) ausgezogen

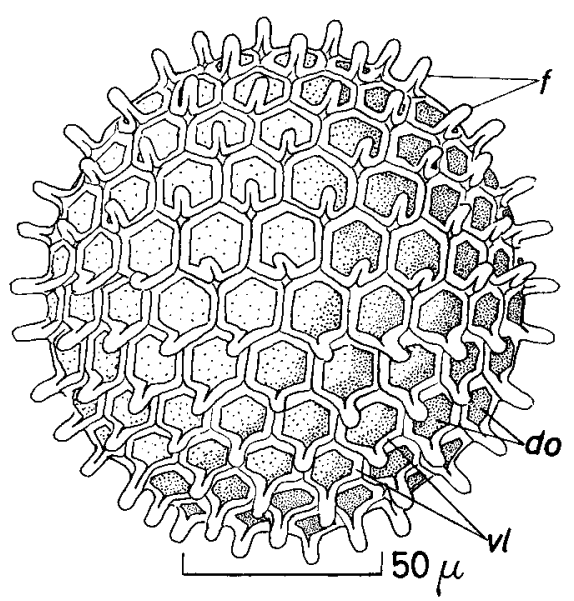

Abb. 2. Modell eines reifen, kugeligen Eies nach dem Ausstoßen aus dem Muttertier. Charakteristisches Merkmal ist die strukturierte Eimembran. do $=$ Dotter, $\mathrm{f}=$ Fortsatz, $\mathrm{vl}=$ Versteifungsleisten

ist. Durch den großen Dotterreichtum (do) und die dadurch verursachte Undurchsichtigkeit der Eier hat es Mühe gemacht, das Strukturbild zu erkennen. Da eine fotografische Aufnahme eines Eies nur den optischen Rand mit seinen sichtbaren Fortsätzen zeigen würde, erschien die Herstellung eines Modells (Abb. 2) zur Veranschaulichung notwendig.

Diese plötzlich erscheinende Strukturierung, die beim Austritt des Eies aus der Cölomflüssigkeit des Muttertieres in das Seewasser zu sehen ist, läßt sich in ihrer Entstehung aus dem oben beschriebenen Formveränderungsprozeß erklären. Die sechseckigen Versteifungsleisten müssen bereits die Oberfläche des scheibenförmigen Eies im Muttertier überziehen. In dem Augenblick jedoch, in dem sich die Scheibe zur Kugel rundet und die Oberfläche sich verkleinert, verringert sich auch der ursprüngliche Wabendurchmesser, und dies hat das $\mathrm{Ab}$ heben jeweils eines Fortsatzes zur Folge.

Ob die Oberfläche des Lanice-Eies eine morphologische Besonderheit dieser Polychaeten-Art ist, läßt sich wegen mangelnder Beobachtungen an Eiern anderer Polychaeten nicht mit Sicherheit sagen. Auch über die Bedeutung einer derartigen Eihüllenstruktur können nur Vermutungen geäußert werden. Neben einer möglichen Aufgabe bei der Besamung, ließe sich auch denken, daß die 
Fortsätze, die dem Ei ein igelähnliches Aussehen verleihen, ein erhöhtes Schwebevermögen bewirken. Letzteres wäre ohne Zweifel eine sinnvolle Einrichtung zur Erhöhung der Befruchtungsquote.

\section{Die männliche Gametenentwicklung}

Wie die Oogenese so vollzieht sich auch die Spermatogenesse innerhalb der Leibeshöhle. Die Spermatogonien lösen sich vom Genitalgewebe und wachsen zu Spermatocyten I. Ordnung heran. Diese flottieren, angetrieben durch die Körperkontraktionen, als abgeflachte Klumpen in der Cölomflüssigkeit. Von einer Eigenbewegung der Spermatocyten in diesem Stadium kann noch nicht die Rede sein. Durch Reduktionsteilung der Spermatocyten I. Ordnung entstehen die Spermatocyten II. Ordnung. Weitere Teilungsschritte erzeugen dann die für die Männchen so charakteristischen, walzenförmigen Spermatidenansammlungen. Erst mit der Umbildung der Spermatiden in Spermatozoen beginnen die nach außen gerichteten Geißeln zu schlagen. Der Walzenkörper bewegt sich nun selbständig durchs Cölom, bis er in seine Spermatozoenbestandteile zerfällt.

$\mathrm{Ob}$ die Spermatiden nur an der Oberfläche des walzenförmigen Körpers aufsitzen oder ob auch das Innere von Spermatiden erfüllt ist, konnte nicht geklärt werden. Denkbar wäre allerdings im Inneren eine Anhäufung abortiver Samenzellen oder Protoplasmamaterial als einstige Nahrungsquelle der heranwachsenden und sich entwickelnden männlichen Gameten.

Der Bau des Lanice-Spermatozoon weicht wohl nicht vom Normaltyp ab (Abb. 1B). Dem kugelförmigen Kopf (kf) sitzt am vorderen Ende eine hyaline Plasmakappe auf, das Akrosom (ac), das beim Einbohren des Spermiums in die Eihülle eine wichtige Funktion einnimmt. Nach hinten schließt sich an den Kopf (kf) das Mittelstück (mi) mit seinen vier runden plasmatischen Körpern an. In ihrer Mitte inseriert der Schwanz (sz) als Geißel. Kopf und Mittelstück sind $3,75 \mu$ groß, während die Länge der Geißel etwa $50 \mu$ beträgt.

Der eben geschilderte Bau stimmt im großen und ganzen mit dem von Schaxel (1912, S. 401) beschriebenen Aricia-Spermium überein.

\section{Abgabe der Geschlechtsprodukte}

Auf welche Weise gelangen nun die Geschlechtsprodukte aus dem Tierkörper ins Freie?

Wie bekannt entwickelten sich innerhalb der Polychaeten verschiedene Methoden, Geschlechtsprodukte abzugeben. Die einfachste Möglichkeit ist das Zerreißen der Körperwand. Dadurch werden die Eier und Spermien frei und können sich außerhalb der Geschlechtstiere vereinigen. Der Tod ist wahrscheinlich die Folge dieses Aktes. In der Abtrennung und späteren Auflösung fertiler Segmente ist eine weitere Möglichkeit gegeben, die Gameten zu entlassen.

Bei den meisten Polychaeten jedoch, auch bei Lanice conchilega, werden die reifen Gameten durch die Wimpertrichter der Nephridien aufgenommen und nach außen abgegeben.

Das Verhalten der Tiere bei der Abgabe der Geschlechtsprodukte wird sehr selten beschrieben, weil es meist unbekannt ist. Da Verfasserin in der 
glücklichen Lage war, diesen Vorgang im Laboratorium zu beobachten, soll er nun exakt beschrieben werden.

Wie bereits erwähnt wurde, lassen sich die adulten Tiere im reifen $\mathrm{Zu}$ stand oder im Zustand beginnender Reife leicht voneinander unterscheiden. Infolge der sich frei in der Leibeshöhle bewegenden Genitalprodukte nehmen die Männchen eine gelblich-weiße, die Weibchen eine rotbraune Färbung an. Auf Grund dieser neugewonnenen Unterscheidungsmöglichkeit war es einfach, die Tiere paarweise in die schon beschriebenen Akkugläser einzusetzen. Die für die Versuche notwendige Anzahl geschlechtsreifer Tiere wurden mit ihrer Sedimentröhre bei ablaufendem Wasser im Watt gegraben und im Labor möglichst rasch in die vorbereiteten Becken senkrecht eingesetzt. Meist entfaltete sich innerhalb weniger Stunden eine lebhafte Bautätigkeit. Die Tiere besserten die beschädigten Röhrenteile aus und bauten den beim Graben verlorengegangenen zweiten Schenkel der u-förmigen Röhre wieder neu. Über Nacht erfolgte dann in den häufigsten Fällen das Aufsetzen der sog. Fransenkrone, wie es von Ziegelmeier (1952, S. 112) beschrieben worden ist.

Da Entwicklungsvorgänge durch Temperaturschocks, konstant hohe bzw. niedrige Temperaturen, in ihrer Geschwindigkeit positiv oder negativ beeinflußt werden können, lag es im Interesse eines normalen Ablaufes der Entwicklungsprozesse, natürliche Temperaturbedingungen zu schaffen. $\mathrm{Zu}$ diesem Zweck wurden die Versuchsbecken in einem ungeheizten Raum aufgestellt. Die Wassertemperaturen entsprachen auf diese Weise den Schwankungen der Außentemperaturen.

Tägliche Temperaturmessungen in den Versuchsbecken ergaben dann analog den Temperaturveränderungen der Außenwasserverhältnisse, kontrolliert und gemessen durch den Hafenmeister in List/Sylt am Lister Hafen, ein langsames Ansteigen der Temperaturen in den Zuchtbecken. Die Meßergebnisse sind aus der folgenden Tabelle zu entnehmen:

\begin{tabular}{ccc} 
Datum & $\begin{array}{c}\text { Temperatur in den Aquarien } \\
\text { in }{ }^{0} \mathrm{C}\end{array}$ & $\begin{array}{c}\text { Temperatur bei Niedrig- } \\
\text { wasser am Lister Hafen } \\
\text { in }{ }^{0} \mathrm{C}\end{array}$ \\
\hline 7. März 1960 & 5,7 & 2,2 \\
8. März 1960 & 5,8 & 1,1 \\
9. März 1960 & 5,8 & $-0,4$ \\
10. März 1960 & 6,3 & 0,2 \\
11. März 1960 & 7,2 & 0,5 \\
12. März 1960 & 7,5 & 1,0 \\
13. März 1960 & 7,9 & 1,5 \\
14. März 1960 & 8,8 & 1,8 \\
15. März 1960 & 8,5 & 2,2 \\
16. März 1960 & 8,9 & 2,3 \\
17. März 1960 & 7,7 & 1,8 \\
18. März 1960 & 7,2 & 1,7 \\
19. März 1960 & 8,1 & 2,1 \\
20. März 1960 & 8,1 & 2,1 \\
21. März 1960 & 8,1 & 2,4 \\
22. März 1960 & 8,5 & 3,2 \\
23. März 1960 & 8,8 & 3,0 \\
24. März 1960 & 10,3 & 3,4
\end{tabular}

Die am 7. März 1960 bei $5,7^{\circ} \mathrm{C}$ eingesetzten Tiere laichten am 24. März bei $10,3^{\circ} \mathrm{C}$ ab. Interessanterweise hat sich bei wiederholten Versuchen herausgestellt, daß die Würmer bei Temperaturen unter $10^{\circ} \mathrm{C}$ im Labor nicht ab- 
laichten. Auch Beobachtungen im Watt entsprachen dieser Feststellung. Bevor die Außenwassertemperaturen nicht $10^{\circ} \mathrm{C}$ erreichten, konnten weder Eier noch junge Entwicklungsstadien in Bodennähe aus dem Plankton gefischt werden. Wahrscheinlich spielt für das Reifen der Geschlechtsprodukte die Temperatur von $10^{\circ} \mathrm{C}$ als Minimalwert eine wesentliche Rolle.

Die am 7. März 1960 eingesetzten Lanice-Pärchen zeigten in den folgenden Tagen und Wochen außer der Bautätigkeit und dem Abtasten des Bodens und der Bäumchen nach Nahrung nichts Auffälliges in ihrem Verhalten. Da sich innerhalb kurzer Zeit in den Versuchsbecken ein reichlicher Algenbewuchs an den Wänden der Becken entfaltete, konnte auf eine Fütterung der Tiere verzichtet werden, was die Pflege bedeutend erleichterte.

Am 24. März fiel eine deutliche Unruhe bei einem Tier auf. Lebhaft kreisende Tentakelbewegungen über dem Röhrenrand wechselten mit tastenden Kriechbewegungen über dem Sediment ab. Schließlich verharrten die in einem großen Bogen um die Röhre gespannten Fangarme. Da weder Steinchentransport noch Nahrungsaufnahme beobachtet werden konnte, schien sich dieser Wurm in einem veränderten Zustand zu befinden. Diese Ansicht wurde noch vertieft durch rhythmische Spannungs- und Entspannungsbewegungen der Tentakeln, die auf eine Pumpbewegung der Tiere hinwies.

Ohne mit dem Kopf über den Röhrenrand zu schauen, stieß der Wurm plötzlich eine Eierwolke (Abb. 3 A) hervor. Nur kurze Zeit blieb die Wolke über dem Röhrenrand stehen. Dann lösten sich langsam die Eier aus dem Verband, um sich frei im Becken zu verteilen.

Es ist wohl kein $Z$ weifel, daß die rhythmischen Spannungs- und Entspannungsbewegungen in engem Zusammenhang mit dem Laichakt gesehen werden müssen.

Das Ausstoßen der Eier wiederholte sich in Abständen von 5-6 Minuten und dauerte in diesem Beobachtungsfall insgesamt 1/2 Stunden. Unter Aquariumsbedingungen sind die Eier in der Lage, einige Stunden im Wasser zu schweben, ohne sofort zu Boden zu sinken und unbefruchtet der Zerstörung anheimzufallen.

Die Beobachtungen am 24. März 1960 standen unter besonders glücklichen Umständen, denn kurz nach dem Ablaichen des Weibchens setzte der Laichakt des Männchens ein. Ohne intensive Tentakelbewegungen, wie sie beispielsweise beim Weibchen beobachtet wurden, lösten sich vom Röhrenrand milchigweiße Schlieren ab (Abb. $3 B$ ). Wie Untersuchungen zeigten, handelte es sich bei diesem Ausstoßprodukt um eine Spermienwolke und nicht, wie anfangs angenommen wurde, um eine Kotfontäne. Allmählich entfernte sich die Spermienwolke von der Röhre und löste sich nebelhaft im Wasser auf.

Man kann annehmen, daß ein chemischer Reiz von den kurz vorher abgegebenen Eiern die Spermienabgabe der Männchen angeregt hat. Eine experimentelle Bestätigung dieser Annahme steht jedoch noch aus.

Wie aus den oben ausgeführten Beobachtungen hervorgeht, verläßt weder das Männchen noch das Weibchen seine Röhre, um den Geschlechtspartner durch Berühren oder Betasten zum Geschlechtsakt aufzufordern, wie es z.B. Herpin (1925) von Nicolea zostericola (Oerstedt) beschreibt. Die Geschlechtsprodukte werden ohne Kopulationsvorgänge frei ins Wasser abgegeben, wo die Spermien die Eier befruchten.

Durch die Abgabe der Gameten in beiden Geschlechtern bahnt sich im Inneren des Tierkörpers eine erstaunliche Umorganisierung an, die von den 


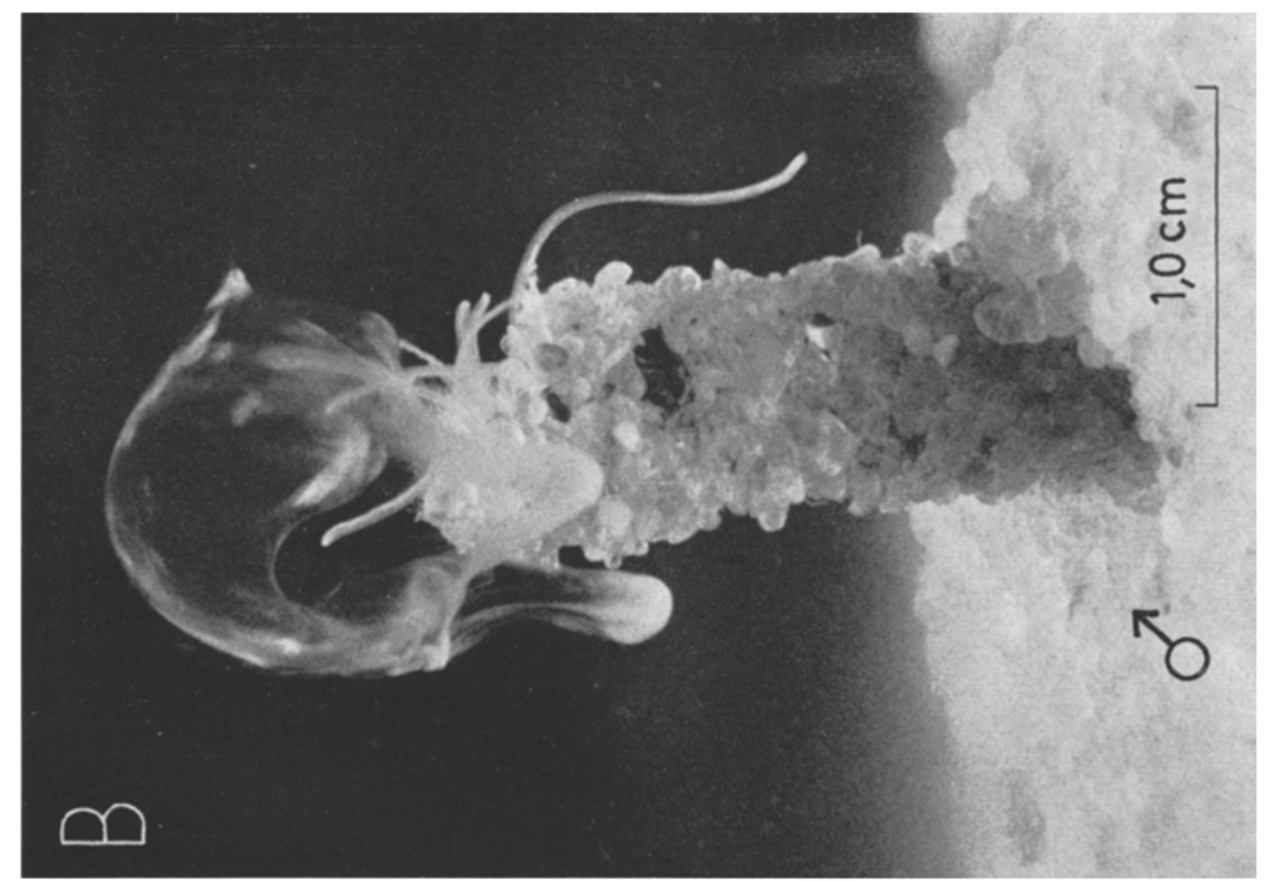

공

:

此

r

है

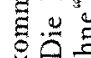

造语

要曹

(

:

ป है

政

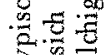

E.

प्रे

긍

을

․․․

고

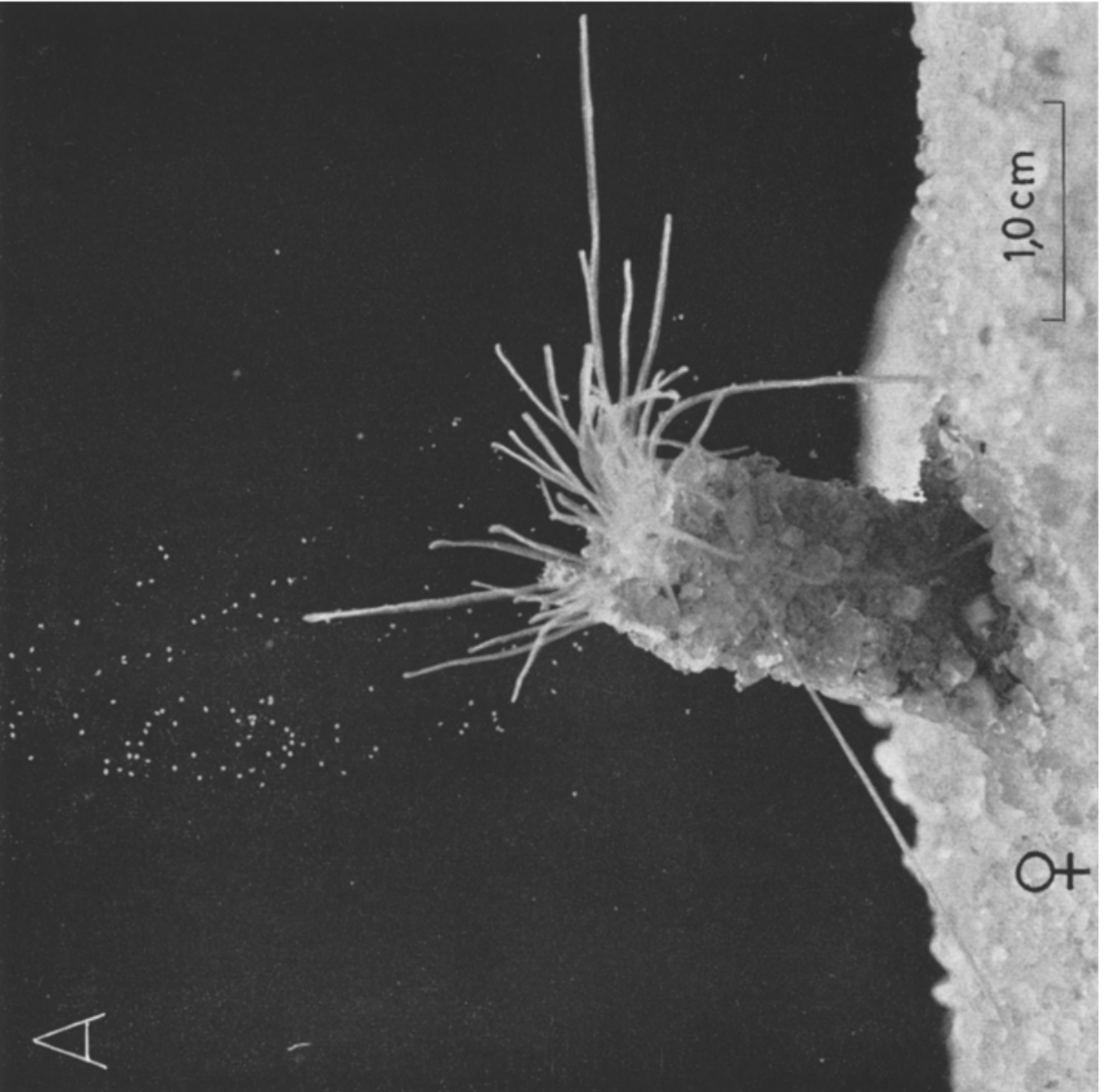

a.

苍

氝

过

羟

产密

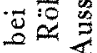

का

它㕰

氙

雪

.

家苛

当

द焉

풍

范

ज्ञ

3011

용

를

䗆

:

过

⿶凵

ㄴ.

ए द्वु

웅 
Würmern überstanden wird und nicht zum Tode führt. Nach dem Ausstoßen der Gameten nämlich müssen die Cölomocyten, die während der Oogenese und Spermatogenese zurückgebildet wurden, ganz plötzlich durch Neubildung wieder ersetzt werden. Man könnte sich vorstellen, daß eine so rasche Umstellung des Körpers nach dem Laichakt einen empfindlichen Eingriff in das Leben der Tiere bedeutet.

E. Die Entwicklungsvorgänge von der Befruchtung des Eies bis zum bodenreifen Stadium

\section{Die Embryonalentwicklung}

Nach der Befruchtung der Eier in den Zuchtbecken wurden diese aus den Becken herauspipettiert und in kleine Glasschälchen übertragen.

Im Kapitel über die Methoden wurde bereits davon gesprochen, daß die Zuchtschälchen mit entkeimtem Seewasser angefüllt worden waren. Die Notwendigkeit allerdings, das Seewasser zu entkeimen, konnte erst nach einigen Mißerfolgen während der. Aufzuchtversuche erkannt werden. Die sehr dotterreichen, undurchsichtigen Eier sind in ihrer langsamen Entwicklung und in der Ausbildung wenig beweglicher Trochophora-Larven den normalerweise auch in filtriertem Seewasser vorkommenden sehr beweglichen Ciliaten nicht gewachsen. Sie werden von diesen befallen und aufgefressen. Die Erhaltung der Entwicklungsstadien war in den ersten Tagen ihres Wachstums erst mit der Entkeimung des Seewassers möglich.

Die Teilung der Eier ist total (Taf. 1, Abb. 2, 3, 4); doch wegen des Dotterreichtums furchen sie sich inäqual (siehe 2-Zellen-Stadium Taf. 1, Abb. 2) nach dem Spiraltyp (Taf. 1, Abb. $4=8$-Zellen-Stadium und Abb. $5=16$ Zellen-Stadium). Innerhalb von 6 Stunden ist das 64-Zellen-Stadium (Taf. 1, $\mathrm{Abb}$. 6) erreicht, an welchem sich bereits große, äquatoriale, in zwei Reihen angeordnete Zellen differenziert haben. (In Taf. 1, Abb. 7 sind sie als Trochoblasten [tr] erkennbar.) Diese 16 Abkömmlinge des 1. Mikromerenquartetts haben die Eigenschaft, Wimpern auszubilden und werden als Trochoblasten bezeichnet.

Mit der Ausbildung von Wimpern ist der Embryo normalerweise in der Lage, seine Eihülle selbst zu zerreißen und abzustreifen. Genaue Kenntnis über den Verlauf dieses Embryonalschritts ist allerdings in den seltensten Fällen bekannt. Diesen entscheidenden Übergang von der Embryonalzeit zur larvalen Periode einmal näher zu betrachten, schien daher besonders wichtig. Hinzu kam noch die Beobachtung, daß die Anfälligkeit und Empfindlichkeit der Embryonen zu diesem Zeitpunkt einen Höhepunkt erreichte, der in manchen Kulturschälchen die Ausgangszahl der Entwicklungsstadien auf die Hälfte reduzicrte.

Nach beendigter Ausbildung der Trochoblasten und damit der äquatorialen Bewimperung des Embryos (Taf. 1, Abb. 6), konnte eine rotierende Bewegung des Embryos innerhalb der Eihülle nicht festgestellt werden. Dagegen war deutlich wahrnehmbar, daß die Wimpern immer an ein und derselben Stelle gegen die Eimembran schlugen, bis schließlich im ganzen Bereich der Wimpernzone die Eihülle zwischen den wabenförmigen Versteifungsleisten durchbohrt war, wie das aus der schematischen Darstellung (Abb. 4) sichtbar wird. 
Wenn auch die Eihülle in der prototrochalen Zone durch den Wimpernschlag zwischen den Leisten durchbrochen war, so blieb die Hülle am vegetativen und animalen Pol unverändert und unzerstört.

In diesem Zustand beginnt eine langsame, richtungslose Bewegung, wobei der Embryo jede Gelegenheit, sich irgendwo festzuhalten, wahrnimmt. So bilden sich Klumpen von Embryonen-Ansammlungen um kleine in die Schälchen unvermeidbar gefallene Fäserchen oder Staubpartikel.

Bei der Festigkeit der Eimembran ist es nicht wahrscheinlich, daß die Embryonen durch einfache Bewegung kreisender oder trudelnder Art in der

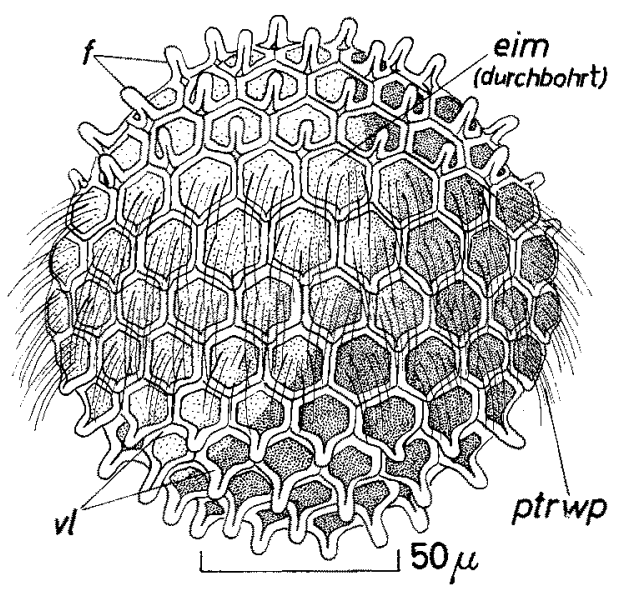

Abb. 4. Modell eines Lanice-Embryos, der mit dem Schlagen seiner Prototrochwimpern die Eimembran in der äquatorialen Zone zerstört hat, die Versteifung der Oberfläche aus eigener Kraft jedoch nicht zerreißen kann. eim $=$ Eimembran, $f=$ Fortsatz, ptrwp $=$ Prototrochwimpern, $\mathrm{vl}=$ Versteifungsleisten

Lage sind, die Versteifung zu zerreißen und die Hülle abzustreifen. Eine mechanische Reibung muß also bei diesem Prozeß des Abstreifens eine Rolle spielen.

Mit einem Pol sich mittels ihrer Fortsätze anheftend, führen die Embryonen bei schiefer Achsenlage ständige Rotationen um die eigene Achse aus, wobei sie bei jeder Umdrehung im Berührungskreis die Unterlage streifen und so durch stetige Reibung ein Platzen der Hülle veranlassen.

\section{Die Larvalentwicklung}

Nachdem sich der Embryo, der sich durch eine breite Prototrochbewimperung auszeichnet, aus seiner Hülle befreit hat, tritt er als Larve in das planktische Leben ein. Mit diesem Entwicklungsabschnitt beginnt eine neue Phase, die nicht nur der Erhaltung der Art dient, sondern vor allen Dingen für ihre Verbreitung von ausschlaggebender Bedeutung ist.

Im Verlauf des pelagischen Lebens kommt es nun zu mannigfaltigen Ausbildungen, die das Schwebevermögen der Larven im freien Wasser erhöhen.

Ganz allgemein durchläuft die Polychaeten-Larve während ihrer Entwicklung verschiedene, durch besondere Merkmale charakterisierte Stadien, die NoLTe (1938, S. 68) wie folgt unterteilt: 
A. Schwimmorgane werden durch primäre Wimperringe repräsentiert. I. ungegliederte Larven mit primären Wimperringen, wie sie Prototrochophora und Trochophora darstellen.

II. gegliederte Larven, die in der Metatrochophora I noch keine Parapodien zeigen, während die Gliederung mit parapodealen Anhängen bei der Metatrochophora II ausgeprägt ist.

B. Um eine Steigerung des Schwebevermögens und der Schwimmfähigkeit zu erzielen, können zur primären Bewimperung sekundäre Schwimmorgane hinzutreten.

Z. B. durch Parapodien und Borsten bei Nectochaeta, durch die Eigenschaft der Körperkrümmung bei Nectosoma und Chaetophora oder durch die Ausbildung einer Umbrella, die sich passiv bei Nectumbrella aktiv bei Mitraria in Tätigkeit befindet.

Der Versuch, die im Verlaufe der Entwicklung entstehenden LaniceLarven in das NoLtesche Schema zu ordnen, gelingt nur insofern, als die Phasen der Prototrochophora, Trochophora, Metatrochophora I und Metatrochophora II ohne Auslassung eines Stadiums durchlaufen werden. Dann erfolgt jedoch ein Entwicklungsschritt, dessen Einordnung Schwierigkeiten bereitet. Ein bislang noch nicht berücksichtigter Vorgang findet statt. Die Larven bleiben auf dem Metatrochophora-II-Stadium stehen und schaffen sich ein Schwebevermögen nicht durch die Bildung von Körperanhängen, sondern durch den Bau einer selbst erzeugten Schleimröhre.

Das sehr lange Planktonleben der Lanice-Larven von etwa zwei Monaten ist, wie die eigenen Studien ergaben, der Beweis für die wirkungsvolle Einrichtung dieses "Schwimmorgans", welches in Form einer hyalinen Röhre auftritt. Aus der Kenntnis anderer Polychaeten-Larven mit durchsichtigen Schleimröhren, stellt Lanice durchaus keinen Sonderfall dar, so daß die Berechtigung zur Einführung eines neuen Begriffs notwendig erscheint. Ich schlage daher die Bezeichnung "Aulóphora" für alle diejenigen Larven vor, die sich mit einer selbst hergestellten Hülle (Röhre) umgeben und wende den Namen erstmals in dieser Arbeit an. Die Eingliederung der Aulóphora in das von NoLTE aufgestellte Schema ist vielleicht sinnvoll unter A. III: gegliederte Larven mit primären Wimperringen und einer selbst erzeugten Hülle. Mit diesem Überblick ergibt sich zwangsläufig die nun folgende Gliederung der Entwicklungsstadien von Lanice conchilega.

Die Schilderung geht im wesentlichen von den am Leben beobachteten Tatsachen aus, wird jedoch da, wo es für eine beweisführende Unterstützung notwendig ist, durch mikroskopisch-anatomische Untersuchungen unterbaut.

\section{Das Prototrochophora-Stadium}

Ausgestattet mit einem äquatorialen Wimperkranz, der aus zweireihig angeordneten Trochoblasten hervorgegangen ist, verläßt die Prototrochophora-Larve die Eihülle und beginnt sich frei im Wasser zu bewegen.

Der als Prototroch bezeichnete Wimperkranz teilt die Larve in eine vordere, am animalen Pol gelegene Episphäre und eine dem vegetativen Pol angehörende Hyposphäre. Auch zeichnet sich bereits in diesem Stadium eine apikale Scheitelplatte ab, die Anlage des späteren Cerebralganglions. Während 
dieser Ausbildung bleibt noch immer die ursprüngliche Kugelgestalt der Larve erhalten. (Taf. 1 Abb. 7).

Ein gleichzeitiges Entstehen des Wimperschopfes (swp) an der Scheitelplatte (s) und ein pygidial gelegener Telotroch (te) leitet zum TrochophoraStadium über (Taf. 1 Abb. 8 a, 8 b).

\section{Das Trochophora-Stadium}

Unter Mitwirkung der drei zonal voneinander getrennten Wimperregionen ändert sich die Fortbewegung der Larve. Die langsame Rotation der Prototrochophora-Larve hört auf und macht einer gerichteten Vorwärtsbewegung Platz. Diese wird durch das Auftreten des Wimperschopfes als Gleichgewichtsund Orientierungsorgan mit steuernder Funktion bewirkt.

Beobachtungen über Vorgänge und Veränderungen im Inneren der Larve konnten wegen des großen Dotterreichtums zu diesem Zeitpunkt noch nicht gemacht werden. Aus diesem Grunde bleibt die Entstehung der Verdauungsorgane mit Mund und After ungeklärt, doch ist es wahrscheinlich, daß es sich um eine Epibolie handelt, wie es bei dotterreichen Embryonen oder Larven üblich ist. Es ist mit Absicht von Embryonen oder Larven in diesem Zusammenhang gesprochen worden, da der Moment der Blastoporusbildung entweder vor oder nach dem Schlüpfen aus der Eimembran erfolgen kann.

Mit einer Streckung in der Längsrichtung wächst die Trochophora am 2. Tag von der kugeligen zur birnenförmigen Gestalt heran (Taf. 1 Abb. 9). Im Inneren des Körpers zeichnet sich als dunkelbraune Zellanhäufung gegenüber einer helleren Randzone die zukünftige Darmanlage deutlich ab. Morphologische Oberflächenveränderungen in Form von Einsenkungen oder Vertiefungen sind nicht zu erkennen.

Erst das weitere Wachstum am 3. Tag der Entwicklung ist die Ursache für eine leichte Neigung des Körpers nach der Ventralseite (Taf. 1 Abb. 10b), wobei eine ventrale Mulde unterhalb des Prototrochs (ptr) entsteht, welche die nun deutlich runde Mundöffnung (md) birgt (Taf. 1 Abb. 10a).

Das mit dem 2. Tag beginnende subtrochale Wachstum geht von zwei paramedian praepygidial gelegenen, auffällig großen Teloblasten (umz) aus, den Abkömmlingen der Zelle $4 \mathrm{~d}$. Auf das Schicksal dieser Zellen und deren Bedeutung für die Metamerie der Larven wird später näher eingegangen.

\section{Das Metatrochophora-I-Stadium}

Am 4. Tag der Entwicklung tritt das charakteristische Merkmal dieses Stadiums, eine wahrnehmbare Gliederung in der Wurmrumpfanlage, deutlich hervor (Taf. 2 Abb. 11). Parallel zu einer sich äußerlich abzeichnenden Segmentierung läßt sich eine Dreiteilung der Darmanlage (da) erkennen. Obwohl Mund (md) und After (af) zum Durchbruch gelangten, war eine Darmtätigkeit noch nicht festzustellen.

Während dieses Stadiums erscheinen auf der Episphäre ventro-laterale, leuchtend rote Augenflecken (a). Später, als Folge morphologischer Veränderungen am Prostomium, verschiebt sich die Lage dieser Lichtsinnesorgane nach der Dorsalseite (Taf. 2 Abb. 13). Eine Reduktion dieser Augenflecken im Ver- 
laufe der Entwicklung wurde nicht festgestellt. So scheint Glaparede (1863, S. 64) bei seiner Betrachtung ein Fehler unterlaufen zu sein, wenn er von seinen untersuchten Larven eine Rückbildung der primitiven Lichtsinnesorgane annimmt und beschreibt ,von welchen (damit meint er die Augenflecken) beim ausgebildeten Thiere bekanntlich keine Spur existirt".

Ein Metatroch kommt bei den Lanice-Larven nicht zur Ausbildung, dagegen kann zu diesem Zeitpunkt der Anfang prototrochaler Wimpernreduktion (ptr Rest) beobachtet werden (Taf. 2 Abb. 12a, 12b). Trotzdem ist die funktionelle Beweglichkeit noch nicht gestört und die Larven führen relativ lebhaft taumelnde, schraubenförmige Bewegungen aus.

\section{Das Metatrochophora-II-Stadium}

Mit dem gleichzeitigen Durchbruch von zwei Paar lateralen Borsten (lb) im 2. und 3. Segment und der Anlage paariger Hakenborsten (hak) im 3. und andeutungsweise im 4. Segment beginnt das Metatrochophora-II-Stadium (Taf. 2 Abb. 12a, 12b).

Wie an späterer Stelle noch zu beweisen sein wird, handelt es sich bei diesen Borstenbildungen um larvale und keine bleibenden Organe. Zu beiden Seiten des Darmes liegen im 1. Segment große, auffällige Zellen (ptrneph), die sich innerhalb kurzer Zeit zu Schläuchen auswachsen. Da ihr Auftreten und ihre Weiterentwicklung (Taf. 2 Abb. 12a, 12b) mit dem Zeitpunkt beginnender Schleimabsonderung übereinstimmt, lag der Schluß nahe, daß diese Zellen das Sekret erzeugen, das zum Bau einer Schleimröhre notwendig ist. Auch Claparede (1863, S. 66) verfiel diesem Trugschluß, wenn er zum Ausdruck bringt, „es ist höchst wahrscheinlich, daß diese Schläuche die Absonderung einer zur Bildung der Wohnröhre erhärtenden Flüssigkeit besorgen. Es ist jedenfalls beachtenswerth, daß das Auftreten fraglicher Schläuche mit der ersten Abscheidung einer Schleimröhre etwa zusammenfällt". Die Sicherheit der Annahme wurde jedoch erheblich gestört, als eine Flimmerbewegung in diesen beiden schlauchförmigen Organen am 5. Tag zu bemerken war. Derartige Bewegungserscheinungen sezernierender Zellen sind unbekannt, und so konnten nur histologische Untersuchungen Aufschluß über den eigentlichen Bau und Charakter der Organe geben.

Die Lösung dieses wichtigen Problems war wegen technischer Schwierigkeiten nicht sehr einfach. Doch schließlich ergab das mikroskopisch-anatomische Ergebnis, daß es sich bei diesen Schläuchen um Protonephridien handelt (Abb. 5).

Frei in der Leibeshöhle beginnend, münden sie in der Nähe des Mundes lateral nach außen. Dem blind im Cölom geschlossenen, leicht v-förmig verlaufenden Nephridialkanal (nek) sitzen zwei Terminalorgane (term) auf. Diese bestehen aus einer lappigen, dem Protonephridium flach aufsitzenden Zelle, deren Basalteil die Wand des Nephridialkanals durchbricht und eine lebhaft schlagende Wimperflamme (wf) in diesen entsendet.

Die durch die Terminalzelle aus der Leibeshöhle aufgenommenen Abfallstoffe werden schließlich mit Hilfe einer zonal beschränkten Bewimperung (wpnek) am Endabschnitt des Kanals nach außen befördert.

In der Primitivität des Baues ähneln die Protonephridien der Lanice-Larven den von Woltereck (1905, S. 178) beschriebenen Archinephridien der 


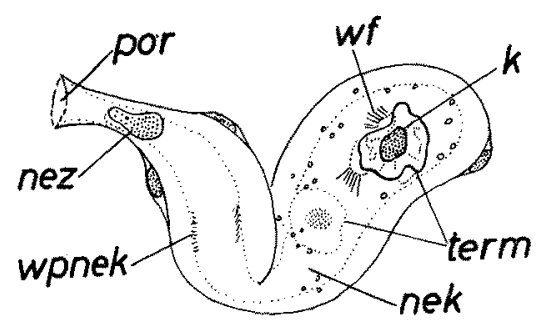

Abb. 5. Protonephridium. Am blinden Ende des Nephridialkanals sitzen zwei Terminalorgane lateral flach auf. $\mathbf{k}=$ Kern, nek $=$ Nephridialkanal, nez $=$ Nephridialzellen, por $=$ Porus, term $=$ Terminalzelle, $\mathrm{wf}=$ Wimperflamme, wpnek $=$ Wimpern des Nephridialkanals

Polygordius-Larve. Dieses Archinephridium besteht aus einer kurzen Röhre, die aus zwei Zellen aufgebaut ist. Einer den Exkretionskanal abschließenden Terminalzelle steht eine zweite Zelle gegenüber, die den Ausfuhrgang bildet. Leider gibt die skizzenhafte Zeichnung WoLterecks keinen Aufschluß über den feineren Bau dieses Organs. Nach Woltereck kompliziert sich das Archinephridium vor seinem Verschwinden durch Verästelung und Bildung von Solenocyten.

Im Gegensatz zu den eigentümlichen Komplikationen der larvalen Exkretionsorgane bei Polygordius bleibt der einfache Bau der Protonephridien bei Lanice bis zu ihrer Auflösung erhalten.

Die Funktion dieser einfachen Protonephridien setzt mit der Nahrungsaufnahme am 5. oder 6. Tag der Entwicklung ein. Sie wird beendet mit der Bildung der ersten Metanephridien im 3. Körpersegment. Die Neubildung der bleibenden Metanephridien macht die larvalen Protonephridien überflüssig, und sie gehen durch Autolyse zu Grunde.

Bevor die Larven jedoch Nahrung aufnehmen können, spielen sich beachtliche Umwandlungen sowohl in der Mundregion als auch am Prostomium $a b$ (Taf. 2 Abb. 13a, 13b). Die ursprünglich runde Mundöffnung vergrößert sich zu einem Oval (md). Dieses ist von einem fein bewimperten Wulst, der späteren Unterlippe, umgeben, während die Oberlippe in parallel zueinander liegenden wulstförmigen Aufwölbungen (medwl) zum Vorderende hin verläuft und gleichsam den Mundverlauf vorzeichnet. Mit dem Aufreißen des Mundes in der zwischen den Wülsten liegenden Furche wird die Episphäre gleichzeitig nach Dorsal gekippt und erfährt damit eine erhebliche Lageveränderung (Taf. 2 Abb. 13b).

Zum gleichen Zeitpunkt fällt auch der Wimperschopf ab, der in der neuen, durch die Verschiebung des Prostomiums entstandenen Lage, nämlich

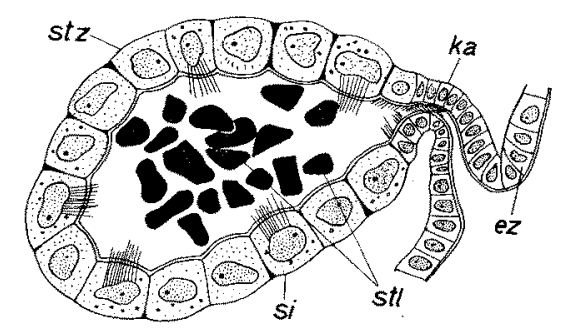

Abb. 6. Frontalschnitt durch die Statocyste einer Metatrochophora II-Larve. ez = Epithelzellen, $\mathrm{ka}=$ Kanal, $\mathrm{si}=$ Sinneszellen, $\mathrm{stl}=$ Statolithen, stz $=$ Stützzellen 
senkrecht zur dorsalen Bewimperung, als Gleichgewichts- und Orientierungsorgan bedeutungslos wurde. Außerdem wird der Wimperschopf durch paarige Statocysten (st) im 2. Körpersegment ersetzt, die als bleibende Organe auch beim adulten Tier anzutreffen sind.

Sie entstehen durch Einsenkung der Epidermis zu einer Blase (Abb. 6), deren einschichtige Epithelwand sich in bewimperte Zellen - Sinneszellen (si) - und dazwischenliegende Stützzellen (stz) gliedert. Diese gegen die Leibeshöhle vorspringende Cyste bleibt durch einen cilientragenden Kanal nach außen offen. Obwohl CLAparede (1863, S. 67) die "Otolithblasen" bei seinen Larven untersucht hat, kann er einen „ähnlichen, äußeren Gehörgang, wie ihn Georg Meissner bei Arenicola aufgefunden haben soll", nicht entdecken. Glaparede konnte auch praktisch den Statocystenkanal nicht sehen, da er, soweit aus seiner Arbeit hervorgeht, keine Schnitte von den Larven angefertigt hat. Dagegen beweisen eigene mit Azan gefärbte Frontalschnitte ganz eindeutig die Existenz des Kanals (ka). Fremdkörper, die durch diesen bewimperten Kanal in die Blase gestrudelt werden, dienen als Statolithen (stl). Wie Frontalschnitte durch ältere Lanice-Larven zeigen (Abb. 8), werden die Statocysten nicht vom Gehirn, sondern vom vorderen Abschnitt des Bauchmarks innerviert. Diese Tatsache deckt sich mit den allgemein vertretenen Ansichten hierüber von Plate (1924, S. 109) und Bütschli (1921, S. 747).

Innerhalb der Ontogenese kann sich der Statocystenkanal schließen und die ursprünglich natürliche Verbindung zwischen Cyste und Außenwelt abbrechen.

Auch die Verfasserin ging von dieser Entwicklungsmöglichkeit aus, weil der Verschluß der Statocyste unter Umständen eine Erklärung für den Orientierungswechsel zwischen den freischwimmenden Larven und den senkrecht im Boden bohrenden Juvenilen hätte sein können. Doch diese Arbeitshypothese konnte auch an zahlreichen Schnitten durch bodenreife Lanice-Larven nicht bestätigt werden. Somit mußte konstatiert werden, daß die Statocysten vom Augenblick ihrer Entstehung bis zur Auflösung durch den Tod der erwachsenen Tiere keinerlei Entwicklungsveränderungen durchlaufen und morphologisch unverändert erhalten bleiben.

Wie bekannt handelt es sich bei der Statocyste um ein Schweresinnesorgan, ein Organ also, welches aus der Erdschwere seine Reize empfängt und darauf reagiert. Über dieses Funktionieren der Statocysten bei den erwachsenen Lanice-Tieren weiß man durch die Untersuchungen BudDENBrocks (1913) an im Sande grabender Polychaeten einiges, obwohl von einer befriedigenden Klärung dieses Fragenkomplexes nicht die Rede sein kann.

BudDENBRock kommt zu der Überzeugung, daß das Vorhandensein von Statocysten die Tiere in die vertikale Grabrichtung drängt und sie gegenüber statocystenlosen sedentären Polychaeten durch größere Sicherheit und Schnelligkeit beim Graben auszeichnet. Dieses sich Hinwenden zur Schwerkraft oder von ihr weg wird als Geotaxis angesprochen.

So muß also das senkrechte Graben von Lanice conchilega ein Ausdruck positiver Geotaxis sein und als gute Fähigkeit einer räumlichen Orientierung im Boden angesehen werden. Soviel sei über das Orientierungsverhalten bodenreifer Tiere und die Bedeutung, die die Statocysten dabei spielen, vorausgeschickt.

Die Ergebnisse Buddenbrocks über die funktionelle Tätigkeit der Statocysten bei sessilen Polychaeten mußten einleitend erörtert werden, um begreif- 
lich zu machen, daß die Gleichgewichtslage der pelagischen Larven von Lanice und ihre ausgesprochene Lageorientierung im freien Wasser, ohne positive oder negativ geotaktische Tendenzen, ebenfalls auf die Statocysten zurückgeführt wird. Trotz veränderter Bewegungsweise zwischen Larven und erwachsenen Tieren unterscheiden sich die Statocysten beider in ihrem morphologischen Bau nicht.

Es braucht nicht besonders betont zu werden, daß das Beibehalten einer ganz bestimmten Gleichgewichtslage der frei im Wasser beweglichen Larven bei ihrer langen pelagischen Lebensweise ein notwendiges und existenzwichtiges Verhalten darstellt.

Um den Unterschied der Bewegungsweise von Larven und adulten Tieren noch einmal klar herauszustellen, muß darauf hingewiesen werden, daß es sich einerseits um eine ausgesprochene Lageorientierung ohne geotaktische Neigung, auf der anderen Seite aber um eine Raumorientierung im Boden mit positiver Geotaxis handelt.

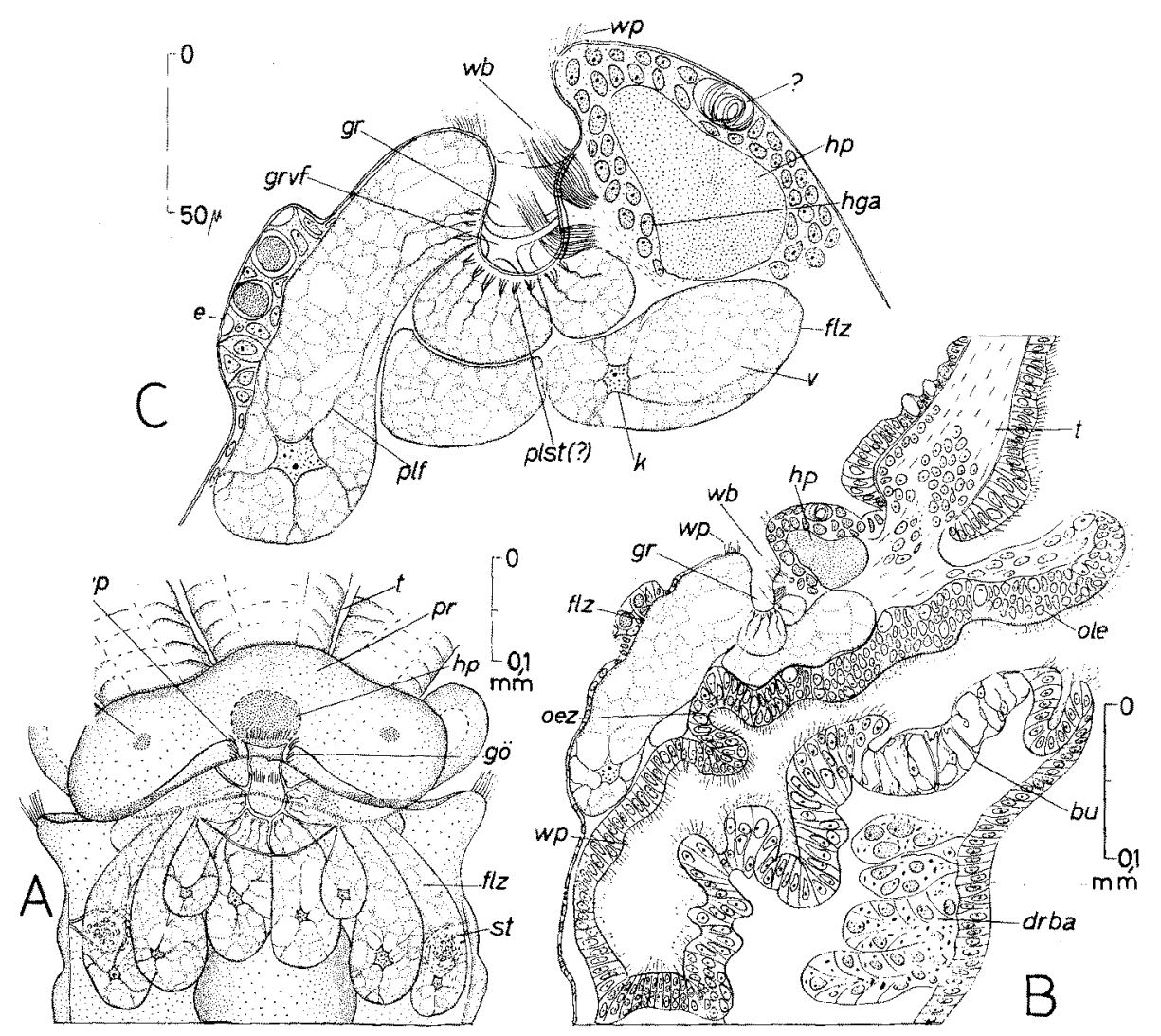

Abb. 7. $\mathrm{A}=$ Totalpräparat einer älteren Aulophora-Larve (dorsal). Median hinter dem Gehirn liegt das Grubenorgan, umgeben von auffällig großen Zellen. B = Parasagittalschnitt durch vordere Körperregion mit Grubenorgan einer älteren Aulophora-Larve. $\mathrm{G}=$ Parasagittalschnitt durch das Grubenorgan (stark vergrößert). $a=$ Auge, bu = Buccalorgan, drba $=$ Drüsen der Basalplatten, $\mathrm{e}=$ Epithel, $\mathrm{flz}=$ flüssigkeitsgefüllte Zellen, gö = Grubenöffnung, $\mathrm{gr}=$ Grube, grvf $=$ Grubenversteifung, hga $=$ Gehirnganglienzellen, $\mathrm{hp}=\mathrm{Ge}-$ hirnpilem, $\mathrm{k}=\operatorname{Kern}$ (mit Plasmafortsätzen), oez $=$ Osophaguszellen, ole = Oberlippenepithel, plf $=$ Plasmafäden, plst $=$ plasmatische Stäbchen $(?), \mathrm{pr}=$ Prostomium, st $=$ Statocyste, $\mathbf{t}=$ Tentakel, $\mathrm{v}=$ Vakuole, $w \mathrm{~b}=$ Wimperbüschel, $\mathrm{wp}=$ Wimpern 
Nach dieser Beschreibung scheint es so, als ob während des Larvenlebens noch ein zusätzlicher Mechanismus wirksam wird, der ein frühzeitiges senkrechtes Zubodengehen verhindert. Eine Aufhellung dieses Problems kann aber nur mit Hilfe physiologischer Experimente geschehen.

Gleichzeitig, also parallel der Statocystenbildung am 5. Tag der Larvalentwicklung, ist das Auftreten eines dorsomedian hinter dem Prostomium gelegenen Organs zu beachten, das zum Zeitpunkt der Seßhaftwerdung der Larven zugrundegeht und somit einen ausgesprochenen Larvalcharakter trägt. Die Gleichzeitigkeit des Entstehens und das Vergehen dieses Organs scheint bemerkenswert und macht eine ausführliche Betrachtung notwendig.

Die Klärung der Anatomie des besagten Larvalorgans stieß auf erhebliche Schwierigkeiten, da die Kleinheit des Objektes (beim Auftreten des Organs sind die Larven $250 \mu$ groß) und das Fehlen irgendwelcher Anhaltspunkte in der Literatur die Arbeit erschwerte. Erst die Anfertigung von Schnittserien älterer Stadien, die bereits im Besitz drei beweglicher Tentakeln sind, konnte Aufschluß über die Morphologie geben.

Abb. 7 A stellt die Lage des Organs in einer dorsalen Übersicht dar und Abb. 7 B zeigt es auf einem Parasagittalschnitt.

Eine runde Offnung (gö) (Abb. 7 A), allseitig von Wimpern (wp) umrahmt, setzt sich in eine schräg nach hinten eingesenkte Grube nach innen fort. Die Einsenkung schließt sich unmittelbar an das Prostomium an, wobei die kopfwärts gerichtete Wand der Grube direkt an das Neuropilem (h) des Gehirns grenzt, welches an dieser Stelle mit einigen großen Ganglienzellen (hga) durchsetzt ist (Abb. 7 C). Die vordere Wand der Grube (gr) wird durch übereinanderliegende, sehr kräftige Wimperbüschel (wb) durchbrochen, die frei in den Grubenhohlraum münden. Eingebettet in einen Zellkomplex aus auffallend großen, gut sichtbaren, miteinander verbundenen Zellen liegt es wie in einem Polstergewebe verborgen.

Der Vakuolenreichtum (v) der Zellen ( $\mathrm{flz}$ ) und der Mangel an körnigen Sekreten deutet darauf hin, daß diese Zellen mit Flüssigkeit angefüllt sind. Sehr große, Fortsätze bildende (plf), chromatinreiche Kerne (k) stehen durch plasmatische, mehrfach aufgespaltene Fasern mit der Grubenwand in Kontakt. Die Enden der eben beschriebenen Plasmafäden gliedern sich meist in drei bis vier stäbchenförmige Ausläufer (plst?) (durch Azan werden sie orange-rot angefänbt), deren Gesamtheit die Grube vor allen Dingen in ihrem unteren Teil wie ein Saum umgibt.

Da am lebenden Objekt retraktile Bewegungen der Grube und dadurch lebhafte Vor- - und Rückzieherscheinungen der in die Grube hineinreichenden Wimperbüschel beobachtet werden konnte, ist es nicht ausgeschlossen, daß es sich um konstraktile Elemente handelt, die als Plasmafäden die großen aufgeblasenen Zellen durchziehen. Da diese Zellen weder Ausführgänge oder -kanäle noch zu irgendeinem Zeitpunkt ihrer Entstehung Granula aufweisen, kann es sich wohl kaum um Drüsenzellen handeln, wie Elrington (1908) festgestellt hat. Seine Erkenntnis beruht auf verschiedenen Schnittserien, die er mit vier verschiedenen Färbemethoden bearbeitete. Die Untersuchung Elringtons bedeutet ohne Zweifel einen großen Schritt vorwärts, da er durch seine Arbeit die Ansicht Claparedes, daß diese großen Zellen Gehirnzellen seien, und Grards, daß sie als Geschlechtszellen anzusehen sind, als Fehldiagnose erkannte.

Auch die Verfasserin hielt diese Zellen zunächst für Drüsenzellen. Doch 
nach der jetzt vorliegenden intensiven Untersuchung kann diese Meinung nicht mehr aufrechterhalten werden. Schließlich muß auch die funktionelle Bedeutung, die Elrington diesen sog. "Dorsal-Drüsen“ zuschrieb, revidiert werden. Sie sollen nach ihm den Schleim liefern, der für die Erzeugung der Larvenröhre notwendig ist. Auf dieses Problem wird jedoch an späterer Stelle eingegangen.

Der Frage, welche Bedeutung dem Grubenorgan der Lanice-Larven zukommt, kann nach der vorangegangenen Erörterung über den morphologischen Bau nun nicht mehr ausgewichen werden. Die enge Verbindung mit dem Gehirn stellt zuerst einmal klar, daß wir es mit einem Sinnesorgan zu tun haben. Doch dadurch wird die funktionelle Begrenzung keineswegs einfacher, da gerade auf dem Gebiet, die Aufgabe von Sinnesorganen zu deuten, viel gesündigt worden ist. Es ist vollständig klar, daß die Morphologie allein kein Aussagerecht besitzt, sondern endgültige Klarheit kann nur durch physiologische Experimente erbracht werden. Dennoch sollen Möglichkeiten der Deutung gegeben werden, um eventuelle Ansatzstellen für spätere Untersuchungen zu skizzieren.

Der Lage nach könnte das Grubenorgan das für die erwachsenen Tiere von Rullier (1951, S. 281) geschilderte Nuchalorgan sein. Allerdings wäre unter diesem Aspekt verwunderlich, warum dieses Organ keine kontinuierliche Entwicklung durchmacht, sondern nach einem katastrophalen Zusammenbruch, unter Vernichtung aller großen flüssigkeitsgefüllten Nachbarzellen, an derselben Stelle wieder neu entsteht. Dieser Tatbestand würde der angewandten Baumethode innerhalb der Lanice-Entwicklung widersprechen und nicht mit dem allmählichen Wachstum als durchgeführtes Metamorphoseprinzip in Einklang zu bringen sein. Außerdem ist das larvale Grubenorgan unpaar, während das bleibende Nuchalorgan eine paarige Anlage darstellt. Auch bleibt es nach Söperström (1920, S. 116) fraglich, ob es unter den Nuchalorganen retraktile Grubenorgane gibt, die sich vor allen Dingen durch fehlende Bewimperung auszeichnen (die bei Lanice gefundenen Wimperbündel in der Grube sind mit den Sinneshaaren der Nuchalorgane wohl kaum vergleichbar). So scheint die Möglichkeit ausgeschlossen zu sein, die grubenförmige Vertiefung an der Grenze des Prostomiums als larvales Nuchalorgan zu deuten.

Vergegenwärtigen wir uns noch einmal, daß dieses Organ ein Larvalorgan ist und daß es in dem Augenblick auftaucht, wenn die Larven mit ihrer selbstgebauten Larvalröhre ins freie Wasser aufsteigen, so ist eine Beziehung zwischen Grubenorgan und Bewegung im freien Wasser höchst wahrscheinlich. $\mathrm{Ob}$ allerdings die Funktion direkt mit der Bewegung und der Orientierung der Larven in Zusammenhang steht, oder ob sie eine Empfindlichkeit gegen Veränderungen der Wassertiefen und der damit verbundenen Druckschwankungen registriert, kann nur als Vermutung ausgesprochen werden.

Mit der Beschreibung dieser Form ist das Metatrochophora-II-Stadium gekennzeichnet, und damit ist die erste Phase der pelagischen Entwicklung von Lanice conchilega, die sich in Bodennähe abspielt, abgeschlossen.

Bevor das Aufsteigen ins freie Wasser erfolgen kann, suchen sich die Larven am Boden einen geeigneten Ort, es können Algen, Sedimentteilchen oder Detritusteilchen sein, und halten sich mit ihren larvalen Haarborsten an demselben fest. (Im Kulturschälchen werden hineingefallene Staubpartikel für diesen Zweck benutzt.) Dann beginnen sie mit der Schleimproduktion, wobei die Beobachtung zeigte, daß der Schleim mit den vorstülpbaren Bewegungen 
des muskulösen Buccal-Organs aus der Mundöffnung ausgeschieden wird. Allerdings ist mit dieser Feststellung noch nichts über die Herkunft des Schleimes gesagt.

Bezeichnenderweise wurde von einigen Autoren, schon so lange die LaniceLarven bekannt und beschrieben sind, nach der Klärung dieser Frage gesucht, da der Besitz einer Schleimröhre eine ins Auge fallende Erscheinung ist.

Weder die „Kittdrüsen“ Cuaparedes (1863, S. 66), die sich als Protonephridien entpuppten, noch die von ElRINGTON (1908) beschriebenen Zellen der vorderen Körperregion hinter dem Oesophagealganglion, die sich als flüssigkeitsgefüllte Zellen des Grubenorgans herausstellten, scheiden Schleim ab.

Nur auf der Ventralseite der Larven konnten im 2. Segment (Taf. 2 Abb. 13 a) zwei große Zellen beobachtet werden, die Schleim erzeugen. Im Laufe der Entwicklung vermehren sich diese Zellen (ba) und liefern endlich die Basalplatten der adulten Tiere.

Ihr Erscheinen deckt sich mit dem Zeitpunkt der ersten Röhrenbildung. Es ist einleuchtend, daß die ersten paarigen Drüsenzellen die anfängliche Schleimproduktion für die Primärröhre nicht bewältigen können. Diese unzureichende Schleimabsonderung spiegelt sich daher auch in der Beschaffenheit der jüngsten Larvenröhre wider (Taf. $2 \mathrm{Abb} .13 \mathrm{c}$ ), die von den Larven am 5. Tag ihrer Entwicklung gebaut wird.

Es handelt sich um eine Detritusröhre und keine rein hyaline Röhre, wie z.B. bei den 16 Tage alten Larven (Taf. 4 Abb. 16b), die bereits einen Drüsenkomplex besitzen, der drei Segmente (2., 3. und 4. Segment) umgreift. Ein Vergleich der drei gezeichneten Larvenröhren (Taf. 2, 3, 4, Abb. 13c, 15c, 16b) zeigt, daß mit zunehmender Entwicklung eine deutliche Abnahme der Detritusbestandteile (de) zugunsten der Schleimteilchen (schl) innerhalb des Baumaterials der Larvenröhre zu beobachten ist. Die Zunahme der Schleimbestandteile läuft also parallel zu den sich vermehrenden Bauchdrüsen. Diese interessanten Beziehungen zwischen Röhrenbeschaffenheit und Entwicklung der Drüsenfelder dürften wohl den klaren Beweis dafür liefern, daß die Drüsenzellen der Bauchseite von Anfang an für die Schleimproduktion verantwortlich gemacht werden können.

Nachdem die Herkunft des Baumaterials geklärt werden konnte, bleibt nun die interessante Frage, wie die Larvenröhre hergestellt wird.

Wie bereits erwähnt, hält sich die Larve mit ihren larvalen Haarborsten am Substrat fest und sondert Schleim aus der Mundöffnung ab, der vom ventralen Entstehungsort in einer Rinne dorthin befördert wird. Die abgesonderte Masse wird durch intensive Wimperbewegungen der Unterlippe und einer Neigung des Kopfes zur Körpermitte (Körpertaille) gestrudelt. Während sich das Tier langsam um die eigene Achse dreht, wird Schleimpaket an Schleimpaket geklebt. So entsteht ein Ring um den Larvenkörper, der die Ausgangsbasis für den weiteren Aufbau darstellt. Gleichzeitig werden die im Mund mit dem Schleim vermischten Nahrungspartikelchen mit verbaut. Auf diese Weise kommt die von den älteren Stadien abweichende Struktur der Detritusröhre zustande.

Bevor die Aufzuchtversuche Aufschluß über die Nahrungsaufnahme und den Röhrenbau in ihrem kausalen Zusammenhang gaben, wurde viel versucht, um die Larven in diesem kritischen Stadium vom 5. und 6. Tag am Leben zu erhalten. Enst die Übertragung der Larven in Kulturschälchen mit ungereinig- 
tem Seewasser (wie im Kapitel über die Methoden aufgezeigt worden ist) brachte das gewünschte Ergebnis.

Da ja nicht bekannt war, zu welchem Zeitpunkt der Entwicklung die Larven ihre erste Larvalröhre bauen und daß neben Schleim noch anderes Material notwendig ist, war das Auffinden geeigneter Nahrung und günstigen Baumaterials im ungereinigten Seewasser eine sehr entscheidende und für die Weiterführung der Arbeit wichtige Tatsache.

Das Seewasser wurde jeweils vor dem Umsetzen der Kulturen frisch aus dem Meer geschöpft und auf die entsprechende Temperatur der Kulturschälchen erwärmt. Messungen ergaben im allgemeinen einen Temperaturunterschied von $3^{\circ} \mathrm{C}$ zwischen Kulturschälchen und frisch geschöpftem Seewasser.

Mit der Anwendung dieser neuen Methode war allerdings viel Arbeit verbunden, da das Seewasser der Kulturschälchen sehr viel öfter gewechselt werden mußte, um physiologische Veränderungen des Wassers auszuschließen. Die Larven, denen nun Nahrung und Baumaterial zur Verfügung standen, entwickelten sich gut weiter.

Nach Fertigstellung der Röhre erhebt sich die Aulophora-Larve vom Substrat und tritt in die eigentliche pelagische Phase innerhalb ihrer Entwicklung ein. Der an dieser Stelle zu setzende Einschnitt ist insofern bemerkenswert, als die pelagische Zeit in ihrer Gesamtheit keine Einheit darstellt, sondern eine einwandfreie beobachtbare $Z$ weiteilung zeigt.

Vom Ausstoßen der Geschlechtsprodukte bis zum 5. oder 6. Tag spielt sich das pelagische Leben der Larven in Bodennähe ab. Nach beendigtem Bau der Detritusröhre allerdings erhebt sich die Larve vom Boden und steigt ins freie Wasser auf. Die Eindeutigkeit einer zweigeteilten pelagischen Phase erklärt auch die Tatsache, daß bis zur vorliegenden Untersuchung weder Eier, Teilungsstadien, Trochophora-Larven noch junge Aulophora-Larven mit dem Planktonnetz im freien Wasser gefischt worden sind, sondern immer nur ältere Stadien, die dann auch beschrieben wurden.

Die im Labor erworbenen Resultate über die Lebensweise der Larven im ersten Abschnitt ihrer Entwicklung mußten, wenn sie richtig waren, am Standort bestätigt werden können.

Aus diesem Grunde wurden zwei Monate, vom 24. April bis zum 24. Juni 1961, alternierende Planktonfänge am Boden und im freien Wasser durchgeführt. Die Proben aus Bodennähe wurden nördlich der Lister Ablaufbahn entnommen und zwar in der Art, daß ein kleines Bechernetz in der Meeresrandzone über das Sediment gezogen wurde.

Die Proben des freien Wassers stammten vom Lister Hafen und wurden mit einem Horizontalplanktonnetz herausgeholt. Der praktischen Durchführung standen insofern gelegentlich Schwierigkeiten im Wege, als bei unruhiger See, wie es im Frühjahr oft der Fall ist, die Gefahr des Zerreißens der Netze bestand und das Plankton nicht geholt werden konnte. Wenn also aus diesen Gründen die Kontinuität der Fänge nicht immer hat gewahrt werden können, so ist das Ergebnis trotzdem eindeutig.

Ergebnis der Planktonfänge:

1. Planktonfänge in Bodennähe: vorwiegend: Eier, Teilungsstadien, Trochophora-Larven, Metatrochophora-Larven und jüngste Aulophora-Larven mit Detritusröhre, weniger häufig: Aulophora-Larven mit weniger als 5 Haarborsten, selten: Aulophora-Larven mit mehr als 5 Haarborsten. 
2. Planklonfänge im freien Wasser:

nie vorhanden: Entwicklungsstadien bis zur jungen Aulophora-Larve, vorwiegend: Aulophora-Larven mit mehr als 3 Paar Haarborsten.

Auch die Planktonfänge verdeutlichen den Unterschied innerhalb der pelagischen Lebensweise der Larvenstadien und bestätigen die im Labor festgestellte Unterteilung.

\section{Das Aulophora-Stadium}

Mit dem Eintritt in das Aulophora-Stadium beginnt, wie bereits erwähnt, das eigentlich pelagische Leben. Die Larven haben die Fähigkeit erlangt, sich vom Boden zu erheben und ins freie Wasser überzugehen. Es fragt sich nun, warum sie gerade jetzt aufsteigen können.

In bezug auf die Schwimmorgane der jungen Aulophora-Larven hat sich einiges verändert. Prototroch und Telotroch sind zugrunde gegangen, und die Zahl der segmental angelegten dorsalen Wimperbögen (dorw) hat zugenommen (Taf. 3 Abb. $14 \mathrm{~b}$ ). Die so ausgestatteten "Larven der Terebella conchilega sind nototroch und leben als gute Schwimmer pelagisch". Diese von KORSCHELt (1936, S. 350) vertretene Ansicht kann nicht unterstützt werden, da die Nototrochie nicht allein ausschlaggebend für die Schwimmfähigkeit der Larven ist. Stellt man sich vor, daß Larven nur mit einer dorsalen Bewimperung versehen sind, ohne ein weiteres Steuerungsorgan zu besitzen, so könnten diese nur kreisförmige Bewegungen, nicht aber gerichtete ausführen. Im Falle der Lanice-Larven muß außer der dorsalen Bewimperung die selbstgebaute Röhre eine Rolle innerhalb der Fortbewegung spielen.

Meine Erwartungen über die funktionelle Bedeutung der Röhre während des freischwimmenden Lebens der Aulophora-Larven trafen wirklich ein und konnten durch Beobachtungen bewiesen werden.

Die Larven klammern sich mit ihren Haar- und Hakenborsten am inneren Rand der Röhre fest und erzeugen durch einen kopfwärts gerichteten Wimperschlag der einzelnen Wimperbögen einen Wasserstrom durch die Röhre, der vom analen zum apikalen Körperende fließt. Der auf diese Weise entstehende Rückstoß bewirkt die Bewegung.

Die Fähigkeit, sich innerhalb der Röhre umzudrehen, versetzt sie zusätzlich in die Lage, Richtungsänderungen vorzunehmen.

Um nun die Existenz eines solchen Stromes durch die Larvenröhre zu beweisen, wurde Karminpulver fein zermahlen in die Kulturschälchen gestreut. Das Pulver verteilte sich bald im Wasser und geriet immer in Larvennähe in eine fließende Bewegung, wobei die einzelnen roten Teilchen wie in einem Sog durch die Röhre transportiert wurden.

So läßt sich mit Sicherheit sagen, daß die Schwimmfähigkeit der Larven weder aus der nototrochen Bewimperung, noch aus dem Besitz einer Larvenröhre, die eventuell spezifisch leichter sein könnte, allein erklärt werden kann, sondern nur aus dem sinnvollen Zusammenspiel beider Faktoren verständlich wird.

Die Larven leben etwa zwei Monate im Plankton, wie aus den Aufzuchtversuchen hervorgegangen ist. Die Entwicklung vom befruchteten Ei bis zu den bodenreifen Stadien dauerte in den Kulturschälchen 58 Tage. Da eine vollständige Entwicklung nur einmal geglückt ist und der Zahl von 58 Tagen 
keine Vergleichszahl gegenübersteht, ist anzunehmen, daß diese Zahl nur einen ungefähren Anhalt bietet. Es muß damit gerechnet werden, daß die Geschwindigkeit der Entwicklung durch die künstlichen Versuchsbedingungen doch beeinflußt worden ist.

Innerhalb der weiteren Entwicklung verändert sich die Aulophora-Larve im wesentlichen durch eine kontinuierliche Segmentvermehrung, die von der praepygidialen Wachstumszone ausgeht. Das Wesen der Lanice-Entwicklung besteht also in einem stetigen Längenwachstum und nicht in einer eigentlichen Metamorphose. Die provisorischen Organe der Larven gehen allmählich in die bleibenden Organe der erwachsenen Tiere über und kennzeichnen damit einen harmonischen Wechsel zwischen Aufbau und Abbau innerhalb der Entwicklungsprozesse. Das Fehlen einer explosionsartig einsetzenden (katastrophalen) Metamorphose kann unter Umständen der Grund der langsamen Entwicklung und des langen pelagischen Lebens der Lanice-Larven sein. Mit dem Längenund Breitenwachstum verknüpfen sich selbstverständlich körperliche Veränderungen, die sowohl deutliche Spuren der Wandlung in der Kopfregion als auch in der Rumpfregion hinterlassen.

\section{a) Morphologische Veränderungen der Kopfregion}

In der Kopfregion vereinigen sich das aus der Episphäre der Trochophora hervorgegangene Prostomium und das Metastomium, welches die Mundregion enthält. Inwieweit auch das 1. Körpersegment in den Kopfteil eingegliedert werden darf, ist fraglich. Denn diese Zuordnung wäre nur auf der Basis einer Verschmelzung zwischen Metastomium und diesem 1. Körpersegment zum sog. Peristomium möglich. Wenn es sich wirklich um ein Zusammenwachsen dieser beiden Bereiche handelt, so muß sich das Ergebnis mit Hilfe der Ganglienpaare und Nerven und deren Verlauf aufzeigen lassen.

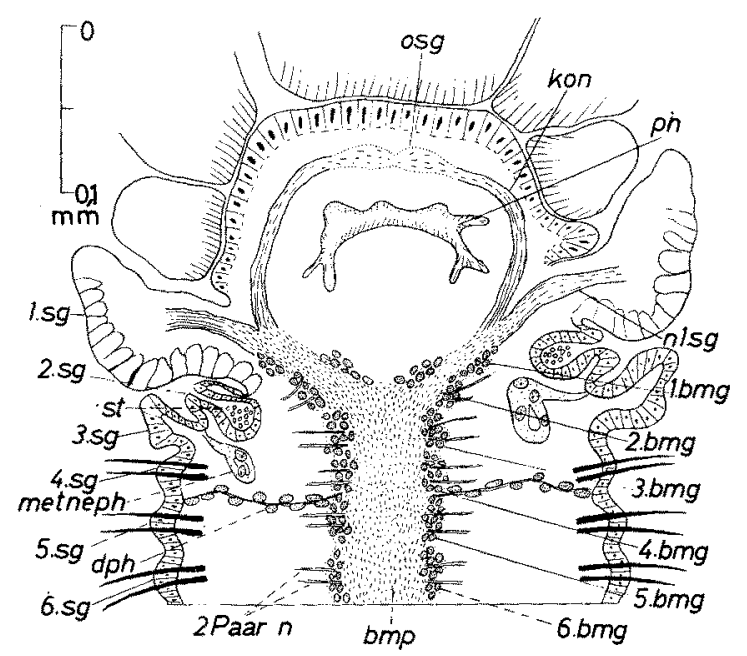

Abb. 8. Kombinationsbild mehrerer Frontalschnitte durch die Bauchmarkregion einer Aulophora-Larve. Das Oberschlundganglion wurde vollständigkeitshalber eingezeichnet. bmg = Baudhmarkganglion, $b \mathrm{mp}=$ Bauchmarkpilem, $\mathrm{dph}=$ Diaphragma, $\mathrm{kon}=$ Schlundkonnektiv, metneph $=$ Metanephridium, $\mathrm{n}=$ Nerv, osg $=$ Oberschlundganglion, ph = Pharynx, sg $=$ Segment, st $=$ Statocyste 
Zu diesem Zweck wurden zahlreiche Schnittserien durch ältere AulophoraLarven hergestellt. Abb. 8 zeigt ein aus vielen Schnitten zusammengesetztes Kombinationsbild, das die Verhältnisse in der Kopf- und vorderen Thoraxregion widergibt.

Wie bereits Quatrefages (1850, S. 368) in seiner grundlegenden Arbeit "Le Systeme nerveux des Annelides“ an Terebella conchilega Sars (Lanice conchilega) gefunden hat, ist innerhalb des Bauchmarks der Thoraxregion in jedem Segment nur ein Ganglion vorhanden. Auch die ursprünglich in der Zweizahl existierenden Konnektive, die die Verbindung zwischen den Ganglien der Segmente herstellen, gehen ineinander über und bilden einen einzigen Stamm.

Diese Aussage stimmt auch mit den eigenen Untersuchungen überein, wie Abb. 8 zeigt. Im 1. und 2. Segment jedoch liegen die Ganglienpaare voneinander entfernt (1. bmg, 2. bmg) und sind nicht durch Kommissuren verbunden. Die Faserstränge, die in das Ganglienpaar des ersten Segmentes einmünden, müssen einerseits als Schlundkonnektiv (kon), auf der anderen Seite als Nervenstrang des 1 . Segmentes (n 1. sg) bezeichnet werden. Ob das zweite Ganglienpaar als Unterschlundganglion angesehen werden kann, wie es KoRN (1960, S. 437 in Abb. 13) bei Larven von Pectinaria tut, bleibt doch sehr zweifelhaft.

Im Gegensatz zu den zwei Paar segmentalen Nerven der übrigen Körpersegmente ist der Nervenstrang des 1. Körpersegmentes sehr kräftig und nur in der Einzahl ausgeprägt (n 1. sg). Die Vermutung, daß dieser 1. Nerv ein Verschmelzungsprodukt ist, konnte durch eventuelle Verwachsungsspuren nicht festgestellt werden.

Es bleibt also die Frage, ob überhaupt von einem Mundsegment geredet werden darf, welches mit dem 1. Körpersegment zu dem sog. Buccalsegment verschmolzen sein soll, wenn nur ein Nervenpaar vorhanden ist.

$\mathrm{Zu}$ den formverändernden Entwicklungsschritten am Prostomium gehört die mit der bereits beschriebenen Dorsalverschiebung wahrscheinlich zusammenhängende ektodermale Aufwölbung der Mediantentakelanlage (ta) (Taf. $2 \mathrm{Abb} .13 \mathrm{~b}$ ) am vorderen Prostomiumrand. Diese Vorwölbung ist mit "starren Härchen" (har) besetzt und erhebt sich über die Oberlippe (ol) "wie ein Blumensträußchen oder eine Schleife vom Damenhut" (Claparede 1863, S. 64). Mit dieser unwissenschaftlich klingenden Außerung hat Claparede jedoch nicht ganz unrecht, denn der Eindruck der knöpfchenartig angeschwollenen Tentakelanlage (ta) (Taf. $3 \mathrm{Abb} .14$ b) ist durchaus verblüffend. Mit fortschreitender Entwicklung wächst der zukünftige Mediantentakel zu einer Kugel heran, die starr und unbeweglich die Oberlippe überragt (Taf. $3 \mathrm{Abb} .14 \mathrm{~b}$, 15a), bis schließlich durch rasches Längenwachstum Bewegungs- und Kontraktionsversuche möglich werden und die typischen Tentakeleigenschaften hervortreten. Neben dem mächtig entwickelten unpaaren Mediantentakel springen knospenartig erst zwei, dann vier Lateraltentakel (ta) vor (Taf. 4 Abb. 18). Allmählich vermehrt sich die Zahl der Fangarme und mit ihr vergrößert sich ihre Basis. Diese Vergrößerung bewirkt eine wulstförmige Verdrängung des hinteren Prostomiumteiles (pr) (Taf. 4 Abb. 16a), der mit zunehmendem Frontaldruck der neugebildeten Tentakeln bzw. ihrer Anlagen weitere Gestaltveränderungen erfährt, die schließlich eine leichte Überkippung über das rumpfwärts sich anschließende Metastomium (Taf. 4 Abb. 17, 18) zur Folge hat. Doch mit dem erstaunlichen Wachstum des Metastomiums bzw. des 1. Körpersegmentes, das nun einsetzt, sind einer weiteren Kaudalverschiebung des Prosto- 
miums Grenzen gesetzt. Wie Taf. 5 Abb. 20a, 20 b und Taf. 6 Abb. 23 deutlich machen, schiebt sich das Metastomium dorsal beginnend langsam kranialwärts und überdeckt den hinteren Prostomiumteil. Gleichzeitig setzt es zur Bildung seitlicher Lappen (1l) (Taf. 5 Abb. 20 a) an. Schließlich greift das Metastomium (1. Körpersegment) mit seinen zu beweglichen Lappen herangewachsenen Lateralwülsten (lw) immer mehr nach Ventral und hüllt das Prostomium fast völlig ein. Durch diese Umwachsungstendenz erhält die Unterlippe erneute Impulse und wächst zu einem beachtlichen Umfang heran (Taf. 5 Abb. $20 \mathrm{~b}$ ).

Als einzige Prostomiumanhänge sind bei Lanice conchilega die Tentakeln anzusehen. Diese können sich stark kontrahieren (sicher auf die Hälfte ihrer Gesamtlänge), können aber nicht in den Mund eingezogen werden, was auf Grund ihrer Prostomiumzugehörigkeit auch nicht verwunderlich ist.

Für das Aulophora-Stadium in seiner pelagischen Lebensweise haben die Tentakeln keine wesentliche Funktion. Erst bei den bodenreif gewordenen Stadien gewinnen sie an Bedeutung, wenn sie nämlich das Baumaterial für ihre Sedimentröhre und Nahrungspartikelchen herbeistrudeln müssen. Beide Aufgabenbereiche spielen bei der Larve noch keine Rolle. Nahrung steht ihnen innerhalb ihres schwimmenden Daseins im freien Wasser reichlich zur Verfügung und die Wimperbewegungen der Mundregion genügen, um die schwebenden Detritusteilchen und Kleintierorganismen in den Mund zu befördern.

Auch für den Bau der Larvenröhre ist die Existenz der Tentakeln noch nicht notwendig, was schon daraus hervorgeht, daß bei der Entstehung der ersten Larvenröhre des jüngsten Aulophora-Stadiums ein beweglicher Tentakel noch nicht vorhanden ist.

Hingegen ist die frühe Entfaltung der Oberlippe (ol) (Taf. 2, 3 Abb. 13b, $14 \mathrm{a}, 14 \mathrm{~b}$ ) für den Röhrenbau von großer Wichtigkeit. Auffällig ist ihre Kapuzenform und die Fähigkeit zu lebhafter Formveränderung.

Wie im Kapitel über die Morphologie der erwachsenen Lanice conchilega angedeutet wurde, kann die Auffassung einer Prostomiumzugehörigkeit der Oberlippe nicht mehr vertreten werden. Sowohl Beobachtungen an lebenden Larven-Stadien als auch zahlreiche Schnittserien (Abb. $7 \mathrm{~B}$ ) widersprechen dieser Ansicht. Die Oberlippe ist vielmehr das Ergebnis einer beachtlichen Zellvermehrung im Vorderdarmdach (ole). Wie die Entwicklung zeigt, überwuchert sie mit zunehmender Ausdehnung das Prostomium und täuscht daher eine Zugehörigkeit zum Prostomium vor.

Die Funktion der Oberlippe spielt beim Röhrenbau, der bereits betrachtet wurde, eine Hauptrolle. Mit aktiven Bewegungen der Ober- und Unterlippe wird das Baumaterial umgriffen und "portionsweise" aneinandergesetzt. Nach der groben Bauarbeit beginnt das "Polieren“. Die einzelnen am Röhrenrand aufsitzenden Schleimpakete müssen in ihren Niveau-Unterschieden ausgeglichen werden. Mit großer Schnelligkeit und Sorgfalt werden mit der Oberlippe Fugen verschmiert, so daß endlich eine ganz glatte Oberfläche der Larvenröhre entsteht und zwar ganz gleichgültig, ob es sich um eine hyaline oder mit Detritus beklebte Schleimröhre handelt.

b) Morphologische Veränderungen der Rumpfregion Bildung der Segmente und ihre Anhangsorgane

Mit dem Abschluß des Metatrochophora-II-Stadiums ist die Bildung der vier sog. Larvalsegmente beendet. Das subtrochale Wachstum geht von zwei para- 
median gelegenen, auffällig großen Telomesoblasten (umz) aus, Abkömmlinge der Zelle 4 d (Taf. $1 \mathrm{Abb} .10 \mathrm{a}$ ). Diese praepygidialen Zellen liefern durch intensive Zellteilung zwei solide Mesodermbänder. Nachdem das Wachstum des ventrolateralen Mesodermstreifens an der Prototrochregion seinen Abschluß gefunden hat, setzt die Aktivität des Ektoderms ein. Inwieweit allerdings die ektodermale Zellteilung und die äußerlich entstehende segmentale Differenzierung die Ursache für die Gliederung des Mesodermstreifens in vier deutliche Segmente ist (Abb. 9), bleibt dahingestellt. Während Iwanoff (1928, S. 64). das Ektoderm als Initiator der mesodermalen Segmentierung ansieht, meint ANDERson (1959, S. 108), daß der Mesodermstreifen von sich aus zur Cölombildung in der Lage ist. Unter Auflösung der inneren Segmentierung der Larvalsegmente bildet sich in diesen ein einheitliches Cölom.

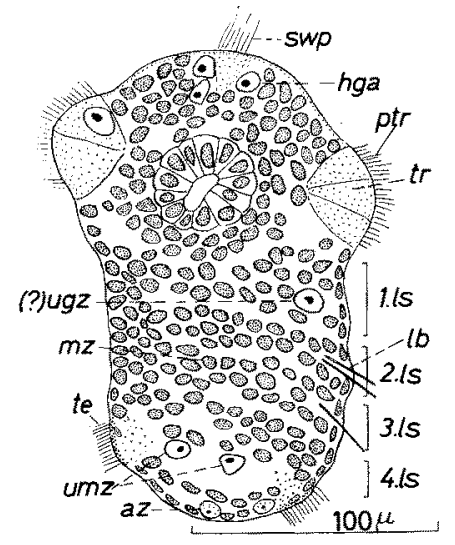

Abb, 9. Totalpräparat einer Metatrochophora I-Larve im Ubergang zur Metatrochophora II-Larve. Larvalsegmente durch segmental gegliederte Mesodermzellen des Mesodermstreifens entstanden. $a z=$ Analzellen, hga $=$ Gehirnpilem, $\mathrm{lb}=$ Larvalborsten, $\mathrm{Is}=$ Larvalsegment, $\mathrm{mz}=$ Mesodermzellen, ptr $=$ Prototroch, swp $=$ Scheitelwimpern, te $=$ Telotroch, $\mathrm{tr}=$

Trochoblasten, ugz = Urgeschlechtszelle, umz = Urmesodermzelle

Auf die Phase der raschen Segmentbildung folgt eine spürbare Entwicklungspause. In dieser Pause befinden sich die Larven, wenn sie in das Aulophora-Stadium eintreten. Diese Zäsur vor Beginn weiterer Segmentierung ist eine Erscheinung, die auch Iwanoff beschreibt. In dieser Tatsache sieht er eine Anderung der Segmentbildung. Bei der folgenden Entwicklung werden die Segmente nicht nur durch die Abkömmlinge der Zelle $4 \mathrm{~d}$ gebildet, sondern ektodermale Zelleinwanderung spielt eine zusätzliche Rolle.

Die vier primär entstandenen Segmente werden von den sekundären Segmenten durch ein kräftiges Diaphragma getrennt. Diese Scheidewand zwischen 4. und 5. Segment wäre somit kein Zufall, wenn man davon ausgeht, daß an dieser Stelle das primäre und sekundäre Cölothel nebeneinanderliegen.

Auch innerhalb der hinter dem Diaphragma liegenden Segmente bleiben die querliegenden Scheidewände oder Dissepimente nicht erhalten. Bis auf die medialen Längswände der einzelnen Cölomsäcke, die die dorsalen und ventralen Mesenterien liefern, werden die Zwischenwände aufgelöst.

Nach der vorliegenden Untersuchung an Lanice conchilega ist eine Unterteilung in Deuto- und Tritometameren (Remane 1949, S. 18) möglich, wobei die Grenze in diesem Fall zwischen 4. und 5. Segment zu ziehen wäre.

Interessanterweise spiegeln sich die Unterschiede zwischen Deuto- und 
Tritometameren auch innerhalb der ektodermalen Differenzierung wider. Im Gegensatz zu den Haar- und Hakenborsten der hinteren Segmente legen diejenigen der ersten vier Segmente durch ihre abweichende Form und ihr andersartiges Verhalten gegenüber den übrigen Anhangsorganen ein beredtes Zeugnis ihres spezifisch larvalen Charakters ab.

Werfen wir zuerst einen Blick auf die larvalen Haarborsten (lb) im 2. und 3. Segment (Taf. 2 Abb. 12 und Abb. 10 A 1). Vom Schaft bis zur Spitze bleiben die einzelnen Haarborsten gleichstark. Nur am äußeren Rand erfährt die Borste eine deutliche Biegung, die eher den Eindruck eines Knickes vermittelt, als beispielsweise die leichte Neigung des oberen Borstenabschnittes der bleibenden Haarborsten. Bei einer Gegenüberstellung beider Haarborstenausbildungen hebt sich die stabil aber durchaus plumpe Form der Larvalborste von der viel zarter wirkenden, zu einer Spitze zulaufenden, bleibenden Haarborste deutlich ab (Abb. $10 \mathrm{~A} \mathrm{2}$ ).

Außerdem besteht ein weiterer Unterschied zwischen larvaler und bleibender Haarborste und zwar in der Anzahl der Borsten in einer Borstensackanlage. Mit den fast gleichzeitig auftretenden zwei verschieden langen Larvalhaarborsten in einer Borstentasche des 2. und 3. Segments scheint die Haarborstenbildung erschöpft zu sein, denn es gelangen in diesen beiden Segmenten keine weiteren Haarborsten mehr zur Ausbildung. Sie erleiden vielmehr das Schicksal eines Larvalorgans, indem sie einfach abfallen (Taf. 4 Abb. 17, 18). Im Gegensatz zu den eben beschriebenen larvalen Haarborsten und ihrer Entwicklung zeigen die bleibenden Haarborsten die Tendenz, ihre ursprüngliche Zweizahl durch weitere Borstenbildungen zu einem Büschel zu vermehren.

Wir finden die dorsalen Haarborstenbüschel bei der erwachsenen Lanice auf 17 Segmente verteilt, nämlich vom 4 . bis zum 20. Segment. Mit dem 21. Segment wird die thorakale Zone verlassen und das Abdomen beginnt. Dies wird rein äußerlich an den veränderten Borsten sichtbar. Weder dorsale Haarborstenbüschel noch ventrale Hakenwülste sind anzutreffen, sondern nur noch die ventralen hakentragenden Flossen.

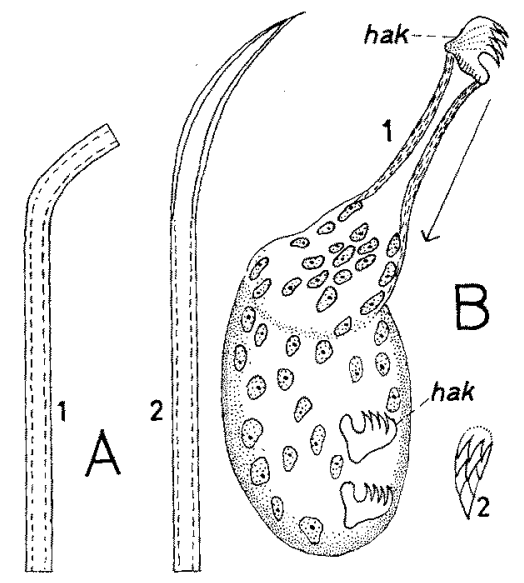

Abb. 10. A 1) Larvalborste mit gleichbleibendem Schaft und Spitze. 2) Bleibende Haarborste (Sdwwingborste) läuft in ihrem oberen Teil zu einer Spitze zu. B 1) Entwicklung der bleibenden Hakenborsten. Die flaschenförmige Aufwölbung mit einem Haken wird im Verlaufe der Entwicklung durch die Schrumpfung des Flaschenhalses in Pfeilrichtung auf dem Hakenwulst eingeordnet. Hier haben sich bereits weitere Haken gebildet. 2) Haken von oben. Alle Abbildungen halbschematisch. hak $=$ Haken 
Im Gegensatz zu den morphologischen Unterschieden der larvalen und bleibenden Haarborsten weisen die der Haken selbst keine Verschiedenheiten auf. Eine Abweichung zeigt sich einzig und allein in ihrem Verhalten. Während die larvalen Hakenborsten des 3. und 4. Segmentes ohne Komplikationen zugrundegehen (Taf. 4 Abb. 17, 18), entwickelt sich die bleibende Hakenborste unter interessanten Umbildungserscheinungen weiter.

Das erste Auftreten paariger ventraler Ektodermalanhänge im 3. und 4. Segment und im Verlaufe der Entwicklung auch in den sich anschließenden Segmenten machte in seiner Deutung erhebliche Schwierigkeiten.

Diese Bildungen wölben sich in Gestalt einer bauchigen Flasche ('Taf. 2 Abb. 13) lateral nach außen. Die Basis des flaschenförmigen Körpers sitzt am Larvenkörper auf, während der freie Teil Bewegungen ausführen kann. Der lateral-ventralwärts gerichteten Lage nach mußten dies die Anlagen der hakentragenden ventralen Wülste der erwachsenen Tiere sein. Die abweichende Form machte jedoch eine Gleichstellung fraglich, zumal der "Bauchcirren“charakter, der von Glaparede (1863, S.65) beschriebenen Terébella conchilega, bei geringer mikroskopischer Vergrößerung bestätigt wurde.

Erst bei näherer Untersuchung mit stärkerer Vergrößerung konnte am oberen Halsende der flaschenförmigen Anhänge ein Haken entdeckt werden, der genau den Haken auf den Wülsten der adulten Tiere entsprach. Wie die weitere Entwicklung zeigte, war die Annahme, daß aus den flaschenförmigen Gebilden die späteren Hakenwülste hervorgehen, richtig und von ClaparedE (1863, S. 65) bereits erkannt worden. Doch die Unsicherheit Claparedes kommt ohne Zweifel in dem Satz zum Ausdruck, wenn er meint, ,welch himmelweiter Unterschied aber zwischen den Bauchcirren unserer Larve und den Hakenwülsten einer reifen Terebella" besteht (gemeint ist Terebella conchi$\operatorname{leg} a)$. So "himmelweit" ist der Unterschied allerdings gar nicht. Wie Abb. $10 \mathrm{~B}$ zeigt, bildet sich zuerst ein Haken (hak), der mit dem Heranwachsen des Anhangs an seinem distalen Ende vom Körper weggeschoben wird. Sollte dieser „gestielte“ Haken die Bildungszone aller weiteren Haken sein? Wenn diese Annahme richtig wäre, müßte allerdings eine „Hakenwanderung" vom Flaschenhals, der vermeintlichen Bildungsstätte, zur Basis der Flasche, dem späteren Hakenwulst stattfinden. Ein derartiges Hinabgleiten von Haken konnte jedoch nicht beobachtet werden.

In Wirklichkeit liegen die Verhältnisse gar nicht so kompliziert, wie es den Anschein hatte. Die Haken werden alle in der Körperwand gebildet. Anfangs liegen sie ungeordnet nebeneinander, später reihen sie sich hintereinander an und zwar in den sechs ersten ventralen Wülsten vom 5.-10. Segment in einer Reihe, in den zehn folgenden vom 11.-20. Segment in zwei Reihen nebeneinander (Taf. 6 Abb. 23).

Nur der erste Haken wird durch die flaschenförmige plasmatische Bildung von den übrigen isoliert und übernimmt auf diese Weise die Aufgabe des Festhaltens, die später von den hakentragenden Wülsten selbst übernommen wird. Im Verlaufe der weiteren Entwicklung, wenn nämlich genügend Haken in der Körperwand gebildet worden sind, schrumpfen die hakentragenden Plasmagebilde, und der für die Larvenzeit so wichtige Klammerhaken ordnet sich in den bereits vorhandenen Komplex von Haken ein.

Wie aus der Beschreibung der segmentalen Anhangsorgane hervorgeht, handelt es sich bei Lanice um keine einheitlichen Parapodien mit einem dorsalen und einem ventralen borstentragenden Ast. Im Laufe der phylogenetischen 
Entwidklung hat der Parapodienstamm eine Verkürzung erfahren und hat zur Isolierung der beiden Aste geführt, zum dorsalen Haarborstenbüschel und ventralen hakentragenden Wulst.

Die Lageübereinstimmung der isolierten Parapodienäste zwischen Larve und Adult und die Ubereinstimmung der Haken- und Borstenmorphologie ist bemerkenswert. Durch diese Erkenntnis öffnet sich vielleicht ein neuer Weg, Larven mit Hilfe dieses artspezifischen Merkmals zu identifizieren. Die Planktonsystematik und insbesondere die der Terebelliden könnte durch eine solche Wissenserweiterung erneute Impulse erhalten.

Abgesehen von den Parapodien, die im Aulophora-Stadium gebildet werden, treten im 3. Körpersegment zwei laterale Lappen (11) auf, deren Bedeutung jedoch noch nicht ganz geklärt ist (Taf. 5 Abb. 20b).

Schließlich bilden sich als letzte Anhänge, gleichsam den Ubergang vom freischwimmenden pelagischen zum seßhaften Bodenleben einleitend, die 3 Paar baumförmig verzweigten Kiemen auf der Dorsalseite des 2., 3. und 4. Körpersegmentes. Ihre Bildung setzt nicht gleichzeitig ein, sondern vollzieht sich schrittweise. Sie beginnt bei den ältesten Aulophora-Stadien und findet ihren Abschluß erst dann, wenn die Jungtiere bereits seßhaft geworden sind.

Das 1. Kiemenpaar entsteht als höckerartige Ausstülpung im 2. Körpersegment lateral der dorsalen Medianlinie (Taf. 6 Abb. 21). Zu diesem Zeitpunkt sind die Larven etwa 54 Tage alt. Diese Larven, deren $5-7$ bewegliche Tentakeln den Prostomiumrand weit überragen, haben die Entwicklung des Thorax abgeschlossen und diejenige der abdominalen Region hat begonnen. Mit zunehmendem Wachstum der Kiemenhöcker verzweigen sie sich (Taf. 6 Abb. 22), und das 2. Paar im 3. Körpersegment bricht durch. Wenn dieses Kiemenpaar das Stadium beginnender Verzweigung erreicht hat, erfolgt der Durchbruch des 3. Kiemenpaares im 4. Körpersegment. Da mit der Ausbildung der Kiemen ein erhöhtes Atmungsvermögen gegeben ist, verwundert es nicht, daß der Zeitpunkt der Seßhaftigkeit mit dem der Kiemenentstehung ungefähr

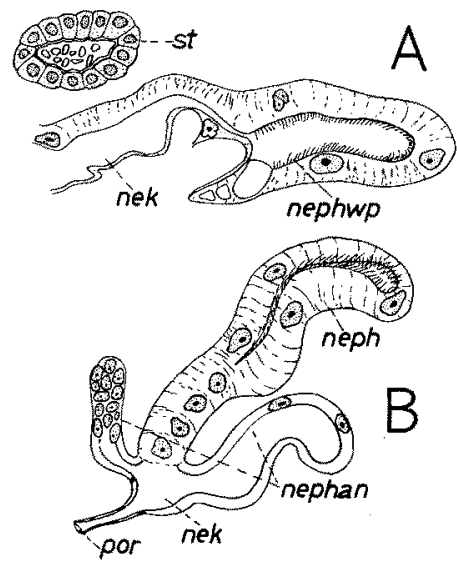

Abb. 11. $A=$ Frontalschnitt durch das mittlere Metanephridium der vor dem Diaphragma gelegenen bleibenden Exkretionsorgane (halbschematisch). Vor dem Nephrostom des Metanephridiums liegt im 2. Segment die Statocyste. B = Die drei Paar Metanephridien vor dem Diaphragma, deren Mediannephrostom schon voll ausgebildet ist, während das vordere und hintere Metanephridium erst in der Anlage zu sehen ist. Sie münden alle drei in einem Porus im 3. Körpersegment nach außen (halbschematisch). nek $=$ Nephridialkanal, neph $=$ Nephrostom, nephan $=$ Nephrostomanlage, nephwp $\Longrightarrow$ Nephrostomwimpern, por $=$ Porus, st $=$ Statocyste 
zusammenfällt. Durch den Besitz der Kiemen ist es den jungen Lanice-Tieren nun auch möglich, in Bodenröhren zu leben, die keinen ausgeprägten Wasserstrom beobachten lassen.

Mit der Betrachtung der Kiemen ist die Erörterung der Körperanhänge abgeschlossen. Es soll nun auf die Exkretionsverhältnisse eingegangen werden.

Bei der Behandlung des Metatrochophora-Stadiums wurde dem Auftauchen der Protonephridien, als den larvalen Exkretionsorganen, ausführlich Beachtung zuteil. Bevor jedoch die Protonephridien autolytisch zerstört werden, legen sich im 3. Körpersegment paarige Metanephridien mit einem gut erkennbaren Wimpertrichter an (Taf. 4 Abb. 18, Abb. 11 A). Diese erste Bildung der bleibenden Nephridien stellt das mittlere der drei vor dem Diaphragma liegenden Exkretionsorgane dar. Sowohl kranial ins 2. Körpersegment führend, als auch kaudal in das 4. Körpersegment hineinreichend, erstrecken sich zwei weitere Metanephridienpaare. Alle drei Metanephridien stehen miteinander in Verbindung und münden gemeinsam in einem Porus (por) (Abb. 11 B) im 3. Körpersegment.

Es besteht wohl kein Zweifel, daß wir es bei den Metanephridien der vorderen Thorakalkammer mit einem Verschmelzungsprodukt der drei ursprünglich voneinander isoliert nach außen mündenden Nephridien zu tun haben (Taf. 5, 6 Abb. 20a, 21).

Sehr viel später setzt erst die Entstehung der hinter dem Diaphragma liegenden Metanephridien ein (Taf. 5 Abb. 20a). Leider konnte ihr Entwicklungsgang nicht verfolgt werden. Der Abschluß der Metanephridienentwicklung ist jedenfalls noch nicht erreicht, wenn die Aulophora-Larve ihr pelagisches Leben beendet und zum Bodenleben übergeht.

\section{Das bodenreife Stadium}

Außerordentlich interessant und den bisherigen Vorstellungen über das Zubodengehen von Larven sessiler Polychaeten widersprechend ist die Beobachtung, daß der Wechsel zwischen freischwimmender Bewegung und seßhafter Lebensweise sich nicht durch das Abfallen der larvalen Bewimperung anbahnt und dadurch die Schwimmfähigkeit zerstört. Die dorsale Bewimperung konnte auch nach dem Absinken der Aulophora-Larven in voller Funktion festgestellt werden. Erst nachdem sich die Jungtiere ins Sediment eingebohrt hatten und Schaft und Bäumchen ihrer Wohnröhre im Boden gebaut waren, hörte die Wimpertätigkeit auf, und die Wimperbögen fielen ab.

Das Argument, das für gewöhnlich als Grund des Absinkens angeführt wird, hat für Lanice conchilega keine Gültigkeit. Demnach muß irgendeine andere Ursache für dieses Phänomen von Einfluß sein.

Betrachten wir noch einmal sehr sorgfältig die Morphologie der zum Übergang bereiten Larven (Taf. 6 Abb. 21). Sie zeichnen sich rein äußerlich durch 7 bewegliche Tentakeln, 1 Paar Kiemenansätze im 2. Körpersegment, 12-14 haarborstentragende Segmente und 10 weitere Segmente aus. Die hakentragenden Wülste sind in den Segmenten 5-10 fertig ausgebildet.

Statocysten sind vorhanden, die drei Paar verschmolzenen Nephridien vor dem Diaphragma und drei Paar Nephridien hinter dem Diaphragma sind ebenfalls ausgebildet. Die dorsalen Wimperbögen erfüllen noch immer ihre Funktion. Die einzige Veränderung bahnt sich allerdings am Grubenorgan an, 
Die großen flüssigkeitsgefüllten Zellen um die Grube beginnen zu schrumpfen, und die kontraktilen Bewegungen der in die Grubenöffnung hineinragenden Wimperbüschel hören auf. Dies ist eine sehr auffallende Tatsache. Obgleich die vorliegende Untersuchung die Morphologie des Grubenorgans klären konnte, ist Vorsicht bei der Beurteilung der Funktion dieses Organs am Platz.

So soll an dieser Stelle nur auf die Auflösung des Grubenorgans hingewiesen werden und auf die Eigentümlichkeit der zeitlichen Übereinstimmung mit der Bewegungsänderung der Larven.

Nur durch Versuche kann die endgültige Lösung dieser Frage geklärt werden.

Abgesehen von einer immer größer werdenden Ảhnlichkeit zwischen Larven und erwachsenen Tieren, lassen sich hinsichtlich ihres Verhaltens Veränderungen bemerken, die auf einen Bewegungswandel hinweisen.

In den Kulturschälchen konnte beobachtet werden, daß die Larven sich zu diesem Zeitpunkt vornehmlich am Boden der Schalen aufhalten. Mit den Tentakeln voran kriecht die Aulophora-Larve über den Gefäßgrund und sammelt Detritus, ım damit ihre hyaline Röhre zu bekleben. Dieses Suchen nach Baumaterial kündet das neue Stadium der Entwicklung an. Es zeigt schon allein in der Neuartigkeit des Benehmens, daß das pelagische Leben ein Ende gefunden hat und die Aulophora-Larve nun zum Bodendasein übergehen will.

Ganz unabhängig von den Fragen, warum gerade zum gewählten Zeitpunkt der Wechsel der Larven vom freilebenden zum seßhaften Stadium erfolgt und ob eine zeitlich beeinflussende Wirkung vom Sediment als günstigem oder nicht günstigem Ansatzpunkt ausgeht, soll zuerst das Verhalten der bodenreifen Aulophora-Larven geschildert werden.

Die Aulophora-Larven, die inzwischen eine Länge von 2,250-3,000 mm erreicht hatten, wurden aus den reinen Seewasserschälchen in Kulturschälchen mit einer etwa $0,7-1 \mathrm{~cm}$ dicken Sedimentschicht umgesetzt.

Das Sediment für diese Versuche stammte vom Lister Haken, einem Standort, an welchem Lanice conchilega in großer Zahl anzutreffen ist. Ganz offenbar war die Beschaffenheit des Sedimentes am natürlichen Besiedlungsort für die Larven günstig, so daß sie dort sehr zahlreich „anwachsen" konnten. Das aus dem Watt geholte Sediment wurde gereinigt und in seinen Kornfraktionen bestimmt. Das Ergebnis ergab ein Schwanken der Korngrößen zwischen 0,518 und $0,333 \mathrm{~mm}$.

Nach der Übertragung der bodenreifen Larven in die vorbereiteten Schälchen bohrten sie sich in den meisten Fällen sofort in das Sediment. Das Verhalten der Larven entspricht hierbei demjenigen, welches Ziegelmeier (1952, S. 120) an erwadisenen Tieren beobachtet und beschrieben hat. Nur über die Art des Einbohrens in den Boden weichen die Beobachtungen ZIEGELMEIERs an adulten Tieren von den eigenen Feststellungen an bodenreifen Larven voneinander ab. Nach meiner Ansicht spielt nicht die Oberlippe die Hauptfunktion bei diesem Vorgang, wie Zregelmerer erläutert, sondern die Tentakeln. Sie schieben sich bei dieser Arbeit zwischen das Bodenmaterial und bewirken durch heftige Kontraktionsbewegungen eine Lockerung des festen Steingefüges. Nach dieser Vorbereitung können die Sandkörner ebenfalls von den Tentakeln beiseite gedrückt werden, und der Körper ist nun imstande, in den entstandenen Hohlraum nachzurutschen.

Die in den Kulturschälchen gebauten, winzig kleinen Wohnröhren besaßen zumeist U-oder sogar W-Form. Eine Notwendigkeit zu diesen Röhrenformen 
liegt nach Ziegelmeier (1952, S. 120/121) weder zur Kotausscheidung (die Tiere sind in der Lage, ihr Hinterende nach vorn umzubiegen), noch zur Atmung (die Kiemen liegen in der vorderen Körperregion) vor. Das kann bestätigt werden. Auch für den Nahrungserwerb scheint eine U-Form nur dann notwendig, wenn die Voraussetzung für die Ernährung nicht günstig ist. Es erwächst somit die Frage, ob die u- oder w-förmige Röhrenform der jungen Lanice Nahrungsmangel anzeigt, oder ob sie eventuell im Zusammenhang mit Wachstumserscheinungen beurteilt werden müssen. Wenn das Wachstum die Ursache für die beschriebene Bauweise wäre und sich diese Ansicht bestätigen ließe, könnte dies der Beweis dafür sein, daß die Tiere, wie oben bereits erwähnt wurde, aus Wachstumsgründen ihre Röhren nicht verlassen.

Was die Größenzunahme der pelagischen Larven betrifft, ist es vielleicht $z$ weckmäßig und aufschlußreich, auf eine Beobachtung hinzuweisen, die innerhalb der Entwicklung der Aulophora-Larven gemacht werden konnte.

Das kontinuierliche Wachstum der Aulophora-Larven einerseits und das unzureichende Dehnungsvermögen der starren Larvenröhre auf der anderen Seite führt uns an dasselbe Problem.

Mit dem Größerwerden der Larven müßte auf irgendeine Weise die zu eng werdende Larvenröhre „mitwachsen“. Theoretisch sind hierfür zwei Möglichkeiten denkbar.

1. Die Larven verlassen mit zunehmendem Wachstum die alte, zu enge Larvenröhre und bauen sich eine neue.

2. Die Larven erweitern ihre Larvenröhre entsprechend dem Körperwachstum.

Für die Verwirklichung der ersten Möglichkeit spricht sehr wenig. Ein Verlassen der alten Larvenröhre würde nämlich bedeuten, daß die Larven zu Boden gehen müßten, um sich dort eine neue Röhre zu bauen. Denn, wie bereits an früherer Stelle ausgeführt worden ist, vermögen die Larven nicht ohne Halt den Anfang des Schleimrings um die "Taille" zu legen. Das wiederholte Einschalten hilfloser Phasen innerhalb der Gesamtentwicklung, denn als solche wären sie zu bezeichnen, erscheint allerdings nicht sehr sinnvoll.

Dahingegen ist die Realisation der zweiten Möglichkeit sehr viel wahrscheinlicher, zumal die Beobachtungen der verschiedenen Larven-Stadien in den Kulturschälchen niemals ein Verlassen der alten Larvenröhren und das Bauen einer neuen zeigten.

Es scheint sich vielmehr um ein ebenso kontinuierliches "Wachstum" der Larvenröhre zu handeln, wie es auch von den Larven selbst bekannt ist. Dieses organische Mitwachsen der Larvenröhre, entsprechend dem Größerwerden der Larven, ist insofern gut denkbar, als die Larven sich purzelbaumartig in ihrer larvalen Röhre hin- und herbewegen können. Somit macht diese Bewegungsweise einen erweiternden Aufbau am breiteren Rand der konischen Larvenröhre und einen Abbau am gegenüberliegenden Röhrenrand durch Abbeißen mit Hilfe der Oberlippe vorstellbar.

Alles spricht also dafür, daß während des Wachstums der Larven in ihrer pelagischen Lebensweise die larvale Hülle nicht verlassen wird, und daß dieses Verhalten mit großer Wahrscheinlichkeit auch bei den adulten Tieren von Lanice conchilega besteht. Doch ist eine endgültige Klärung dieser Frage, ob die U- oder W-Form der Lanice-Jungtiere eine notwendige Wachstumserscheinung ist, nur durch Experimente möglich. 
Wie die adulten Tiere, so bauen sich auch die Jungtiere auf den Röhrenschaft ein Sedimentbäumchen auf. Im Gegensatz zur passiven Bauweise des Röhrenschaftes werden die Steinchen des Bäumchens (Stammteil und Fransenkrone) aktiv aneinandergefügt (Abb. 12). Mit Hilfe des Mediantentakels wird das Material aus dem Umkreis der Röhre herangestrudelt und zu einem kegelförmigen Berg um den Röhrenfuß angehäuft. Aus diesem herangeschafften

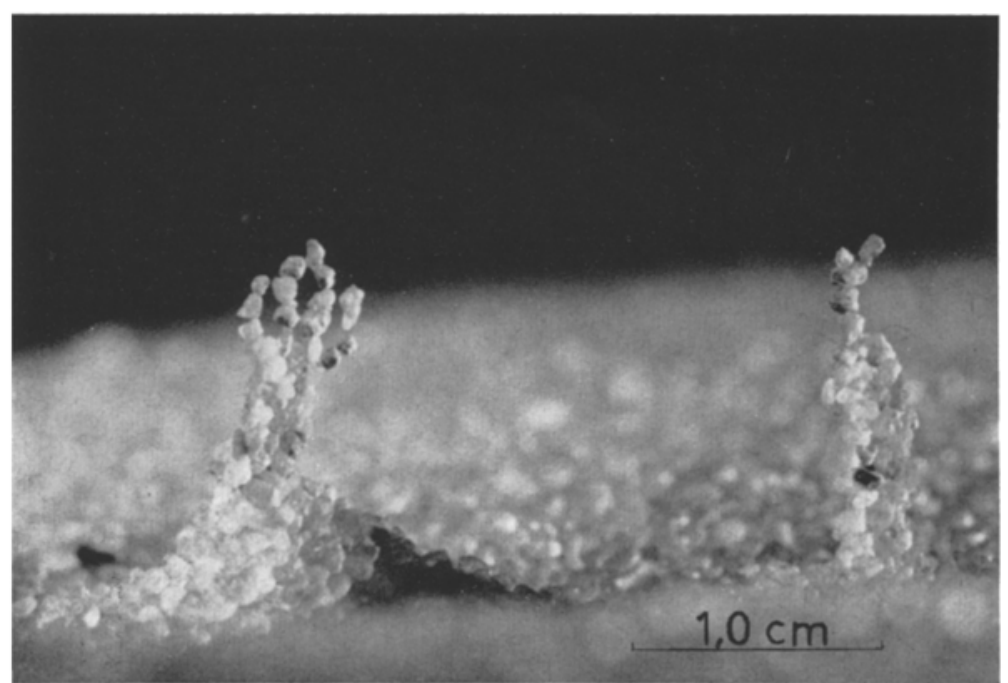

Abb. 12. Lanice-Bäumchen seßh haft gewordener Jungtiere. Das Bäumchen, dessen Schaft durch die Anhäufung von Sediment kegelförmig verschüttet ist, besitzt bereits die typische Verästelung. Die einzelnen $Z$ weige des Bäumchens bestehen aus aneinandergereihten Steinchen

Steinchenmaterial angelt sich das Tier mit großer Sorgfalt die passenden Steinchen heraus. Die Lateraltentakel umgreifen dann die ausgewählten Steinchen und führen sie einzeln zum Mund. Hier umschließt sie dann die Oberlippe und hüllt sie mit Schleim ein. Steinchen für Steinchen wird auf gleiche Weise vorbereitet und endlich durch die Oberlippe auf den Röhrenrand gesetzt.

Die Fertigstellung dieses kunstvollen Bäumchens ist nach wenigen Stunden erreicht. Dann kann das Abtasten der einzelnen Äste der Fransenkrone nach Algen und Kleintieren beginnen.

Mit dem Bau des Röhrenbäumchens ist die auffällige äußerliche Entwicklung beendet.

\section{F. Zusammenfassung}

1. Die gesamte Entwicklung von Lanice conchilega (Pallas), vom befruchteten $\mathrm{Ei}$ bis zum bodenreifen Stadium, wurde untersucht und beschrieben.

2. Die Geschlechtsreife der männlichen und weiblichen Würmer beginnt im April und dauert bis Ende Juni.

3. Die sich innerhalb der Cölomflüssigkeit entwickelnden Geschlechtsprodukte färben die Männchen milchig-weiß und die Weibchen rotbraun.

4. Eier und Spermien werden durch die Gonodukte ins Wasser abgegeben. Hier findet die Befruchtung statt.

5. Die dotterreichen Eier teilen sich total inäqual nach dem Spiraltypus. 
6. Sechs Stunden nach der Befruchtung ist das 64-Zellen-Stadium erreicht. Der Embryo durchbricht mit seinen Prototrochwimpern die Eimembran zwischen wabenförmigen Versteifungsleisten. Das Abstreifen der Eihülle durch eigene Bewegungen ist nicht möglich. Nur mit Hilfe mechanischer Reibung kann die Hülle zerstört werden.

7. Ein kurzes Prototrochophora-Stadium ist nur durch einen äquatorialen Prototroch ausgezeichnet.

8. Mit der Bildung des Telotrochs und der Scheitelwimpern ist das Trochophora-Stadium erreicht.

9. Das von zwei paramedian praepygidial gelegenen Teloblasten ausgehende Wachstum der Trochophora-Larve führt zu einer deutlichen Gliederung der Rumpfanlage im Metatrochophora-I-Stadium.

10. Nach dem Durchbruch der larvalen Haarborsten und der Bildung der Haken beginnt das Metatrochophora-II-Stadium der Lanice-Larven.

Im 1. Körpersegment bilden sich Protonephridien aus, im 2. Körpersegment paarige Statocysten und hinter dem Prostomium das Grubenorgan.

11. Das retraktile Grubenorgan schließt sich an den hinteren Hirnteil an und wird von sehr großen, wahrscheinlich flüssigkeitsgefüllten Zellen umgeben. Zwei Wimperbüschel ragen in die Grube und bewegen sich lebhaft. Ob die Funktion dieses Organs mit der freischwimmenden Bewegung etwas zu tun hat, bleibt nur Vermutung.

12. Mit dem Auftreten ventraler, schleimabsondernder Basalplatten beginnt die Larve sich eine Röhre aus Schleim und Detritus zu bauen.

Mit zunehmender Ausbildung von Basalplatten ändert sich die Röhrenbeschaffenheit zugunsten einer einheitlichen Schleimröhre.

13. Mit Hilfe der selbstgebauten Röhre erhebt sich die Larve vom Boden und geht zum eigentlich pelagischen Leben über.

14. Für dieses Stadium wurde der Name Aulophora eingeführt.

15. In der Kopfregion der Aulophora-Larve vereinen sich das Prostomium und das Metastomium. Die Eingliederung des 1. Körpersegmentes, nämlich als Verschmelzungsprodukt zum sog. Buccalsegment oder Peristomium, kann auf Grund der vorhandenen Ganglienpaare und der Nerven nicht unterstützt werden.

Innerhalb des Bauchmarks gehen die einzelnen Ganglienpaare ineinander über und bilden einen einzigen Stamm. Im ersten und zweiten Segment liegen die Ganglienpaare voneinander entfernt. Sie sind nicht durch Kommissuren verbunden. In das erste Ganglion mündet sowohl ein kräftiger Nerv als auch Faserstränge des Schlundkonnektivs. Verschmelzungsspuren sind am ersten Nerv nicht zu erkennen.

16. Als einzige Prostomiumanhänge gelten die nicht in den Mund einziehbaren Tentakeln.

17. Die Oberlippe wächst zu einem kapuzenförmigen Lappen heran, der nicht zum Prostomium gehört, sondern als Zellvermehrung des Vorderdarmdaches anzusehen ist.

18. Mit zunehmender Segmentierung wächst vor allen Dingen die Rumpfregion der Larve.

19. Zwei Paar larvale Borsten im 2. und 3. Segment lassen sich gut von den bleibenden Haarborsten unterscheiden. Diese Larvalborsten werden abgeworfen.

20. Innerhalb der Hakenentwicklung wird der erste Haken durch ein plasma- 
tisches Flaschengebilde vom Körper weggeschoben, während alle übrigen Haken der zukünftigen hakentragenden Wülste innerhalb der Körperwand gebildet werden.

21. Im 2., 3. und 4. Segment werden baumartig verzweigte Kiemen ausgebildet.

22. Wenn die Beendigung der erwähnten Organe erreicht ist, beginnt das Bodenleben.

23. Aus welchem Grund die Larve immer zu einem bestimmten Zeitpunkt zu Boden geht, konnte nicht einwandfrei geklärt werden.

24. Am Boden verhalten sich die Jungtiere wic die adulten Tiere von Lanice conchilega. Sie dringen kopfwärts in das Sediment und bauen ihre erste Sedimentröhre senkrecht in den Boden. Auch ein Bäumchen wird angefertigt, und damit ist der Entwicklungskreis geschlossen.

\section{G. Literaturverzeichnis}

Anderson, D. T., 1959: The embryologie of the polychaete Scoloplos armiger. - Quart. J. micr. Sci., 100, pp. 89-166.

A t te ms, C. Graf, 1902: Beiträge zur Anatomie und Histologie von Scoloplos fuliginosa Clap. - Arbeiten aus dem Zool. Inst. d. Univ. Wien u. d. Zool. Station in Triest, 14, H. 2.

B a te, Sp., 1851: Entwicklungsgeschichte von Terebella medusa Sav! - Annals and Magazine of Natural History, Ser. 2, 8, pp. 237-239.

Ben ham, W., 1927: External sexual differences in the terebellid worms. - Zool. Soc. Proc. London, pt. 1, pp. 141-148.

Bud d en brock, W. v., 1952: Vergleichende Physiologie. Bd. I, Sinnesphysiologie.

Buddenbrock, W. y., 1913; Über die Funktion der Statocyste im Sande grabender Meerestiere. - Zool. Jahrb. Abt. Allgem. Zool., 33.

$\mathrm{B}$ ü $\mathrm{t} s \mathrm{ch}$ l i, O., 1921: Vergleichende Anatomie. Bd. I, Berlin.

Cla parede, Ed., I863: Beobachtungen über Anatomic und Entwicklungsgeschichte wirbelloser Tiere (Anneliden) an der Küste der Normandie. - Leipzig, Verl. Wilh. Engelmann.

Cila pa rede, Ed., und $\mathrm{Mets} \mathrm{chnik}$ of f, E., 1869: Beiträge zur Entwidklungsgeschichte der Chaetopoda, - Zeitschr. wiss. Zool., 19, pp. 163-205.

Gunn ing ha m, J., 1887: Nephridia of Lanice conchilega. - Soc. Edinb. Soc. Proc., 14, p. 238.

Cunning ham, J., and R a mage, A., 1888: The Polychacta Sedentaria of the Firth of Forth. - Trans. R. Soc. Edinburgh., 33, p. 635.

Def re tin, R., 1952: Glandular system of Lanice conchilega. - C. R. Soc. Biol. Paris, 146, pp. $91-93$.

Dehorne, Ar., 1935: Sur le trochosphonge des cellules nervenses geantes des Lanice conchylega Pallas. - C. R. Soc. Biol. Paris, 200, pp. 1783-1785.

De horne, Ar., 1922: Les nephrocystes smaragdiferes de Lanice conchylega. - C. R. Soc. Biol. Paris, 87, pp. 1307-1308.

Drasche, R. v., 1883; Beiträge zur Entwicklung der Polychaeten. - Zool. Anz., 6, pp. $506-507$.

E I ringto n, G. A., 1908: Some points in the structure of the Larva of Lanice conchilega. Cellule, Louvain, 25, pp. 103-114.

F a uve 1, P., 1907: Recherches sur les otocystes des Annelides Polychaetes, - Ann. Sci. Nat. Zool. Paris, Ser. 9, 6, pp. 144.

Fewkes, J., 1883: On the development of certain worm larvae. - Mus. Comp. Zool. Harvard, Bull., 11, pp. 167-208.

Friedrich, H., 1938: Polychaeta in Grimpe-Wagler, Tierwelt der Nord- und Ostsee. Liefg. 32, Leipzig.

Gessne r, F., 1957: Meer und Strand. Deutscher Verlag d. Wiss. Berlin.

Gia rd, A., 1878: Sur le Wartelia, genre nouveau d'Annelides consideres a tort comme des embryons de Terebelles. - Bull. Sci. Dep. du Nord. Paris, Ser. 2, 1. 
Grasse, D., 1959: Traité de Zoologie. Anatomie Systematique, Biologie. Tome V, Annelides. Paris.

Gustafson, G., 1930: Anatomische Studien über Polychaeten-Familien. Amohinomiden und Euphrosynidac. - Zool. Bidr. Uppsala, Bd. 12, S. 305.

Hä cker, V., 1897: Pelagische Polychaetenlarven. - Zeitschr. wiss. Zool. 62.

H a n n erz, L., 1956: Larval development of the Polychaete Families Spionidae Sars, Disamidae Mesnil and Poccilodhaetidae nov. Fam. in the Gullmar Fjord (Sweden). - Zool. Bidr. Uppsala, $\mathbf{3 1}$.

He $\mathrm{r}$ p in, R., 1925: Recherches biologiques sur la reproduction et le devellopment de queque Annelides Polychaetes. - Bull. Soc. Sci. Nat. de L'Ouest de la France, Nantes, Ser, 4, 5, pp. $1-250$.

Hessle, Ch., 1917: Zur Kenntris der terebellomorphen Polychaeten. - Zool. Bidr. Uppsala, 5, pp. $39-258$.

H of ker, J., 1920-22: Verslag emtrent de Polychaetenlarven, van 15-29. Mei te Helder gevonden. - Tydschr. Ned. Dierk. Vereen. Ser. 2, 18.

I w a n off, P., 1928: Die Entwicklung der Larvalsegmente bei den Anneliden. - Zeitschr. f. Morph. Oekol. d. Tiere, 10, pp. 62-167.

Kleinenberg, N., 1886: Die Entstehung des Annelides aus der Larve von Lopadorhynchus. - Zeitschr. f. wiss. Zool, 44.

Ko r n, H., 1960: Das larvale Nervensystem von Pectinaria Lamarck und Nephthys Cuvier (Annelida, Polychaeta). - Zool. Jahrb. Abt. Anat. u. Oekol., 78, S. 427-456.

Korschelt-Heider, 1936: Vergleichende Entwidklungsgeschichte der Tiere. Jena.

Krohn, A., und Schneider, A., 1867: Über Annelidenlarven mit porösen Hüllen. Arch. Anat. Physiol. Reichert's, pp. 498-508.

K ük entha 1, W, 1928 -34: Handbuch der Zoologie. Bd. 2, Teil 2, Vermes, Polymera von F. Hempelmann.

Lankester, E., 1873: A note on the evolution of Terebella. - Ann. Nat. Hist. London. Ser. 4,11, p. 87 .

Leuckart, R., und Frey, H., 1847: Beiträge zur Kenntnis wirbelloser Tiere. - Braunschweig.

Ma u, W., 1882: Uber Scoloplos armiger O. F. Müller. - Zeitschr. wiss. Zool., 36, p. 389.

McIntosh, W. G., 1900-23: A monographie of the British Annelids. Part. II, Polychaeta, vol. IV, Part. 1, pp. 139-146, London.

M e y er, E., 1887: Studien über den Körperbau der Anneliden. - Mitt, d. Zool. Station zu Neapel, 7.

Me is en heimer, J., 1910: Die Exkretionsorgane der wirbellosen Tiere. - Ergebnisse u. Fortschritte d. Zool., 2.

Miln e, Ed., 1845: Observations sur le developpment des Annelides (Terebella nebulosa). Ann. d. Sci. Nat. Zool. Ser. 3, Teil 3, pp. 145-182.

Newe 11, G. E., 1948: A contribution to ouer knowledge of the history of Arenicola marina L. - J. Mar. Biol. Assoc., 27, pp. 554-580.

Nilss o n, D., 1911-12: Beiträge zur Kenntnis des Nervensystems der Polychaeten. Zool. Bidr. Uppsala, 1.

Nolte, W., 1937: Die Zucht und Konservierung der Polychaetenlarven. - J. Conseil, 12, pp. $51-76$.

Nolte, W., 1938: Annelidenlarven. Nordisches Plankton. Kiel. u. Leipzig, Liefg. 24, pp. $171-282$

Nordenskiold, E., 1901: Einige Mitteilungen über die Gattung Wartelia Giard. Ofv. finska vet. soc. forhandl., $\mathbf{4 3}$.

Plate, L., 1924: Allgemeine Zoologie und Abstammungslehre. 2. Teil, Sinnesorgane der Tiere, Jena.

Quatrefages, A. De, 1850: Etudes sur le types inférieurs de l'embranchement des Annelides, Mémoire sur le Système nerveux des Annelides. - Ann. Sci. nat. Zool. Ser. $3,10$.

Re mane, A., 1949: Probleme der Sprossungssegmente. - Verh. Dt. Zool. Ges. Mainz.

R omieu, M., 1923: Recherches histologique sur le sang et le corps cardiaque des Annelides polychaetes. - Arch. Morph. exp. gen. Paris, 17, pp. 1-339.

Rulli er, F., 1951: Etude morphologique, histologique et physiologique de l'organe nucal chez de Annelides Polychaetes Sédentaires. - Ann. de l'Institut Oceanographique, Paris, Nouv. Ser, 25, pp. $207-341$ 
Sal ensky, W., 1884: Etudes sur le developpment des Annelides. - Arch. Biol. Liège. Pts. Pileolaria, Aricia et Terebella. 4, pp. 143--264.

S a r s, M., 1845: Zur Entwicklung der Anneliden. - Wiegmanns Arch. Naturg., 1.

$\mathrm{Sch}$ a x e 1, J., 1912: Versuch einer cytologischen Analysis der Entwicklungsvorgänge 1. Teil: Geschlechtszellenbildung und normale Entwicklung von Aricia foetida Clap, - Zool. Jahrb. Abt. Anat., 34.

Se ila cher, A., 1951: Der Röhrenbau von Lanice conchilega (Polychaeta). - Senckenbergiana, 32.

Södcrström, A., 1920: Studien über die Polychaetenfamilien Spionidae. - InauguralDissertation, Uppsala.

Söd erström, A., 1927: Uber segmental wiederholte "Nuchalorgane" bei Polychaeten. Zool. Bidr. Uppsala, 12.

St o r c h, O., 1913: Vergleichend-anatomische Polychaetenstudien. - K. Acad. Wiss. Wien. Sitzungsber., 122.

Strunk, C., 1930: Exkretion-Physiologie Studien an den Polychaeten Polymnia nebulosa und Lanice conchilega. - Zool. Jahrb. Jena. Allgem. Zool. Phys., 48, pp. 385-398.

Th a m d r u p, H., 1935: Beiträge zur Okologie der Wattenfauna auf experimenteller Grundlage. -- Medd, Komm. Havunders., Ser. Fisk. 10, p. 125.

Th or s o n, G., 1946: Reproduction and larval development of Danish marine bottom invertebrates. - Medd. Komm. Danm. Fisk. Havunders., Ser. Plankton, 4, pp. 1-523.

Wille moes-S uhm, R., 1871: Biologische Untersuchungen über niedere Meerestiere. Zeitschr. wiss. Zool., 21, pp. 396-480.

Wils on, D. P., 1932: On the mitraria larva of Owenia fusiformis Delle Chiaje. Phil. Trans. Roy. Soc, London, Ser. B, 221.

W ils on, D. P., 1936: The development of Audoninia tentaculata Montagu. - J. Mar. Biol. Assoc., 20, pp. 567-579.

Wils on, D. P., 1948: The larval development of Ophelia bicornis Savigny. - J. Mar. Biol. Assoc., 27, pp. 540-553.

Wils on, D. P., 1948: The relation of the substration to the metamorphosis of Ophelia larvae. - J. Mar. Biol. Assoc., 27, pp. 723-760.

Wohl en berg, E., 1937: Die Wattenmeer-Lebensgemeinschaft im Königshafen in Sylt. Helgol. Wiss. Meeresunters. 1.

Woltereck, R., 1904: Beiträge zur praktischen Analysis der Polygordius Entwicklung nach dem Nordsee- und Mittelmeertyp. I. - Arch. Entw. Mech., 18, pp. 377-403.

W ol te reck, R., 1905: Zur Kopffrage der Anneliden. - Verh. Dt. Zool. Ges., pp. 154 bis 186.

$Z$ i e ge l m e i e r, E., 1952: Beobachtungen über den Röhrenbau von Lanice conchilega (Pallas) im Experiment und am natürlichen Standort. - Helgol. Wiss. Meeresunters., 4.

Zi e g l e r, H., 1913: Aus der Entwicklungsgeschichte eines Röhrenwurmes. - Zool. Anz., 44, S. $586-592$.

\section{Abkürzungen}

$\begin{array}{ll}\text { a } & =\text { Auge } \\ \text { af } & =\text { After } \\ \text { al } & =\text { Alge } \\ \text { ap } & =\text { Analpapille } \\ \text { ba } & =\text { Basalplatte } \\ \text { bl } & =\text { Blastomeren } \\ \text { bu } & =\text { Buccalorgan } \\ \text { da } & =\text { Darmanlage } \\ \text { de } & =\text { Detritus } \\ \text { do } & =\text { Dotter } \\ \text { dorw } & =\text { dorsaler Wimperring } \\ \text { dorwp } & =\text { dorsale Wimpern } \\ \text { dph } & =\text { Diaphragma } \\ \text { ed } & =\text { Enddarm } \\ \text { ep } & =\text { Episphäre } \\ \mathrm{flz} & =\text { flüssigkeitsgefüllte Zellen }\end{array}$

$\begin{array}{ll}\mathrm{gr} & =\text { Grubenorgan } \\ \mathrm{h} & =\text { Haarborste } \\ \text { hak } & =\text { Haken } \\ \text { hakflo } & =\text { hakentragende Flossen } \\ \text { hakwl } & =\text { hakentragende Wülste } \\ \text { har } & =\text { starre Härchen } \\ \mathrm{hy} & =\text { Hyposphäre } \\ \mathrm{km} & =\text { Kiemen } \\ \mathrm{lb} & =\text { Larvalborsten } \\ \mathrm{ll} & =\text { Laterallappen } \\ \mathrm{lt} & =\text { Lateraltentakel } \\ \mathrm{lw} & =\text { laterale Wülste } \\ \mathrm{ma} & =\text { Magen } \\ \mathrm{mak} & =\text { Makromeren } \\ \mathrm{md} & =\text { Mund } \\ \mathrm{me} & =\text { Mediantentakel }\end{array}$




$\begin{array}{ll}\text { medwl } & =\text { mediane Wülste } \\ \text { metneph } & =\text { Metanephridien } \\ \text { mik } & =\text { Mikromeren } \\ \text { oe } & =\text { Oesophagus } \\ \text { oel } & =\text { Oltröpfdhen } \\ \text { ol } & =\text { Oberlippe } \\ \text { ph } & =\text { Pharynx } \\ \text { pi } & =\text { Pigment } \\ \text { plfs } & =\text { Plasmaflasche } \\ \text { por } & =\text { Porus } \\ \text { pr } & =\text { Prostomium } \\ \text { ptr } & =\text { Prototroch } \\ \text { ptrneph } & =\text { Protonephridien } \\ \text { py } & =\text { Pygidium }\end{array}$

$\begin{array}{ll}\text { s } & =\text { Scheitelplatte } \\ \text { schl } & =\text { Schleim } \\ \text { sg } & =\text { Segment } \\ \text { st } & =\text { Statocyste } \\ \text { strem } & =\text { strukturierte Eimembran } \\ \text { swp } & =\text { Scheitelwimpern } \\ \mathrm{t} & =\text { Tentakel } \\ \text { ta } & =\text { Tentakelanlage } \\ \text { te } & =\text { Telotroch } \\ \text { tr } & =\text { Trochoblast } \\ \text { ul } & =\text { Unterlippe } \\ \text { umz } & =\text { Urmesodermzelle } \\ \text { wl } & =\text { Wulst }\end{array}$

